Aus dem Laboratorium der L. und Th. Land a n schen Frauenklinik, Berlin.

\title{
Über den wahren Hermaphroditismus des Menschen und der Säugetiere.
}

Von

Ludwig Pick.

Hierzu Tatel LX-XIII und j̄ Textfiguren.

Teil I:

In halt:

Seite

Einleitung: Begriffsbestimmung und Einteilung des wahren Hermaphroditismus .. . . . . . . . . . . . . . 119 Teil II:

a) Das untersuchte eigene Material beim Siiugetier: Fünf Fälle von Hermaphroritismus verus beim Sclowein

b) Zusammenstellung der sicheren Fiule von Hermaphroditismus verus beim Menschen nelsst Bericht über die histologische Nachuntersuchmng des Falles Ernst Salén.......... . 163 Teil III:

Tabellarische Üborsicht der in Teil II berichteten Fäle von Hermaphroditismus verus................... 17 Teil IV:

Die morphologischen („phänomenologischen“) Gesetzmässigkeiten beim Teil V: Hermaphroditismus verus des Monschen und der Sïuger . . . 178

Das Adenoma tubulare testiculare ovarii beim menschlichen Weibe 201T Tuil VI:

Epilritische Betrachtungen zur Ätiologie des Hermaphroditismus verus und seine Beziehungen zum Pseudohermaphroditismus. Die praktischen Prinzipien der Geschlechtsfestsetzung beim Hermaphroditismus und dic Kategorien der "Neutren" beim Menschen . . . . . . . . . . . . . . . . 216

Teil VII:

Allgemeine Znsammenfassung . . . . . . . . . . . . . 231

\section{Teil I.}

\section{Die Begriffsbestimmung und Einteilung des Hermaphroditismus verus.}

Hermaphroditismus bedeutet die Mischung entgegengesetzter Geschlechtsmerkmale in einem Individuum. Jedes Srstem des Hermaphroditismus muss also an die Umgrenzung und Einteilung der Geschlechtscharaktere anknüpfen. 
John Hunter und nach ihm Darwin haben zuerst den primären Geschlechtscharakteren als sekundäre diejenigen somatischen Kennzeichen gegenübergestellt, die mit dem FortpHanzungsakt in keiner direkten Beziehung stehen. Die primil ren Geschlechtsmerkmale umfassen danach das Genitale als Ganzes; alle anderen sind sekundäre.

Die alte Einteilung hat in der Folge mancherlei Kritik und Änderung erfahren - ich neme Brandt $\left.(7)^{1}\right)$, Laurent Kurella (42), Ell is (13), neuerdings Poll (52a). K a m merer (30) und Stein a ch (63). Sie ist durch die Abgrenzung primärer, sekundïrer und tertiärer Merkmale (Brandt: La nrentIurella) erweitert, andererseits ach durch die Cmwertung des, Sekundären" in kansalem und zeitlichem simne ihrer ur" sprünglichen rein morphologisch-deskriptiven Absicht verlustig gegangell.

Ich lege meinen Cutersuchungen die von P'oll (52a and b) gegebene Einteilung der (ieschlechtsmerkmale zugrunde, die anch 'Tandler und Grosz (166) als die "derzeit beste" benemen. Sie unterscheidet die essentialen oder germinalen, allein durch die gegensitzliche Verschiedenheit der Keimzellen (Gameten) gegebenen Sexualmerkmale voll den a $\mathrm{k} z \mathrm{i} d \mathrm{entalen,}$ stellt also den gametischen Geschlechtsdifferenzen, die allein (Jolı annes I üller) das Geschlecht des Individuums, ob männlich oder weiblich, bestimmen, alle übrigen als somatische gegenübel.

Diese akzidentalen Merlimale gliedern sich wie folgt:

a) genitale subsidare:

¿) interne:

(j) externe;

b) extragenitile :

i) interne ;

3) externe.

$\mathrm{Zu}$ den genitalen subsidiären inneren Charakteren gehören die Leitungswege nebst ibren akzessorischen Drüsen; zu den äusseren die konjungalen Werkzeuge und die Brutapparate: zu den extragenitalen inneren Merkmalen z. B. die Stimmorgane, die psychischen Geschlechtsqualitäten; zu den extragenitalen äusseren die Körperbedeckung, Behaarung, Fürbung etc.

1) Die Zahlen beziehen sich auf die Literaturübersicht am Schluss. 
H.A. ') als Vischung entgegengesetzter Geschlechtscharaktere kann danach entweder die essentialen (germinalen) oder die akzidentalen Charaktere einbeziehen oder natürlich auch gleichzeitig diese wie jene.

Die Mischung der akzidentalen Geschlechtscharalktere bedeutet den in der Weltliteratur viel erörterten, mit mehr als tansend Fallen kasuistisch belegten falschen odel unechten H.A. (H. A. spurius, Pseudohermaphroditismus oder Scheinzwittertum). Hier besteht bei dem an sich geschlechtssicheren, also entweder sicher männlichen oder sicher weiblichen Individum ein grösserer oder kleinerer gegengeschlechtlicher Komplex von akzidentalen Merkmalen.

Demgegenüber ist nun allerdings eine reine, sozusagen umschriebene Vischung der essentialen Geschlechtsmerkmale; d. h. der beiderseitigen Cameten für die höheren Metazoen nicht möglich. Die Existenz der Gameten ist hier an die durch die Keimdrüsen (Gonaden) ${ }^{2}$ ) gegebenen und als Hoden und Ovarium makroskopisch und mikroskopisch geschlechtsspezifisch gebauten Hilfsapparate gebunden, und die Vischung der Gameten in einem Individuum bedeutet zugleich das Vorhandensein der beiderseitigen Keimdrüsen. Da aber der gesamte Zellbestand der Keindrüsen ausschliesslich der Gameten den inneren genitalen subsidiären Apparaten zurechnet, besteht in dem Vorhandensein von beiderlei Keimdruisen zugleich eine Mischung essentialer (gametischer) und akzidentaler (somatischer) Charaktere.

Diese Tatsache ist von vornherein im Ange zu behalten. wenn wir die Mischung essentialer Geschlechtscharaktere in einem Individuum als echten, wahren Hermaphroditismus zu der Vereinigung gegengeschlechtlicher akzidentaler charaktere bei einem Individuum als Psendohermaphroditismus in Gegensatz bringen, und der wahre H.A. ist in diesem Sinne notwendig identisch mit dem glandulären $(\mathrm{H} . \mathrm{A}$. bisexualis = biglandularis: $\mathrm{z}$. B. bei Kitt [3 b], S. 110).

Sofern der wahre H. A. gelegentlich bei den Vertretern einer physiologisch getrenntgeschlechtlichen Spezies beobachtet wird, ist

1) Ich setze H. A. = Hermaphroditismus: Ps. H. A. = Pseudohermaphroditismus.

2) "Gonade" gilt einerseits als Bezeichung des Hilfsapparates der Gameten, findet aber andererseits anch für die Keimdrïse als Ganzes Anwendung; vergl. z B. bei Tandlel und Grosz (66), S. 2 bezw. S. 30, 78, 8 ; 
el als sporadischer, pathologischer oder teratologischer, d. h. als Yissbildung charaliterisiert gegenüber dem physiologischen oder funktionellen, der für eine ganze Spezies die Norm darstellt.

Es ist bekannt und bei allen Erörterungen iiber den wahren H.A. der Säuger und des Menschen in einer Art ron Tradition immer wiederholt worden, dass dieser wahre funktionelle $H . A$. besonders rerbreitet bei den Wirbellosen vorkommt - bei Gastropoden (Mollusken); Hirndineen, Plathelminthen etc. - und diss wahrer H.A. - sei es physiologisch oder pathologisch - auch bei den niederen Vertebraten, Cylostomen, Fischen und Amphibien existiert, ohne dass freilich gerade auf den hier sehr wesentlichen Cmstand der starken Cnterschiede der Keimdrüsen bei diesem physiologischen und pathologischen H. A. niederer Tiere genügend hingewiesen wille. Hier bestehen alle möglichen Varianten: vämmlich rollkommen getrennte Keimdrüisen, oder Hoden und () varium als ..)votestis" oder "Zwitterdrüse", oder beiderlei Keimzellen in einer Lrüse vereinigt (../witterdrüse" im eigentlichen sinne $\left.{ }^{1}\right)$ ): kontemporïre Reifung mit der Möglichkeit der Selbstbefruchtungr (Ascidien ['Tunikaten|), alternierende - proterandrische oder protogrne - Funktion je einer leimdrüse oder auch Funktion nur einer Keimdrüse bei dauernder lunktionslosigkeit der anderen oder fehlende Funktion bei sonst gut ausgebildeten Apparaten (st tephan's [it| H. A. potentialis |s. potis| foecundus und sterilis).

Ich betone diese verschiedenen Kombinationen, weil sie das Verfehlte der nicht selten erhobenen Forderung erweisen (vergl. Finkenbrink [17], v. Rosthorn [56], Bucura [S|, Bayer [2], IL enge [.6]), für den wahren $H . A$. im allgemeinen und im besonderen gerade für den der höheren Wirbeltiere getrennte und funktionielende Keimdrüsen oder doch mindestens geschlechtsreife lieimzellen beiderlei Geschlechts - neben ausgebildeten männlichen und weiblichen Geschlechtsgängen - als merlüsslich zu betrachten. Der Schwerpunkt der Definition des wahren Hermaphroditismus liegt allein in der Mischung der germinalen Geschlechtscharalitere, d. b. der Gameten, aber weder in der besonderen Anordnung noch in der kontemporären Reifung oder Funktion der Keimzellen.

Ja, auch hier ist noch eine Einschränkung oder, wenn man will, eine Erweiterung der Definition notwendig, insofern nämlich

1) Vergl. Kopsch und Szymonowicz (36) in Teil IV. 
,Hischung der (iameten " beim H. A. verus nicht notwendig die Nischung der fertigen, befruchtùngspotenten Keimzellen bedeutet, sondern die heterosexuale Mischung auch durch geschlechtszellspezitische Vorstufen der fertigen sexualzellen - durch Gametogonien oder Gametozyten - gegeben sein kam. Terschiedenheiten dieser Art sowohl wie auch der vorhergenannten Kombinationen zeigen sich gerade in den Fällen des wahren H.A. der Vertebraten. ${ }^{1}$ )

Bei den Myxinoiden (Schleimaalen), die zu den Cyklostomen zählen, funktioniert bei jungen Fischen der hintere Abschnitt der hier umparen Gonade als Hoden, wathend der vordere Teil der Keimdrüse sich als Ovarium erweist, als solches aber erst später in Funktion tritt. Mit dem Erreichen des Reifezustandes des Ovarialanteils hört der Hodenabschnitt der Genitaldrüse zu funktionieren auf. Hier besteht also H. A. verus in Form der Proterandrie. Der vordere Abschnitt der Keimdrüsen der Gonade ist eine weibliche leimdrïse, auch in dem Stadium, in dem noch keine reifen Eizellen gebildet werken und lediglich ()vogonien volihanden sind, ebenso wie der Fierstock eines jungen menschlichen Embryo durch die hier ausschliesslich vorhandenen Ovogonien als weibliche Keimdrüse unzweifelhaft charakterisiert ist.

Anders bei dem physiologischen H. A. der Teleostier-(Knochentisch-)gattungen Serranus und ('hrysophrys, die zu den Perciden (Barschen) bezw. Sargiden (Brassen) gehören. Hier ist in die Wand des Ovariums ein wohlbegrenzter Hoden eingelagert, und es ist ein Vas deferens vorhanden (Wi ed e rsh e im [73], S. 601), das den ganzen Ovarialkanal umschliesst. Für Serranus (S. scriba C., Schriftbarsch oder Sägebarsch) behauptet ein so zuverlässiger Autor wie Cori (9) noch ganz jüngst wieder die Selbstbefruchtung; bei Chrysophrys (Chr. aurata L., Goldbrasse) findet gegenseitige Befruchtung statt. ${ }^{\text {}}$ )

1) Tourneux (68), vor ihm (1880) sclion Mac Leod (zitiert bei Tourneux), hatten neben dem funktionierenden Ovarium des weiblichen Maulwurfs ein physiologisch funktionierendes Testikelrudiment mit Zwischenzellen festgestellt, also bei einem Säuger (Insektivolen) eine physiologische Zwitterdruise, deren weiblicher Anteil in Funktion war. Nach Tandler und Gros z (S. 96 und 139) handelt es sich dabei lediglich um die im Maulwurfsovarium mächtig entwickelte Glandula interstitialis, wie sie in ähnlicher Massivität im Ovarium des Pferdes oder Esels zu finden ist.

3) Vergl. ferner bei Haempel (27) weitere Teleostierspezies mit physiologischem wahren H.A.: Box salpa L, Goldstriemen; Sargus annularis L., Geissbrasse; Pagellus erythrinus C., Rotbrasse; Pagellus mormyı'us C., 
Ein wahrer H.A. existiert unter den anuren Amphibien ${ }^{1}$ ) so stark gehïuft, dass er bei den Raniden fast physiologisch erscheint (T andler und Grosz [66], S. 79/s0). Hier existieren beim Frosch ausser münnlichen und weiblichen Tieren noch sogenannte intermediäre Formen oder P fl ü ger'sche Hermaphroditen mit Zwitterdrüsen (Hoden und Ovarium vereinigt), die der Mehrzahl nach spüter zu mämnlichen, in geringer Zahl auch zu weiblichen 'lieren werden. Für die Bufonen wiederum ist als ein physiologischer Befund das Biddersche Organ ${ }^{2}$ ) bekannt, das entweder am oberen Ende eines normal funktionierenden Hodens Eier in verschiedenen Fntwicklungsstadien führt oder das umgekehrt (W. Waldeyer $[70]$, S. 418 o.) neben einem funktionierenden Orarium zuweilen auch Spermien ausbildet. Im ganzen also bei Cyklostomen, Fischen und gewissen Amphibien ein wahrer Hermaphroditismus von gewiss wechsehnder Morphologie und Funktion! ${ }^{3}$ )

Bei den Vögein und den Säugetieren ist der wahre H. A. lediglich als unbestreitbar pathologischer oder teratologischer beobachtet und zwar als eine sicherlich sehr seltene Missbildung, obschon er, wie unsere eigenen Befunde zeigen, wenigstens für eine bestimmte Säugetierspezies in einem immerhin übersehbaren Verhältnis $\mathrm{zu}$ finden ist.

Fül den wahren H. A. del Vögel hat z. B. Poll (52a) in einem anch aus anderen Grunde (vergl. unten) bemerkenswerten Fall - Ovirium links, Hoden rechts bei Pyrrhula pyrrhula - die gleichzeitige Existenz der männlichen und weiblichen Geschlechtszellen erwiesen. Dagegen ist dieser Nachweis bisher noch für keinen Fall eines wahren H.A. der Säugetiere und des Menschen

Marmorbrasse. Andere Fischspezies zeigen inkonstanten oder gelegentlichei wahren H. A.: Gadus morrhua L., Dorsch; Scomber scomber L., Makrele; Clupea harengus L., Hering; Lota vulgaris C., Rutte; Trutta fario L., Forelle; Cyprinus carpio L., Karpfen u. a.

1) Betreft's der Urodelen vergl. H. A. verus bei Triton (L a Valette St. George, zitiert bei $\mathrm{Kerm}$ a u er [33a], S. 335).

2) Dass (K e r m an e r [33 b], S, 455 o.) der Ovotestis der Kröte „dem indifferenten Zustand der Keimdrüse entspricht", ist ebenso unrichtig, wie dass (33 a, S. 335) er hier eine ,entschieden pathologische Form “ darstellt.

3) H. A. effectivus successivus bei den Myxinoiden, effectivus antogamus bei Serranus, reciprocus bei Chrysophrys, potentialis foecundus bei den Raniden und Bufonen nach dem Stephanschen Schema. 
erbracht ${ }^{1}$ ), und darum wird es verständlich, wenn eine Reihe von Autoren sich gegen die Anerkennung dieser Form mehr oder weniger energisch striubt.

Das Material des H.A. verus bei Mensch und Saugetier ist zuletzt 1909) durch Ernst $\mathrm{Sau}$ erbeck ( $5 \$$ ) einer sehr kritischen und eingehenden Sichtung unterzogen worden.

sa u e rbeck, dem das besondere Verdienst zukommt, zuerst systematisch auch den H.A. und insbesondere den wahren H.A. der Säugetiere in einer für das Problem höchst förderlichen Art verwertet und die Vorteile der vergleichenden Methode diesen Fragen nutzbar gemacht zu haben, lïsst schliesslich als s ichere Fälle, die allen Anforderungen genügen, für das Süugetier sieben Beobachtungen einschliesslich einer eigenen gelten), sümtlich beim Schwein, und für den Menschen zwei, die Beobachtungen von Ernst salén (j7) und simon (60). Dazu als „sehr wahrscheinliche" für die Sïuger drei ${ }^{3}$ ) (zwei Fälle beim Reh und einen bei der Ziege) und für den Menschen fïnf. ${ }^{4}$ ) In den ersteren ist die mikroskopische Lntersuchung eine unzulingliche, in den letzteren ist trotz mikioskopischer Lintersuchung die Qualitiit der (Geschlechtsdrüisen (einer oder beider) wegen atypischer, immer wohl stark hypoplastischel Ausbildung nicht unbedingt sicher (l. c.. S. 6(i7).

Für den Menschen ist inzwischen noch ein sicherer, auch mikroskopisch genau untersuchter Fall von Uffred u z z i $(69 \mathrm{a}, \mathrm{b}, \mathrm{c})$ und schliesslich ein Fall von Gudernatsch (23) beigebracht worden, der freilich im Sinne ron Sa u erbeck eher \%u den "sehr wahrscheinlichen" zählt.

Wemn ich von dieser letzteren Kategorie hier ganz absehe und mich, zunächst unter Ausschluss des später genau zu beschreibenden Falles von Ernst Salén, lediglich an die sicheren Fälle halte, so sind hier in der 'Tat in keinem Falle in Hoden und Eierstock beiderlei Geschlechtszellen erwiesen.

1) Betreffs des Falles P ï z (53) siehe unten.

3) Beobachtungen von Garth (20), Fall 1 und 2, Kopsch und Szymonowicz (66), Becker (3), Pütz (53), Reuter (55).

3) Boas, Fall 1 und 2; if a yer; siehe Tabelle III, S. 672, Fall VIII bis $\mathrm{X}$ bei $\mathrm{S}$ a uerbeck (58).

4) Blacker-Lawrence, Gast, OboTonski, Schmorl, Zimmermann; siehe Tabelle III, S. 674, Fall III-VII, 1. c. Gelegentlich (1. e. S. $697,698,703$ und 704) werden freilich auch die sehr wahrscheinlichen Fuille zu den sicheren gezäblt. 
Während der Eierstock in allen diesen Beobachtungen ${ }^{1}$ ) Eizellen enthält, entweder Primordialfollikel oder auch weitere Entwicklungsstadien der Primordialfollikel bis zu Corpora lutea, sind (vergl. bei Sa uerbeck, l. c., Tabelle VI) in den Kanälchen des Hodens niemals Archispermiozyten oder spermatogonien, geschweige denn höhere Stadien der Spermiogenese zu finden.

Dabei sind (vergl. unten) unter diesen zehn Fällen Hoden und Eierstock neunmal doppel- oder einseitig zu einer Zwitterdrïse (Ovotestis) rereinigt; im Falle Renter's (5.5) fand sich der Hoden rechts, das Ovarium links.

Der Hoden in allen diesen Fällen entspricht in seinen histologischen Qualitäten ganz dem gewöhulichen /ustande des Hodens beim H.A. spurius masculinus, und weiter gleichen diese Hoden der wahren und falschen Hermaphroditen histologisch wieder vollkommen den Hoden des Kryptorchen, deren feineren Aufbau die Cntersuchungen von Langhans (41), Finotti (18), Fílicet et Branca (15), Spangaro (61) u. a. kennen gelehrt haben. Dass diese Übereinstimumng, die sich auf alle histologischen Details erstreckt, tatsiichlich besteht, ist nach dem rorliegenden Material für den Menschen wie für das Säugetier ${ }^{2}$ ) ganz ausser Zweifel. Es bedarf dazu, wie ich gegenüber Kermauner (33b) ausdrücklich bemerke, keiner neuen vergleichenden Untersuchungen.

Jedenfalls ist so die Bedentung der Frage, ob die männliche Keimdrüse auch beim Fehlen der germinalen Charaktere allein durch ihre somatischen Bestandteile als männliche charakterisiert ist, eine das Gebiet des H. A. überschreitende, weit allgemeinere, entsprechend dem relativ liäufigen Vorkommen des Kryptorchismus bei Mensch und Silugern.

Was zunatchst die Forderung der Geschlechtsreife bezw. Funktion der Keimdrüsen für die Anerkemung des Sexus und im besonderen für die Anerkennung des doppelten Geschlechts der Keimdrüsen beim H.A. verus anlangt, so halte ich diese im Prinzip für verfehlt. Das betont auch Sa uerbeck (l. c., S. 340

1) Betreffs der genauen morphologischen Einzelhciten rergl. Teil IY.

2) Vergl. bei $S$ a u e r be c k (58), S. 865, Abs. 3, betr. des H. A. rerus und spurius beim Sehwein; ferner S. 694, allgemein betr. der histologischen Übereinstimmung der Hoden bei H.A. verus, spurius und Kryptorchismus ich kann diese histologische Identität nach eigenem Ylaterial bestätigen; für die Übereinstimmung bei Kryptorchen und Scheinzwittern vergl. neuerdings $\mathrm{H}$ of st a t te (28), ferner Verfasser (51 a). 
und 690) in aller Schärfe. Ebenso entfält mit der Ablehnung dieser Forderung der weitere Schluss (Finkenbrink [17], v. Rosthorn [56], Menge [46]), dass für den Menschen und die Saugetiere, da getrennte und funktionierende Keimdrüsen beiderlei Geschlechts nicht erwiesen seien, überhaupt nur von Pse u d o hermaphroditismus gesprochen werden müsse. ${ }^{1}$ )

Wenn Menge bei der Diskussion des H. A. verus alle Individuen, deren Keimdrüsen nicht funktionieren, wenn sie sich auch morphologisch sonst irgendwie bezeichnen lassen, als .geschlechtslos" charakterisiert, so wilre dies, wie es Sa u erbeck in ahnlichem Zusammenhang (I. c., S. 690) sehr richtig ausdrückt, "logisch gleichwertig mit der Forderung, keinen Menschen ror Nachweis der Vater- oder Mutterschaft zu dem einen oder anderen Geschlecht zu zählen". Und es würde aus gleichem Grund das lirytorchische, nicht hermaphroditische oder pseudohermaphroditische, Individuum, dessen sonstige sekundäre, accidentale Geschlechtscharaktere im Sinne des Männlichen stets in aller Vollkommenheit vorbanden sind, zu einem Yeutrum, ein Schluss, der kaum ernstlich diskutiert zu werden braucht.

Auch Kermauner (33b) hall die Forderung der Funlition als Kriterium der bestimmten Sexualität der Keimdrüsen für zu weitgehend, aber er verlangt doch immerhin für die Diagnose des echten H.A. den Nachweis von Keimzellen beiderlei Geschlechts, und es lauft schliesslich auch auf das Nämliche hinaus, wenn Sauerbeck das einschichtige Epithel in den Samenkanälchen des Hodens in seinem Fall von H. A. verus beim Schwein im Sinne der französischen Autoren (Prenant, Félicet et Branca) analog den häutigen Befunden im ektopischen Hoden als "sekundär eimheitlich" auffasst, und ihn danach, , welln auch nur implicite", alle wesentlichen Elemente der Keimdrüse, also auch die Samenzellen enthalten lässt, deren Produktion für eine spätere Lebenszeit des 'lieres nicht auszuschliessen wäle.

Abgesehen davon, dass nach den neuen Ergebnissen der Entwicklungsgeschichte diese besonders von den französischen Forschern vertretene, unicistische" Auffassung der Spermiogenese endgültig erledigt ist, bült aber Sauerbeck an anderer Stelle

1) So auch Kitt (30̃), S. 110, der aber bei Anwesenheit der Genitaldrüsen zweierlei Geschlechts „im rein anatomischen Sinne“ die Bezeichnung als Hermaphroditismus verus anerkennt.

Irchiv f. mikr. Annt. Bd. S4. Abt. If. 
mit Entschiedenheit den Standpunkt inne, dass man bei H.A. nicht minder als bei normalen Individuen oder überhaupt nicht hermaphroditischen Individuen auf eine männliche oder weibliche Drüse zu erkemnen hat, sobald ein histologisches Bild vorliegt, das nur in der Entwicklung des einen Geschlechts existiert. Yit anderen Worten: auch olne die spezifischen Keimzellen wird das Geschlecht durch den organspezitischen Ban der Gonade sicher bestimmt, also, worauf es für die Frage des wahren und falschen H. A. hauptsächlich ankommt, anch obne münnliche Keimzellen durch eine sonst charakteristische Keimdrüse diss minnliche Geschlecht des Individuums oder bei gleichzeitig vorhandenem Ovarium der H. A. verus.

Für diese eigentlich selbstverständliche Anschanung, die ich in allen ihren folgerungen vertrete, lisst sich, insbesondere auch gegenüber den neuerlichen Ausführungen Kermauners, mehr als ein Argument anführen.

Sicherlich treten die somatischen Zellkomplexe, die immerhalb der (xonaden in den besonderen Dienst der Reifung und Generation der Geschlechtszellen gestellt sind, schon dadurch in einen Gegensatz zn allen anderen somatischen akzidentalen (ieschlechtscharikteren. Diesem Umstand trägt der allgemeine Sprachgebranch insofern Rechnung, als vielfach, so auch an anderer Stelle (52a) bei Poll, nicht die Gameten, sondern die Gonaden als prim it re (essentiale) Geschlechtsmerkmale in Gegensatz zu allen übrigen als sekundären gebracht werden, und diese Auffassung ist so verbreitet, dass T a udler und Glosz, obne die Bedeutung der Keimzellen als Träger der eigentlich primären Merkmale zu verkennen, sie für ihre den biologischen Grundlagen der sekundäreu Geschlechtscharaktere gewidmeten Untersuchungen ausdrücklich akzeptieren (vergl. 1. c., S. 12 oben und S. 3, 130 und 133).

Die gegensätzliche Stellung des somatischen Keimdrüsenanteils gegenüber allen anderen akzidentalen Geschlechtsmerkmalen findet sich aber noch in einer anderen ausserst wichtigen Beziehung, und es sind gerade die eben genannten Untersuchungen von Tandler und Grosz, die sich mit diesen Verbältnissen sehr wesentlich beschäftigen.

Die Keimdrüse besteht neben dem generativen Anteil, der die Produktion bezw. Reifung der Gameten besorgt, aus einem innersekretorischen Anteil, der interstitiellen Drüse, die im Hoden 
durch die Leydigschen Zwischenzellen, im Ovarium durch den gelben Körper und die den L e y d i g schen Zellen korrespondierenden, bei den verschiedenen Tierspezies nicht gleichmässig entwickelten Zwischenzellen repräsentiert ist. Alle sekundüren Geschlechtscharaktere ${ }^{\text {) }}$ ) entstehen (vergl. Tandler und Grosz; auch Steinach) phylogenetisch wie ontogenetisch unter dem schon intrauterin tütigen Einfluss der von der interstitiellen Drüse gelieferten geschlechtsspezifischen Keimdrüsen- oder Sexualhormone, vielfach nicht ohne gleichzeitige Hormonwirkung seitens anderer "komplementïrer" innersekretorischer Drüsen (Schilddrüse, Thymus, Hypophyse, Glandula pinealis, Nebenniere). Sie sind, um es so auszudrücken, plyssiologische Produkte der Harmonie der Hormone. ${ }^{2}$ )

Wie für den generativen somatischen Keimdrüsenteil durch seine engen Beziehungen zur Produktion und Reifung der Keimzellen, so besteht auch für den innersekretorischen Gonadenteil eine unbestreitbare Sonderstellung gegenüber allen anderen sekundüren somatischen Charaliteren. $\mathrm{Er}^{\mathrm{r}}$ ist im Verhältnis $\mathrm{zu}$ diesen von ubbrragender sexual-spezifischer Bedeutung, und da wenigstens im allgemeinen gerade in den Hoden der Fryptorchen sowie der I'seudohermaphroditen und wahren Hermaphroditen im Gegensatz zu der Mangelhaftigkeit der generativen Bestandteile der imerselrretorische Abschnitt, d. h. der Zwischenzellenbestand mit dem des normalen Hodens in del allgemeinen und speziellen Struktur übereinstimmt, so besteht lier ein für die Entscheidung der Geschlechtszugebörigkeit (Männlichkeit) durchaus wesentliches Merkmal. Sind es nach 'Tandler und Grosz (1. c., S. 133) die Gonaden, die "als primüre (essentiale) Merkmale die Geschlechtszugehörigkeit eines Individuums eindeutig bestimmen",

1) Nach Poll zum mindesten eine Anzahl der akzidentalen Charaktere, nämlich die "versiblen".

Nach Tandler und Grosz ist in der Ontogenese die Abhängigkeit von den Keimdrüsenhormonen für die phylogenetisch jüngsten Sexualcharaktere am ausgeprägtesten.

2) Die von Plato und späteren Autoren vertretene Auffassung der Zwischenzellen als Hilfsorgane der Spermiogenese wird von Tandler and Grosz mit Rücksicht auf gewisse neue Befunde Goldmanns (Einwanderung


nicht unbedingt abgelehnt; wohl aber die Theorie Kyrles, nach der die Leydigschen Zellen der Regeneration des Hodenparenchyms dienen sollen (vergl. 66, S. 86, 90, 115, 116, 120, 121 und 122). 
so ist damit neben die geschlechtsbestimmende Valenz der Gameten die geschlechtsspezitische Bedeutung der Zwischenzellen - wenn auch nur in biologischem Sinne - gesetzt. Es wïrden nach alledem Hoden aus typisch geordneten Samenkanälchen und Zwischenzellen auch ohne männliche Geschlechtszellen meines Erachtens als Hoden nicht zu bezweiteln sein.

Nun ist aber weiter der völlige Mangel ron Geschlechtszellen in den Hoden der Kryptorchen und der Pseudohermaphroditen keineswegs eine undurchbrochene Regel. Einmal gibt es hier, wenn auch selten, Falle einer regelrechten Spermiogenese. Sie ist von $\left(\operatorname{arth}^{1}\right) \%$. B. in den retinierten Hoden eines schweinekryptorchen gesehen (vergl. Sauerbeck [58|. S. (69:3 0.), und ron Merkel (47) in dem Falle eines münnlichen 52 jährigen Pseudohermaphroditen, wo bei der gleichzeitigen Anwesenheit von Scheide, Uterus und Tuben die Hoden an der Stelle del Eierstöcke, also innerhalb der Bauchhöhle, gelegen waren. ${ }^{2}$ )

Lnd weiter ist insbesondere für den Hoden der menschlichen Fryptorchen, bei denen die Möglichlieit einer lntersnchung in Altersserien gegeben ist, häutig genug entweder vollständige Spermiogenese (von Uffreduzri [69 d] neuerdings in $10 \%$ der Kanälchen im retinierten Hoden; vergl. auch einen Fall bei Basso [1]) oder mangelhafte Spermiogenese oder doch wenigstens, wie in der jüngst von Tandler und Grosz untersuchten serie. in den Hoden kindlicher Kryptorchen ein Bestand an pathologisch veranderten Urgeschlechtszellen oder Spermatogonien festgestellt worden. ${ }^{3}$ ) Also unvollkommene Spermatogenese oder zerfallende, zugrunde gehende Ureier, aber doch immerhin männliche (ieschlechtszellen.

Erwagt man, dass z. B. in den Tandler und Groszschen Priparaten zur Zeit der Pubertat in den kryptorchischen Hoden diese Elemente spurlos verschwunden waren, so liegt darin ein

5) Garth (1. c.) betont mit Recht die Notwendigkeit. in jedem einzelnen dieser Fälle auch bei den wahren Hermaphroditen möglichst umfassende Üntersuchungen der ganzen Hodensubstanz vorzunehmen; vergl. auch Simon (60), S. 24, unter Bezugnahme auf die Feststellungen Finot is.

*) Vergl. auch Sau erbeck (S. 353 o.), der für die Ektopie der Hoden, auch die der echten Zwitter, alle Übergänge vom Zustand der "sekundären unification cellulaire" bis zum normalen, geschlechtsreifen Hoden feststellt.

3) Auch ich selbst habe bei gelegentlichen Untersuchungen in Leisten. hoden Jugendlicher zweifellose Elemente der Geschlechtszellreihe gefunden. 
höchst bedeutsamer Hinweis darauf, dass auch in den „geschlechtszellosen", sonst geschlechtsspezifisch gebauten Hoden der H. A. und Ps. H. A. in früherer Zeit Geschlechtszellen vorhanden waren. Es ist möglich, dass sich die geschlechtsspezifischen männlichen Strukturen der Hodenkanälchen überhaupt nur bilden, wenn wenigstens für eine kurze Phase der Ontogenese münnliche Keimzellen gegenwärtig sind. Jedenfalls ist der Gedanke eines passagären Bestehens von Keimzellen (oder beim Ps. H. A. andersgeschlechtlichen Keimdrüsengewebes), eines Unterschiedes dessen, was gefunden wird, von dem, was tatsächlich dagewesen ist, gelegentlich der Erörterung dieser Fragen wiederholt zu finden. So bei S a u erbeck (58, S. $350,352,831,872$ und 873$)$, bei Kelmauner (33b, S. 457 ; auch $33 \mathrm{c}$, S. 494) und neuerdings bei Gudernatsch (23. S. 269).

Aber selbst wenn wir alles Hypothetische ausschalten, machen sicherlich die tatsachlichen Befunde zugrundegehender Geschlechtszellen in jugendlichen kryptorchischen Hoden für diese ganze Gruppe histologisch sonst vollkommen übereinstimmender Keimdruisen der Kryptorchen und der männlichen Pseudohermaphroditen die nilmlichen Vorgünge nicht nnwahrscheinlich, und die Abtrennung .,mancher", d.h. geschlechtszelloser Formen des Kryptorchismus (Ke rmaun er, 33 b, S. 459) zu einer durchaus künstlichen. Alle Individuen dieser Art sind danach auch von diesem Gesichtspunkt aus durch Hoden ohne Keimzellen in ihrer Mämnlichkeit genügend charakterisiert, und der "Krypt o $\mathrm{ch}^{*}$ trägt seinen Namen mit ebenso gutem Recht, als im System des Pseudohermaphroditismus vom weiblichen Scheinzwitter der mänıliche geschieden wird, auch wenn sein Hoden keine männlichen Geschlechtszellen auffinden lässt. Und mit nicht minderer Berechtigung endlich ist der im kleinsten entsprechend gebaute Anteil des Ovotestis wirklicher $\mathrm{Hoden.}$

Eine besonders radikale Stellung nimmt gegenüber der Auffassung dieser keimzellosen Hoden als wirkliche Hoden neuerdings Kerma uner $(33 \mathrm{~b})^{1}$ ) ein. Das Einzige, was in dem histo-

1) Kermauner, der an anderer Stelle (33a) die Zwitterdrüsen (Ovotestis) der Säugetiere und des Menschen in der Zusammenstellung Sa uerbecks anerkennt, sie dort, vorläufig noch auf eine bisexuale Anlage der Keimdrüsen zurückführt" und "die Möglichkeit der Existenz hermaphroditischer Eier für diese Fälle zugibt", hat diese Anschauung, wie er übrigens selbst andeutet (S. 446), neuerdings seiner radikaleren Überzeugung geopfert. 
logischen Bilde des Hodens der bisher bekannten Zwitterdrüsen ${ }^{1}$, bei Mensch und Säugern an den Hoden erinnert, sind die Katlälchen, und "Kanälchen allein beweisen noch keinen Hoden". Der nämliche $Z$ weifel bezüglich der „Hoden“-Natur gilt für die analog gebauten, als münnliche angesprochenen Keimdrüsen der männlichen Pseudohermaphroditen und "mancher": Kryptorchen. Kermanner stiitzt sich hierbei auf folgende embryologische Erwägung:

Ein Rete (= Markschliuche) wird in völlig homologer Form im Hoden sowohl wie im Ovarium angelegt. Da , ein Teil zum mindesten des ganzen Kanalsystems der 'Tubuli contorti rom Rete abstammt" und als "das natürlichste wohl anzunehmen ist, dass nur Teile, welche deutliche Spermatogenese antweisen, ant die Keimstränge zurückgefüln't werden dürfen", die ..ander'en aber auf das - vielleicht übermässig gewucherte - Rete", so sind alle diese hodenähnlichen Gebilde der Orotestes, nicht minder logischerweise die histologisch analogen der Pseudohermaphroditen und gewisser Kryptorchen, lediglich adenomatöse Fehlbildungen seitens des ovariellen Rete (Adenoma retis |3:b| S. 459); sie sind Hodenimitationen, Scheinhoden (Pseudotestes), die cine Scheinmännlichkeit der Keimdrüsen, eine Psendoandrie, vortäuschen.

Diesen Beweis balte ich in allen l'unkten für misslungen. Unhaltbar ist die Behauptung Kermaners, dass die Hoden del Hermaphroditen (und Kryptorchen) a lle in durch die Kanälchen an den Hoden erinnern. Die im histologischen Bilde oft so stark vortretenden $Z$ wischenzellen werden dabei vollkommen übersehen. Unhaltbar ist der angenommene Unterschied der Embryogenese der Geschlechtszellen führenden Tubuli contorti ron der Entstehung der hiutig ganz analog gebauten geschlechtszellosen Kanälchen. Töllig unhaltbar ist auch die Annahme der Genese der Tubuli contorti aus dem Rete. Über ihre Abstammung aus den Keimsträngen bezw. dem Keimepithel besteht nach den neuen Untersuchungen (vergl. W. Felix, 14) keinerlei Zweifel. Selbst die Tubuli recti entstammen nicht dem Reteblastem; sondern den inneren Enden der Hodenstränge (vergl. ferner das Keibelsche Schema, 32, S. 23, Fig. 8).

1) Auch der Fall Reuters würde dabei inbegriffen sein, da der Bau des Hodens sich von dem des männlichen Teils der Zwitterdrüsen nicht unterscheidet. 
In dem nämlichen Sinne ist auch v. Rosthorns (56) Autfassung der Zwitterdrüsen (Ovotestis) als glandulürer Pseudohermaphroditismus strikt abzulehnen. Die "Zwitterdrüsen" der Säuger und des Menschen enthalten neben dem Eierstocksteil wirklichen $\mathrm{Hoden}$, sie sind Beweisstiicke eines wahren sexualen Dimorphismus der Keimdrïsen und damit des wahren Hermaphroditismus.

Ganz gewiss ist der H. A. verus dieser Form nicht nur von der oft postulierten bisexuell-funktionellen, sondern auch von derjenigen, zuerst charakterisierten Form verschieden. für die in den zum Ovotestis vereinigten Gonaden zugleich eine Mischung del Gameten iiberhaupt (resp. der Gametogonien oder Gametozyten) besteht.

Ebenso wie nach den bisherigen tatsächlichen Feststellungen bei der Kombination eines Ovariums mit einem greschlechtszellIosen Hoden die Ovula $\%$ rur vollen Reife (eventuell Funktion ?) ${ }^{1}$ ) gelangen können, wäre auch bei der Kombination geschlechtszellenführender Keimdrüsen die volle Ausreifung entweder im Ovarium oder im Hoden möglich.

Es würden sich danach für den wahren pathologischen oder teratologischen H. A. der Süuger und des Menschen (nnbeschadet der Anordnung und Verteilung der Keimdriisen im einzehen) a priori folgende Möglichkeiten ergeben.

I. Hoden und Eierstock mit beiderlei (jameten in roller Geschlechtsreife ${ }^{2}$ ) (Funktion).

II. Hoden und Eierstock mit beiderlei Gameten

1. mit Geschlechtsreife (Funktion) del (iameten einer Keimdrüse

a) des Ovariums;

b) des Hodens;

2. Reifung der Gameten in keiner der beiden Drüsen.

III. Hoden ohne Keimzellen, Eierstock mit Keimzellen

1. reifend (funktionierend);

2. nicht reifend.

1) Die Funktion eines Abschnittes der Zwitterdrüse (des Ovariums) ist in den Fällen von $H$. A. verus an sich prinzipiell nicht in Abrede zu stellen; so führte in dem Falle von $\mathrm{B}$ oas von $\mathrm{H}$. A. Iateralis beim Reh das Tier ein Junges bei sich.

2) Hierher würde, falls die durch die selır spärlichen Spermieli des Samens bewiesene Spermatogenese in den Hodenkanälchen mikroskopisch hätte demonstriert werden können, der Fall $\mathrm{P}$ ï $\mathrm{t} z$ zählen. 
(Betreffs „Ovarium ohne Keimzellen", Hoden mit Keimzellen vergl. unten: Anmerliung.)

Ich möchte entsprechend der speziellen Differenzierung des generativen lieimdrüsenanteils in germinale und vegetative Geschlechtszellen (Benda) die Gruppen I und II als wahren rein germinalen (oder essentialen) Hermaphroditismus, die Gruppe III als wahren vegetativ-germinale ${ }^{1}$ ) Hermaphroditismus bezeichnen. Gruppe I würde in reinster Form dem funktionellen wahren H. A. von Tandler und Grosz, Gruppe II. 2) und III, 2 dem morphologischen wahren H. A. dieser Autoren entsprechen, Gruppe II, I und III, 1 mit einseitiger Reifung der lieimzellen im Eierstock bezw. im Hoden und bloss morphologisch charakterisiertem Hoden bezw. Ovarium würden eine Intermediärstellung zwischen dem funktionellen und dem morphologischen innehalten. Jedenfalls bezeichnen bemerkenswerterweise auch Tandler und und Grosz die Differenzen \%wischen der funktionellen und morphologischen (truppe lediglich als graduelle.")

Sowohl für den germinalen wie für den regetativ-germinalen H. A. wären die beiderlei Cronaden als getrennte Drüsen oder vereinigte Ovotestis möglich, nach dem bekannten Schema von Klebs als bilateraler $H$. A. oder als unilateraler $H$. A. bei vorhandener: sei es münnlicher oder weiblicher oder fehlender Keimdrüse der anderen Seite oder aber als H. A. lateralis bei münnlicher der cinen, weiblicher Keimdrüse der anderen Seite. Sauerbeck hat alle diese Möglichkeiten der Anordnung und

1) Würde man (rergl. Fall Gudernats ch [23], atch Kitt [35̄], S. 113 u.) ein Ovarium ohne vïllig sichere Keimzellen nur nach seinem charakteristischen Bau - Mark und Rinde mit Keimepithel und typischem Rindenstroma oder mit. Follikeln ohne Eizellen (S a u erbeck [58], S. 691) - in gleichem Sinne wie einen lediglich aus gewundenen Kanälchen ohne Samenzellen bestehenden Hoden akzeptieren, so würde einmal sub III auch die Kombination von Hoden mit männlichen Keimzellen und Ovarium ohne Keimzellen möglich sein und ferner (Fall Gudernatsch) als eine dritte Form der wah re rein vegetative Hermaphroditismus bestehen.

Der Fall Gudernatsch, dessen Präparate dem VIII. Internationalen Zoologenkongress in Graz vorlagen, wird in der Tat durch A. Kohn-Prag. Tandler and Grosz und, nach der Angabe von Gudernatsch, auch von den Kongress-Mitgliedern als $\mathrm{H}$. A. verus mit Orotestis begutachtet.

3) Diese Formen des H. A. verus der Säuger und des Menschen würden in Stephans allgemeinem Schema des H. A. unter die Kategorien des H. A. potentialis foecundus und sterilis bezw. rudimentarius glandularis entfallen. 
Verteilung der Gonaden in sein erweitertes Klebssches Schema eimbezogen (vergl. l. c. S. 666,670 und 6!) 1 nebst Tab. II) und in seiner tabellarischen Analyse der einschlägigen Fälle von Vensch und Tier zur Anwendung gebracht. ${ }^{1}$ )

Wir erhalten danach im Sinne von Klebs-Sauerbeck den $H$. A. verus als:

I. bilateralis

a) mit getrennten,

b) mit vereinigten Keimdriisen.

II. unilateralis (dexter oder sinister)

a) mit getrenten,

b) mit vereinigten lieimdrüsen, dabei

a) mit vorhandener Keimdrüse der anderen Seite (completus) als

«ca) Hoden (masculinus),

(3) Eierstock (femininus)

(B) mit fehlender Keimdrïse der anderen Seite (incompletus).

III. lateralis (alternans bei lít t)

a) mäunliche Keimdriise rechts (masculinus dexter),

b) männliche Keimdrüse links (masculinus sinister).

Jede einzelne Form dieses /wittertums könnte in unserem Simne als ein rein germinaler oder als ein vegetativ-germinaler,

1) Eine kritische Besprechung der verschiedenen Schemata des H. A. und Ps. H. A. liegt nicht in meiner Absicht. Sa uerbeck vergleicht und kritisiert die Modifikationsversnche, die Kaplan (1895), Benda (1895) und Siegenbeck van Heukelom (1898) an dem von Sauerbeck selbst beibehaltenen und erweiterten $K l$ ebsschen Schema des $H$. A. vornehmen. $\mathrm{Halb}$ a hat es durch die Berücksichtigung der sekundüren und psychischen Geschlechtsmerkmale erweitert; die , sekundären" sind hier im Sinne Hu n ter Darwins die extragenitalen Charaktere unter Ausschluss der besonders gestellten psychischen Eigenschaften; Kermauner hat die anatomische Reduktion im sinne Bendas noch verstärkt. Tandler und Grosz schlagen vor, die von $P_{0} l 1$ angegebene Einteilung der Geschlechtsmerkmale auf die Einteilung des $H$. A. zu übertragen.

Das hei diesen Reduktionen vortretende, anch ron Sa nerbeck (1. c. S. $663,831-832,875-876$ ) bekämpfte Prinzip, bestimmte Formen des H. A., namentlich den $H$. A, externus als zufällige " Missbildungen von besonderer; sozusagen unspezifischer, eventuell grobmechanischer Ätiologie (als „PseudoPseudohermaphroditismus", j8, S. 832) vom Gebiet des H. A. abzutrennen, ja, den Ps. H. A. vom wahren H. A. im gleichen Sinne ätiologisch abzulösen, halte ich fül falsch (vergl. darüber unten). 
eventuell auch als ein lein vegetativer $H$. A. vorkommen, beim H. A. verus unilateralis die eventuell vorhandene Kieimdrüse der Gegenseite dabei übrigens gleichtalls entweder lieimzellen fülıren oder nicht und sie im ersteren Falle entweder ansreifen oder nicht ausreifen lassen, - eine nicht geringe Fülle ron \öglichkeiten, die allerdings, wie alsbald zu zeigen ist, durch die Tatsachen eine sehr wesentliche Einschränkung exfihrt.

Und doch sind damit - wenigstens rom theoretischen standpunkt aus - die fül den wahren H. A. offenen Möglichkeiten noch nicht einmal erschöpft.

Ich habe oben auf die sexualspezitische Bedentung des innersekretorischen Anteils der Keimdrüse, die spezitisch funktionierende (Steinach) interstitielle Drüse des Hodens und des Eierstoclis verwiesen und auf den als solchen sichergestellten formativen Einfluss der Keimdrüsenhormone zum mindesten anf einen Teil der sekundïren Geschlechtscharaktere. Wom wirklich, wies st e in ach nnd mit ilum ' $\mathrm{T}$ and der und Gros anmohmen. im differenzierten Hoden weibliche und im differenzierten orarjum mïnnliche Zwischenzellen („Pubertätszellen“ nach steinach) eingesprengt sein kömuten, so würde dem bisher allein bekannten und erürterten Keimdrüsen - Hermaphroditismus der' generativen Anteile ein solcher der innersekretorischen Anteile an die reite gestellt werden müssen. Er würde, den im übrigen geschlechtsspezitischen Bau von Hoden und Ovarium vorausgesetzt, rielleicht noch am ehesten als eine eigentümliche Form des wahren $H$. A. - als ein Hermaphroditismus verus glandulo-interstitialis - zu gruppieren sein. Und er würde sich von den Folmen des rein generativen H. A. verus nicht nur dadurch unterscheiden, dass hier die hermaphroditische Mischung in einer an sich einfachen, ausserlich nicht veründerten und anscheinend typischen Kieimdrüse rollzogen ist, sondern vor allem dadurch, dass mit der Sicherstellung dieser Form sich das physiologisch-kausale Moment in das bisher gezwungenermassen rein deskriptiv gehaltene Schemia des H. A., einführt. Zugleich würde nach den obengenannten Forrelationen der interstitiellen Drüse des Hodens und Eierstocks zu den „komplementăren“ inneren Drüsen des Organismus die kausale Störung über das Gebiet des glandulo-interstitiellen Hermaphroditismus der Keimdrüse mehr oder minder weit in das übrige polyglandulare System hinausgreifen. Es ist möglich, dass das, 
was wir heute in rein morphologischer Fassung als Pseudohermaphroditismus bezeichnen, in dieser Form des glandulo-interstitiellen Hermaphroditismus mehr oder weniger aufginge, und es ist natürlich weiter auch möglich, dass dieser als eine weitere Komplikation $z u$ den Mischungen der rein generativen Keimdrüsenanteile mehr oder weniger regelmässig hinzuträte.

Allerdings steht, was nicht $z u$ vergessen ist, diese Form des H. A. vor der Hand überhaupt nur auf dem Papier. ${ }^{3}$ ) Das erkemen auch Tandler und Grosz ausdrüicklich an. Cnsere Kenntnisse über die morphologische Identifizierung der männlichen und weiblichen interstitiellen Drüse und ihre physiologische Wirkung im einzelnen sind bisher so mangelhafte, dass mit einer ernsthaften Prüung der Hypothese zurzeit noch nicht der Anfang gemacht werden kanm. So bleibt also als sichere Form des wahren $\mathrm{H}$. A. zunachst allein der $\mathrm{H}$. A. der generativen Anteile der Gonaden.

Irüfen wir die Klebs-Sauerbecksche schematische Aufstellung, die gemäss unserer eigenen obigen Einteilung (germiniler, vegetativ-germinaler und rein vegetativer wahrer $H$. A.) vervollständigt ist, an der Hand der tatsächlichen Befinde, so ergibt sich nach dem bisherigen Material ${ }^{2}$ ) zunächst der Aus-

1) Vergl. unstren Befund im äusserlich unveründerten Ovarium des Falles V. Er betrifft in den äusserlich niclst verïnderten Eierstock versprengte Zwischenzellen und Samenkanälchen, stellt also doch eigentlich nur eine Abart des Orotestis dar.

*) Vergl, die eingangs (den Fall Sa lén schliesse ich [vergl. S 125] vorläufig aus) gegebene Aufzählung der Fälle von H. A. verus bei Mensch und Säugern. Dabei müchte ich auf die von $\mathrm{Kitt}(35)$ neuerdings erwähnten Fille von Hermaphroditismus biglandularis s. bisexualis (=- verus) hinweisen. Kitt zitiert: H. A. alternans biglandularis (..früher lateralis genannt") beim Schwein (Gurlt, Pütz, Münchener Sammlung) und beim Kalb (Schl u mpt, Soulié, Münchener Sammlung); H. A. unilateralis (biglandularis) beim Stier (M a scagni) und H. A. bilateralis (glandularis) beim Schaf (Scriba, Garlt), bei der Ziege ( $G$ urlt, Guinard), beim Eselsfüllen ( $H$ unter) und bei einer hörnertragenden scheinbaren Rehgeiss (Kitt). Fig. 51 stellt das innere Genitale bei einem H. A. biglandularis alternans des Kalbes dar; Fig. 52 das Nämliche bei einem Schwein.

Kitt erwähnt ausdrücklich, dass Johne, Bonnet, Sticker und er selbst auch histologische Feststellungen von bisexuellen Zwittern bei Haustieren vorgenommen haben.

Weiter finden sich in der französischen Literatur Beobachtungen von glandulärem H. A. bei Säugern, z. B. berichten Bou in und Ancel $(6 a, b)$ 
fall der Gruppen Ia und II a. Alle bisher bekannten sicheren Falle wahren Zwittertums mit doppelten Keimdriisen zeigen diese nicht getrennt, sondern, wie schon oben bemerkt, zur doppeloder einseitigen Zwitterdrüse vereinigt.

Weiter ergibt sich der vollkommene Ausfiall der rein germinalen Formen in unserem Sinne. In sämtlichen bisher bekannten Fällen der Zwitterdrüsen, ebenso in den beiden sicheren Fallen von $H$. A. verus lateralis (Reuter, Ki ingsburg) mit linksseitigem Ovarium und rechtsseitigem Hoden, ist der $H$. A. verus ein vegetativ-germinaler in lem Sinne, dass ler Hoden keine Geschlechtszellen, das Ovarium dagegen zweifellose Eizellen enthält. ${ }^{1}$ )

$E_{s}$ ist dies ein l'unkt von prinzipieller Bedeutung: nicht nur in rein morphologischem Betracht. Denu es ist, wie schon vorher angedentet, gar kein Zweifel: die immer von neuem anftauchende Opposition gegen den $H$. A. verus beim säuger und

wiederholt über solche. In der englischen bezw. amerikanischen Literatur gibt nuterdings $\mathrm{K}$ ings burg (34) eine Mitteilnng vom $\mathrm{H}$. A. verus lateralis beim Schwein mit histologischer Untersuchung. Neummonatliches Tier mit änsserem männlichen Genitale. Normaler Penis. Am Perinaeum ein vulvaähnlicher Wulst (,ridge"). Tagina und Uterus vorhanden. Keine Vaginalanwendung. Linkes Uterushorn mit Tube, Fimbrie und likeinbohnengrossem Eierstock; keine Spur von Hoden. Epididymis und Vas deferens auf dieser Seite. Rechts typischer IIoden, $2.5 \mathrm{~cm}$ lang, mit typischem Nebenhoden und Vas deferens. Kein Ovarium. Rechte Tube blind am Nebenhodenkopf endigend. Vom Ovarium wird das mittlere Drittel oder etwas mehr auf Serienschnitten mikroskopisch untersucht. Normales Ovarialstroma. Follikel (1 Graaf scher) zum Teil mit Ovula; kein Hodengewebe links. Im rechtsseitigen Hoden typische kryptorchische Struktur. Epithel einschichtig, vakuolisiert: zahlreiche typische Zwischenzellen.

Ein sicherer Fall von Orotestis beim Schwein ist ferner im Göttinger Pathologischen Institut seinerzeit unter $\mathrm{O} r$ th (laut gefl. persönlicher Mitteilung von $\mathrm{Or}$ th an mich) untersucht worden.

Ich habe es absichtlich unterlassen, die Sa u erbecksche Zusammenstellung des wahren $\mathrm{H}$. A. bei Sängern auf ihre Vollständigkeit zu prüfen oder sie insbesondere noch durch den einen oder anderen der genannten Fälle zu ergänzen. Ich sehe fïr die Frage darin keinen besonderen Nutzen mehr.

1) P iitz sah in seinem schon wiederholt zitierten Fall bei einem H. A. verus unilateralis dexter incompletus, $d$. h. bei rechtsseitiger $Z$ witterdrüse und links überhaupt fehlender Drüse, neben reifen Eifollikeln im Ovarium Spermatozoen im Sperma. Doch gelang der Nachweis irgendwelcher Zellen der samenbildenden Reihe bei der mikroskopischen Untersuchung des Hodens nicht.

Der Fall Gudernatsch entspricht unserer rein regetativen Form (vergl. oben S. 134). 
beim Menschen begründet sich letzten Endes darin. dass die gleichzeitige Existenz von Hoden und Eierstock mit ihren „unumginglichen charakteristischen Bestandteilen, den Keimzellen beiderlei Geschlechts", bisher von niemandem gezeigt worden ist. Daher die wiederholten Versuche - ich nenne hier Siegenbeck van Heukelom und W. Nagel $(48 \mathrm{~b})$ - alle Fülle von .Hermaphroditismus verus beim Menschen" in rïcksichtsloser, zum leil übrigens gewiss berechtigter Kritik zu beseitigen. Daher das Bestreben, die keimzellenlosen Hoden der Zwitterdrüsen zu Fehlbildungen eines Eierstocksrete zu degradieren. Daher die Bemühungen K erma un er's, für die Genese des Hermaphroditismus eine besondere doppeltgeschlechtliche Bildungstendenz überhaupt zurückznweisen und den gesamten Psendohermaphroditismus als eine rein lokale Genitalmissbildung im mechanistischen Simne aus einer zeitlichen Inkongruenz in der Eatwicklung der Wolffschen und Vüllerschen Gänge - zu begründen und inn in Annäherung an andere Genitalmissbildungen, wie die cloakenmissbildungen, seiner Eigenheit und Sonderstellung zu entkleiden.

Gibt es, so folgert $K$ erma un e $r(33 \mathrm{~b}, \mathrm{~S} .446)$, keine echten Hermaphroditen, bei denen Hoden und ovarium durch männliche und weibliche lieimzellen charakterisiert werden, so muss auch der Begrift des Pseudohermaphroditismus fallen.

Diese Folgerung ist falsch, weil die I'rimisse nicht stimmt. Es gibt in der' $T$ at auch für den Menschen einen wahren germinalen Hermaphroditiums, einen Hermaphroditisums, bei dem beide Geschlechtsdrüsen die spezifischen Geschlechtszellen enthalten. Ich werde den tatsăchlichen Beweis dafür erbringen. und ich gebe im folgenden eine eingehende, soviel als tunlich durch Abbildungen erlïuterte Beschreibung einer derartigen Beobachtung.

Ich lasse ilur aber zunachst eine Reihe von fünf eigenen Fällen des wahren $H$. A. beim Säuger vorangehen, die ich selbst untersucht habe. Sauerbeck hat die bis in das Kleinste gehende Übereinstimmung des H. A. der Säuger, des Ps. H. A. wie des wahren H. A., mit den Verhältnissen beim Menschen durch seine schon oben genannten Cinternehmungen in vergleichender Analyse erwiesen und damit die ganze Lehre mit einem Schlage auf eine weit breitere, gesichertere Grundlage gestellt. Insofern möchte ich gerade die Darstellung meiner Befunde beim Säugetier mit den von 
mir beim Xenschen gemachten Feststellungen verbinden. Meine Beobachtungen betreffen, wie alle bisherigen sicheren Fälle von H. A. verus beim Tier, das Schwein. Die relativ bedeutende Anzahl - fünf Fälle gegenüber den sieben sicheren sau erbecks aus der (iesamtliteratur der letzten 27-28 Jahre - habe ich aus dem Material des Berliner stidtischen Schlachthofes in den Jahren 1910-1913 mit der tatkraftigen und interessevollen Unterstützung des städtischen Schlachthofarztes Herrn Dr. Max Schmey zusammengebracht.

Meine Beobachtungen schliessen sich an die von Sauerbeck zusammengestellten von sicherem $H$. A. verus beim Schwein unmittelbar an. Ich will an der Hand der einzelnen Befunde prïfen, wieweit durch meine Ergebnisse die von Sauerbeck aus seinen Untersuchungen für den $\mathrm{H}$. A. verus abgeleiteten „phïnomenologischen Gesetze" sich bestïtigen bezw. erweitern lassen. "\%u dem nümlichen \%weck gebe ich auch eine kurze Wiedergabe des älteren Si monschen Falles von $H$. A. verus beim Menschen und der beiden neuen Falle von Uffreduzzi (69a, b, c) und (rudernatsch (23).

Freilich kommen bei allen diesen Cntersuchungen und Befunden des $\mathrm{H}$. A. verus nicht allein die rein morphologischen Detailfeststellungen in Frage. Die Bedeutung der positiven und jetzt nicht melur angreifbaren Begründung des wahren H. A. ist eine weit umfassendere, ja, grundsïtzliche für die Auffassung des H. $A$. velus überhaupt.

Durch den sicheren Nachweis des H. A. verus, durch seine gesetzmissige Kombination mit dem Ps. H. A. in seinen verschiedenen Abarten ist die Einheitlichkeit des H. A. gewälırleistet, zunächst natürlich im rein anatomischen Sinne. Aber darin liegt zugleich gewiss auch ein starker Hinweis auf eine gemeinsame Ätiologie aller Formen des H. A., des wahren wie des falschen.

Wir werden auf diese Fragen nach der Darstellung der tatsichlichen Befunde, die ich nun folgen lasse, einzugehen haben.

Teil II.

\section{a) Fünf eigene Fälle von Hermaphroditismus verus beim Schwein.}

Sämtliche ron mir untersuchten Tiere waren etwa 8 Monate alt. Die Kontrollorgane wurden von gleich alten männlichen und weiblichen normalen und kastrierten Scliweinen, von sogenannten „Borgs" bezw. „Nonnenschweinen", unter'sucht. 


\section{Fall I.}

Das Tier hat nach dem mir gegebenen Bericht Auffälliges an seinem äusseren Genitale, der Scheide und seiner Körperform nicht gezeigt. Der Gesamteindruck des Tieres war cin weiblicher und ebenso wie der Befund ter inneren Organe ohne eine Abweichung.

Ich nehme diese Angabe einfach all notam, da ich sie nicht habe nachprüfen kïnnen.

Ich erhielt den obersten Abschnitt der Scheide mitsant dem Uterus, den breiten Intterbündern und den Auhüngen in einem Stïck iTaf. XIII, Fall 1: Die oberste Scheide plus Cterusteil (ut) (Cervix und Corpus) war 9) cm lang.

Die Schnittfliche zeigt den Muskelschlauch der Scheide selır lirititig entwickelt; er ist etwas von vorn nach hinten abgeplattet, bei einem Querdurchmesser von $2 \neq \mathrm{mm}$. Das Lumen ist mit normaler Schleimhaut ausgrokleidet, stellt sich als ein querer Spalt dar. Zu beiden Seiten des Lumens von Muskalatur umgeben. aber doch schon am Rand des Durchschnittes erscheinen zwei deutliche Lumina (Gg) (Vasa deferentias.

Die Uterushörner (ulh), die ans der Trennung des unpaaren Teiles an normaler Stelle hervorgehen, sind krittig entwickelt, je etwa $33 \mathrm{~cm}$ lang und $2, \overline{\mathrm{cm}}$ dick. Die Dicke sinkt da, wo sic nach abwäirts umbiegen, auf $2 \mathrm{~cm}$. Schliesslich folgt unter besonderer Krümmung abgesetzt an jedem ILom ein $1 \mathrm{~cm}$ langer, $7--\& \mathrm{~mm}$ dicker, schnell verjüngter Endabschnitt.

Diesen Ende liegt jederseits ein Pol eines Kürpers an, der seinem ganzen F̈llsseren nach sofort als Hoden (h) imponiert. Er besitzt die Mabe links $4,5: 4.5: 3 \mathrm{~cm}$, rechlts $4.5: 4: 4 \mathrm{~cm}$, ist, abgesehen von seiner Verkleinerung gegen tie Norm. von normaler Form; seine bläulich-graue Oberfliche ist von nicht verdickter normaler Albuginea itherzogen.

Jederseits liegt aber der dem Ende des Uterushorns genühertc Hodenpol nicht frei, sondern wird von einer relativ flachen, kappenartigen Auf ligerung (o) umfasst, die uberall ganz scharf abgesetzt ist. Sie besitzt links wie rechts eine kleingebuckelte Oberfliche, die mit der glatten Aussenfläche der Hoden stark kontrastiert, eine derbe Konsistenz und eine durchscheinende, opakgelbe Farbe an manchen der kleinen Höcker. Die Maßje dieser Auflagerung betragen links: $1.9: 1,0: 0,8 \mathrm{~cm}$; rechts : $3: 2,3: 0,5 \mathrm{~cm}$.

Der Durchschnitt erribt beiderseits eine exquisite "Zwitterdriise" ${ }^{\text {" }}$ die kappenartigen Organe sind typische Ovarien. Das linke (vergl. auf Taf. IX: Fall 1 [links] o und h) zeigt neben einem Corpus luteum einige erbsengrosse zystische Follikel bezw. Follikelzysten mit klarem Inbait; das rechte typische kleinere und grössere Corpora latea und einige kleinere zystische Follikel bezw. Follikelzysten oder mehr grauliche solide Abschnitte.

Etwa dem mittleren Teil der Grenze gegen den Hoden entsprechend besteht jederseits eine bedeutende Ansammlung kleiner weiter Blutgefässe, die sogar etwas in die Hodensubstanz hinein einschneidet; sie entspricht dem Eierstocksmark (vergl. Taf. IX m). Im übrigen zieht zwischen Hoden und Eierstock als Fortsetzung der Albuginea testis eine feine weissliche Membran die scharfe Grenze; sie ist auch unterbalb des Eierstocksmarks in aller Schärfe vorhanden (vergl. Taf. IX). 
Die Durchschnittsfläche des Hodens (in seiner grössten Dicle) entspricht in ihrer bräunlichen Farbe der Norm. Auffällig ist nur der Mangel einer irgendwie nennenswerten Septierung und ror allem das Fehlen eines eigentlichen Hilus bezw. eines Corpus Highmori. obschon der Schnitt genau gregen den Kopf des beiderseits sehr kräftigen Nebenhodens (Taf. XIII, Inh) gefühlht ist. Ilieser setzt etwa gegenüber dem aufgelagerten Eierstock an, bei rinem beiderseits sehr lockeren, frei beweglichen Verhältnis des Nebenhodenliopfes zum Hoden. Auf dem Durchschnitt des Nebenhodenkopfes besteht sehr excuisite Lïppohenzeichnung. Die Hydatiden fehlen.

Die Länge des in seiner Form iturchius typischen, normal alygeplitteten. ca. $1 \mathrm{~cm}$ breiten Nebenhodens beträgt links etwa $1 \mathrm{t}$ cm, rechts $16 \mathrm{~cm}$. Er zieht mit gegen den Hoden gerichtetem schitten Rand längs des Hudens. und dann im freien Rand des Ligamentun latum so hernu, dass die Übergangsstelle in clas Vas deferens jederseits etwal dal liegr, wo die Uterushärner in ihr kurzes, verjiungtes Endstück auslaufen rergl. 'T:if. XIII! Das Yas deterens (Gil) zicht damn in typischen Schliingelungen zwischen den Blittern der zarten Ligamenta lata parallel zum liturushorn jederseits gegen den oberen Teil des unpararen Gebirmutterabschittes.

Dass es beiderseits auf der Schnittfliche der Scheide zutige tritt: ist schon erwähnt.

Auf die Konvexitait des rechten Vebenhodens tritt rom verjïngtcn Ende des Lterushorns ein $6 \mathrm{~cm}$ langer, fast stricknadeldicker String mit feinem Lumen iiber, der als Tube (rt) imponiert (vergl. anch unten dit mikroskopische Untersuchnng). Er lituft blind who Ostium auf der Nebenhorlenohertiache ans und ist der Furche zwischen Hoden and Ovarium unmittelbar benachbart. Links fehlt jetle Andeutung eines solchen Stranges.

\section{Mikroskopische Untersuchung.}

Härtung in 10prozentigem Formalin; Paraftineinhettung; Färbungen : Hïmilant-Eosin; van Gieson; Orcein nich Unna-Tänzer: Elastinfürbung nach Weigert (mit Karmin- und Parakarmin-Torfäbungy).

1. Es ergeben sich vollkommen normale Verhiiltnisse, die einer besonderen Beschreibung nicht bedürfen: a) tïr das $Y$ as d ef erens im (linken! Liganentum latum; b) fül den Kopf des (linken) Nebenhodens. Jice Flimmern der hohen Zylinderzellen sind vielfach erhaltes.

2. Ferner zeigt normale Verhältnisse ein unerer Schnitt kur\% vor dem blinden Endstiick des U terushorns und durch den Anfangsteil des nnmittelbar daneben gelegenen Samonleiters; der Schnitt triftt beide Organe.

3. Schnitte einer scheibe, die quer vom distalen Ende des Genitalschlauches (der $\mathrm{Sch}$ e ide) abgetragen wird, erweisen das makroskopisch jederseits sichtbare Lumen als Qucrschnitt des Vas deferens. Letzteres ist hier leicht geschlängelt, so dass es auf einzelnen Schnitten zweimal in verschiedener Richtung getroffen erscheint, aber frei von besonderen traubenförmigen Aussackungen.

4. Querschnitte durch den rechten Nebenhoden and den feinen. seiner Konvexität aufgelagerten Strang (Taf. XIII, rt) zeigen diesen als Tube. 
Die Muskulatur ist gut entwickelt, die Mucosa granz glatt, von Epithel entblïsst. Im Lumen abgestossene Epithelien, Kerne und Zerfallsprodukte.

5. Schnitte durch den Körper des linken Nebenhodens bestiitigen aut diesel Seite das vollkommene Fehlen der Tube.

6. Schnitte der rechten $\mathrm{Z}$ witterdr üse. Eine grosse Scheibe, die Eierstock und Hoden enthält, wird nach Formalinhäirtung in Paraftin eingebettet. Ausser den genannten Methoden ['ntersnchung von Crefrierschnitten des Hodens mit Hämalaun-Suduntärbung.

Hoden und Eierstock sind auch im mikroskopischen Prïparat scharf getrennt. Die trennende Bindegewebslige ist ziemlich lerb und kernarm (siehe 'Taf'. IX, Fig. 1, ao und at).

Das Eierstocksstroma ist nur an wenigen Stelien das typische, ierle, an kleinen Spindelzellen reiche. Neist ist es viel wemiger kernreich. stellenweise lockerer, stellenweise straffer, vielfach mit reichen Beimengungen wirrer Geflechte feiner elastischer Fasem versehen. Prinärfollikel sind nur sehr vereinzelt aufzufinden. Dagegen sind Wachstums- (Fig. 1, wfei) und Reifestadi‘n der Primordialfollikel in geschlossener Reihe vorhanden, bis zur Bildung: grösserer und kleinerer, wiederum ganz typischer Corpora lutea (cl). Eine Beschreibung dieser Formen erübrigt sich, da gegen die Norm auch nicht die leiseste Abweichung besteht. Daneben findet sich zystische Degreneration einzelner eiloser Follikel, cinige Male mit kleinen papilliaren, von den Gramulosazellen ïberzogenen Erhebungen der Theca follicnli.

Besonders bemerkenswert ist. diss eine Anzahl ron Entwicklungsstadien der Follikel, anch grosse und grösste Formen, durch die miichtigen Curpora lutea beiseite geschohen. erdrückt, ahgeplattet und zum Schwind gelloracht werilen.

An der schon makroskopisch gekennzcichneten Stelle des Markiteils ( $m$ auf Taf. IX) besteht eine starke Hiiufung weiter gewundener Arterien und Venen. Das kernarme Bindegewebsstroma umschliesst hier auch einige atrophische Kanälchen, von einschichtigem niedrigen Zylinterepithel umsiumt (atrophische Markstränge?).

Der $\mathrm{H} \circ$ de $n$ bietet an allen Stellen das nämliche Bild ohne irgendeine Abweichung. Er ist durch ïbcrall nur schmale, einfach fibröse, lockere Septen in unregelmässig konturicrte, verschieden grosse Lüippchen geteilt, wie schon die Lupenvergrösserung dentlich demonstriert, aber ohne eine besonders erkennbare Regelmässigkeit. Ein Corpus Highmori ist auch mikroskopisch nicht ersichtlich. Die einzelnen Lobuli bestehen lediglich aus

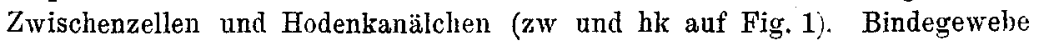
ist innerhalb der Läppchen nur in zartester konzentrischer Lage mit platten Kernen als Tunica der Samenkanälchen vorhanden; diese führt allerfeinste elastische Fasern.

Die Zwischenzellen sind gross, von 16,5 " mittlerem Durchmesser, prononciert polyedrisch, stark mit Eosin gefürbt, frei von Pigment, Kristallen und, wie die Sudanbehandlung der Formalin-Gefrierschnitte beweist, auch von Fett. Sie sind in die Maschen eines Netzes zarter Blutkapillaren ein. grelagert.

Archiv f. mikr. Anat. Bd. 84. Abt. II. 
Die Samenkanülchen sind bei 105ّ "mittlerem Durchmesser durchweg lumenlos, solide oder doch nur mit Andeutangen eines Lumens versehen, in den verschiedensten $R i c h t u n g e n$ getroffen, auch dichotomisch verbunden, von polyedrischen Epithelien, die zur Tunica hin öfters mehr längliche pallisadenartige Form aufweisen, als einziger Zellart gefüllt. Die Kerne sind im allgemeinen länglich, oft unregelmässig konturiert, diffus gefärbt.

Diese Epithelien sind bis anf die aussersten Lagen in ausserordentlich reichem Nabe scheinbar vakuolisiert, d. h. sie enthalten am Sudanpräparat grosse, oft zellfiillende Fettropfen, die den Kern unter entsprechender Formänderung an dic Wand drängen. So können eventuell Siegelringformen entstehen. An den Hämalaun-Eosinpräparaten sieht das Lumen der Samenkanälchen allermeist geradezu siebförmig aus.

Das quantitative Verhältnis von $Z$ wischenzellen und Samenkanülchen innerhalb der Läppchen steht schätzungsweise wie $3: 2$, eher noch mehr zilgunsten der Zwischenzellen; jedenfalls sind diese in kolossalen Mengen vorhanden. Die typische Albuginea $($ ca. $0,5 \mathrm{~mm}$ ) an der Obertlache des Hodens ist ebenso wie dic äusserste Stromalage des Ovariums von Keimepithel entblösst.

\section{Fall II.}

Für den zweiten Fall steht das ganze änssere und innere Genitale vollstïndig zur Verfügrung. Nur ist die Urethra mit der Harnblase durch den ïblichen . Schlïchterschnitt" algetrennt, und dabei der Genitalschlauch mit durchschnitten, so dass das Priiparat in zwei getrennten Teilen vorliegt.

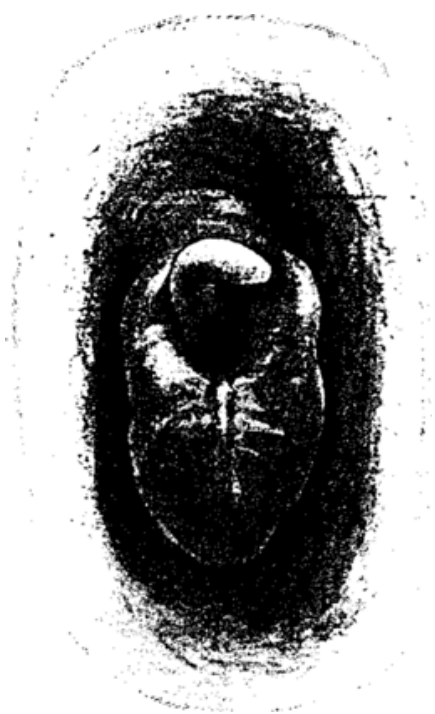

Fig. 1.

Ausser einer abnormen Bildung der iusseren Scham bestanden nach Bericht irgendwie äusserlich bemerkbare Missbildungen nicht. Der Gesamteindruck war ohne Auffulligkeiten der eines weiblichen Tieres. Auch die inneren Organe waren abgesehen vom Urogenitalapparat ohne Missbildung.

Das äussere Genitale (vergl. Textfigur 1) macht einen verbildeten, aber im ganzen doch weiblichen Eindruck. Die $7 \mathrm{~cm}$ langen Labien, schwärzlich grau pigmentiert und mit einigen starren Borsten besetzt, bilden unter Verwachsung in ihrem unteren und mittleren Teil ein relativ bedeutendes, dick vorspringendes Hautpolster (Scrotumrudiment?). Zwischen den nicht verwachsenen Teilen führt oben eine rundliche Öffnung von $7 \mathrm{~mm}$ Durchmesser in die Tiefe, und darüber liegt frei ein über $4 \mathrm{~cm}$ langer, also im Vergleich zur Yorm stark hypertrophischer, klitorisähnlicher Körper, der nach unten und links hakenförmig gekrümmt ist. In seinem oberen Umfang besteht ein $1 \mathrm{~cm}$ tiefer Präputialsack. 
Der normale kleine kegel- oder zungenförmige Hautanhang am ventralen Winkel der Vulva fehlt.

Von unten her ziehen zwei kaum zentimeterlange Hautfalten jederseits mit freiem Rand von den Labien zur Unterfläche der Klitoris und bilden hier ein ganz kurzes breites Frenulum.

Die genannte öffnung entspricht dem Eingang in den Sinus urogenitalis, der als ein über $18 \mathrm{~cm}$ langer und fast $2 \mathrm{~cm}$ dicker zylindrischer Schlauch, von gelblich grauer Schleimhaut ausgekleidet, dorsalwärts zieht. Der lichte Durchmesser betriigt dem Eingang entsprechend $7 \mathrm{~mm}$.

Auf dem Durchschnitt ist er unterhalb der glatten Mucosa von seinem hintersten Abschnitt an rings von einer gelbrötlichen, stark vaskularisierten, weichen, nach aussen durch eine dünne weissliche Kapsel scharf begrenzten Masse - der Pars disseminata prostatae (siehe Taf. XI, Fig. 2) - mantelförmig umgeben, die unmittelbar bis an die Schleimhaut reicht, mit ihr in ganzer Breite zusammenhüngt. Sie ist ventral und an den Seiten mächtiger, während sie dorsalwärts an Masse abnimmt. Die grïsste Ausbildung erreicht sie ventralwärts mit fast $5 \mathrm{~mm}$ Dicke, etwa $10 \mathrm{~cm}$ vor der Sinusmündung, dann nimmt sie mündungswïrts schnell an Dicke ab, und zwar zuerst ventralwärts, so dass hier $8 \mathrm{~cm}$ vor dem Orificium ihre Kontinuitait bereits ca. $1 \mathrm{~cm}$ nnterbrochen ist. $6 \mathrm{~cm}$ vor der Sinusmündung ist sie nur noch dorsalwiirts als schmaler Saum erhalten und $3 \mathrm{~cm}$ vor der Sinusmündung ganz verschwunden. In den mittleren Alsschnitten des Sinus legen sich ventralwïrts rechts und links seitlich von der Mantelmasse die Muskelzüge des Musculus urethralis an.

Über das Corpus prostatae ist nichts Sicheres anszusagen. Die grossen Vestibulardrïsen tehlen.

Auf den Schlauch des Sinus urogenitalis unmittelbar aufgelagert, von dichten Fettmassen umgeben, ist die Fortsetzung der Klitoris als solider, anscheinend $11 \mathrm{~cm}$ langer, drehrunder Strang von $6 \mathrm{~mm}$ Durchmesser. In Wirklichkeit ist er noch einige Zentimeter länger, da er auf der Dorsalflïche des Sinusrohres S-förmig verläuft und ausserdem kurz hinter dem äusseren Eingang in den Urogenitalsinus in scharf S-förmiger Windung als knopfförmiger Vorsprung sich von rechts her in den Sinus vorwölbt.

Der hinterste Abschnitt des Klitorisstranges ist oben und seitlich von Muskeln eingefasst. Beiderseits dicht neben ilm laufen etwas vor seiner Mitte die in Form und Aussehen typischen bleistiftdicken runden Mutterbänder in das Fettgewebe der Labien aus.

Die Verbindung des Sinus urogenitalis mit der Scheide und Harnröhre ist, wie schon erwähnt, durchtrennt. Durch die Schnitte des Schlächters ist zogleich vom hintersten Sinusabschnitt ein Stück mit entfernt. Das Lageverhältnis der Scheide zum Sinus urogenitalis (ob unmittelbare Fortsetzung des letzteren oder Eintritt in ihn ,von hinten her" [vergl. Sauerbeck, S. 356 und 343]) und die Beschaffenheit ihrer Einmündung (ob verengt?), ebenso wie die Einmündungsart der Vasa deferentia und der Prostatakörper ist wegen dieser Kontinuitätstrennungen nicht sicher zu bestimmen.

Das Scheidenlumen, von vorn nach hinten abgeplattet, ist weit, misst von rechts nach links $45 \mathrm{~mm}$. Die Vaginalwand ist verdünnt, nur etwa 
$3 \mathrm{~mm}$ dick (gegen $4-\overline{\mathrm{mm}}$ der Norm). An jeder Seite ist auf dem Durchschnitt in den verschiedenen Höhen der Scheidenwand und in symmetrischer Anordnung je ein körniges Körperchen von etwa $2 \mathrm{~mm}$ Durchmesser zu sehen (.Pseudosamenblasen “) (Taf. XIII, Fall 2, psisa). Die Seheidenschleimhaut ist graurot, rauh. -

Der Uterus mit seinen Hörnern (vergl. Taf́. XIII) ist hier in cine Pyometra kolossalsten Lmfanges umgewandelt: sie enthielt etwa 15 Liter graugelben, geruchlosen Eiters. Das rechte Horn ist wcit über mannskoptgross, das linke kindskopfgross.

Das Endometrium stellt sich als eine typische pyogene Membran dar. Das Perimetrium ist von fiddigen und breiteren lamellösen Adhïsionen besetzt, die Ligamenta lata sind grauweisslich verdickt, und haben ilhre natiirliche Transparenz zum grössten Teile cingebüsst. An ihrem unteren tiand sitzen an der Abtrennungstläche cinige haselnussgrosse weiche Lymphdrüsen mit gleichmässig graugelblicher trüber Schnitttliiche. Der Sack des linken Uterushornes hat nach Entlecrung und filltigem Colliıps einen Aussenkontur von $\$ 3 \mathrm{~cm}$, der des reeliten grösseren (ull) von $82 \mathrm{~cm}$.

Scheide plus inpaarer (ut) Uterusteil messen bis zur Teilungsstelle $20 \mathrm{~cm}$. Die weite Scheide geht in das miichtip erweiterte, etwa doppeltmannsfaustgrosse Cavum uteri allmählich iiler.

Eine Stenose oder cin Verschluss des erweiterten Genitalschliuches ist am Präparat nicht ersichtlich. Er muss also an der rom Schliichter durchtrennten Stelle, d. h. am untersten Endr der erweiterten und in ihrer Wand verdünnten Schcide gesessen haben. Beide L'terushörner endigen unter miichtiger kenlenförmiger Auftreibmg hlind. Hier schliesst sich ummittelbar die Keimdrüse an.

Sie besteht hicr jederscits aus zwei scharf abgesetzten und in Konsistenz und Aussehen verschiedenen Anteilen. Der eine derselben - links $4,5: 4: 3 \mathrm{~cm}$; rechts $4: 3,5: 2,8 \mathrm{~cm}$ - erscheint ohne weiteres als typischer IIoden (h) mit blaugrauer glatter Obertliiche: der andere - links $4: 2,5: 1,2 \mathrm{~cm}$, rechts etwas grösser wie der Hoden - als Ovarium (o). Die Hoden sind, abgesehen von ihrer Verkleinerung gregen die Norm, von gewöhnlicher Form, aber gegen die aufliegenden Ovarien abgeplattet: die Oberfläche ist ron normaler Albuginea iiberzogem. Die Ovarien, besonders das rechte, sind reich gebuckelt, teils durcli opakgelbe Körper, teils durch vorspringende transparente kleinere und grössere Zysten.

Auf dem gegen den Kopf des kräftigen Nebenhodens geführten Durchschnitt (vergl. Taf. IX, Fall 2 [rechts]) fällt an den Hoden (h) der Mangel der regelmässigen Septierung des brüunlichen Purenchyms und das Feblen des Corpus Highmori auf. Der linke Eierstock (o) enthält auf dem Schnitt neben einer Reihe bis erbsengrosser Corpora lutea einige über erbsengrosse glattwandige zystische Follikel; der rechte (Taf. IX) ein halbes Dutzend bis bohnengrosser gelber Körper (cl) und an der Peripherie an zwei diametralen Stellen je eine walnussgrosse und eine klein-walnussgrosse Zyste mit glatter, weisslich-grauer Innenfläche und klarem serösen Inhalt (fc).

Das $Z$ wischengewebe an beiden Ovarien ist trüb grauweisslich. Eine besonders reichliche Ansammlung, zumal am rechten Ovarium über der Mitte 
der Grenzlinie gegen den Hoden hin, bildet eine ausgesprochene Markschicht (m).

Als scharfe Grenze zwischen Hoden und Eierstock ist zwischen beiden Organen die Albuginea des Hodens fortgesetzt. Auf dem Durchschnitt (Taf. IX) wird die breite kappenartige Umfassung des Hodens durch den Eierstock lesonders dentlich.

Der Kopf des Nebenhodens vergl. Taf. XIII, rnh liegt wiederum im Verhältnis zum Eierstock am Gegenpol des Hodens, mit diesem äusserst locker verlumden. Der Nebenhoden selbst ist kräftig entwickelt, von normaler, nur etwas platter liorm und $1 \mathrm{~cm}$ Breite, mit scharfem Rand gegen den Hoden hin. Er zieht beiderseits im freien Rand des Ligamentum latum gegen das verschlossenc Ende der Uterushörner, ist rechts $10 \mathrm{~cm}$ lang, links auf nur $7 \mathrm{~cm}$ deutlich verfolgbar, da er dann hicr zwischen derbe grauweissliche bindegewebjge Alhäsionsmembranen eingelagert ist. Hydatiden fehlen beiderseits.

Vom Ende des rechten Uterushornes bezw. des grossen Sackes aus ist auf den rechten Nebenhoden, dann im scharfen freien Rand der Epididymis unmittelbar neben dem Ovarium verlaufend, ein $7 \mathrm{~cm}$ langer lichtbräunlicher: reichlich stricknadeldicker Strang fortgesetzt (rt [hys|). Er ist etwas transparent, hat eine sehr dünne Wand und ein relativ weites Lumen. Links ist lieser strang (1t) weniger deutlich ausgesprochen. Irgendwie an das Fimbrienende erinnernde Billungen fehlen.

In der Nähe des Endes der Uterushörner liegt auch der Übergang der Nebenhoden in die Samenleiter (Gd), die im Ligamentum latum gegen den unpaaren Uteruskïrper verlaufen, auf ihrem Wege dorthin aber sich hier wegen der Verdickung und Trübung der Ligamente schwerer verfolgen lassen.

\section{Mikroskopische Untersuchung.}

(Technik wie im vorigen Falle.)

1. Der Querschnitt eines der runden Mutterbänder und

2. der Klitoris ist olne Abweichung.

3. Eine Scheibe quer zur Lüngsrichtung des Sinus urogenitalis (nach hinten von seiner Mitte entnommen [vergl. Fig. 2 auf Taf. XI]).

Das Epithel ist mehrschichtig, etwa nach Art des menschlichen Übergangsepithels angeordnet. Dnter der Epitheldecke im mïssig kernreichen fibrösen Stroma eine verschieden mächtige kleinzellige Infiltration: streckenweise fehlt über dieser auch die Epitheldecke mehr oder weniger, eventuell ganz. Die den Sinusschlauch umlagernde (für das blosse Auge gelbrötliche) Prostatamasse (pdpr), die in diesem Bereich des Sinus (vergl. oben) ihre grösste Entfaltung besitzt, besteht aus ziemlich locker aufgebauten, aber dicht aneinander geschlossenen, verzweigten tubulösen Einzeldrüsen. Die Tubuli führen ein einschichtiges niedrig-kubisches Epithel, das von den Kernen fast ausgefüllt ist: die grösseren Ausführungsgänge haben eine mehrschichtige Epithelauskleidung. Das Drüsenstroma, das mit dem Schleimhautstroma zusammenhängt, ist teils einfaches, ziemlich kernarmes Bindegewebe, teils mehr Jocker, flüssigkeitsreicher, mit Hämalaun leicht bläulich tingiert. Da und dort liegen kleinzellige Infiltrate zwischen den Tubulis. 
Überall zwischen den grossen tubulösen Einzeldrüsen, namentlich aber zwischen ihnen und der Schleimhautoberfläche, finden sich weite kavernöse dünnwandige venöse Blutgefüsse, oft in starker Hïufung (cc).

Auch die hintersten Abschnitte des Sinus wurden untersucht, mit den geschilderten gleichenden Befunden.

Die äussere Úmkapselung des Schlauches des Sinus urogenitalis wird durch einen kriiftigen Musculus urethralis (mur) gebildet. Nur fehlt an diesem die physiologische dorsale Unterbrecliung.

t. Querschnitt der Scheidenwand ror ler Einmündung in den Sinus urogenitalis.

Das geschichtete Plattenepithel ist lis ant geringe Reste verloren gegangen. Die Oberfläche der freiliegenden Tunica propria der Sehleimhaut ist auf das dichteste von kleinen Rundzellen durchsetzt. An wenigen Stellen senlit sich die Oberfläche in Form einer knrzen, aber weiten bauchigen Tasche ein, die mit einschichtigem Epithel ansggekleidet ist. Dieses Epithcl besteht aus niedrig-zylindrischen Elementen. deren dunkel gefïrbter Kern die basalen zwei Drittel des Zelleibes einnimun, wiilrend das innere geren das Lumen gerichtete Drittel gleichmässig trübes. stark mit Eosin gefïrbtes Plasma enthïlt.

Dic beiden Körperchen, die auf dem Durchschnitt symmetrisch zn beiden Seiten des Scheidenschlauches gelegen sind (Taf. XIII, pssia), habon eine drüsig-traubige Zusammensetzung, links ausgesprochener als rechts. Jedes der makroskopischen Granula besteht aus einer kleinen Anhïufung driisiger, besonders rechts stärker dilatierter Riiume. Jedes Agrgregat ist von einem dicken Mantel einigermassen konzentrischen Binlegewehes ungeben. das, zugleich in das Innere dringend, die einzelnen Kavititen trennt. Sie besitzen eine einschichtige Epithelauskleidung, die aber in ilırer besonderen Natur deswegen an vielen Stellen sich schwer feststellen lïsst. weil dis Epithel sich hier von der Linterlage losgelöst und im Inneren der Rüume zu lockerer Masse zusammengeballt hat. Dabei durchsetzen verschieden grosse unregelmässige Ansammlungen kleiner Rundzellen nnd Eiterkörperchen das Stroma und mischen sich im Innern der Räume mit den alogeschilferten Epithelien.

5. Linkes Vas deferens.

Das Vas deferens ist durch eine reichliche Ansammlung von Eiterkörperchen und Rundzellen in einer schaumig-vaktoliiren Grundmasse (Schleim?), die durch Eosin stark grefärbt ist, ausgedelnnt. Das Epithel ist erhalten, aber reduziert und abgeflacht, das subepitheliale Stroma der Mucosa verdünnt, von gelapptkernigen eosinophilen Leukozyten durchsetzt. Die übrige Wand ist frei. Hornes).

6. Wand der Pyometra (Stiick von der Konvexität des rechten

Das Oberfläclenepithel und der Drüsenapparat des Endometriums ist vollständig verloren gegangen. Das Stroma der Schleimhaut ist sehr locker, ödematös, an der Oberfläche von einer granulierenden Lage eingenommen, neben deren strotzenden Kapillaren kleine Extravasationen sichtbar werden. Die Muskelwand ist frei.

7. Querschnitte aus der Kontinuität des rechten Nebenhodens. 
Die Struktur des Nebenhodens ist ohne Abweichung von der Norm, der Flimmerbesatz des Epithels sehr gut konserviert.

Der Strang im freien Rand des Nebenhodens stellt sich als muskulöser, von einem einschichtigen Epithel ausgelileideter Schlauch dar. Die niedrigzylindrischen Zellen sind von den länglichen kräftig gefärbten Kernen fast gefüllt, an der Oberfläche mit einem Cilienbesatz versehen. Es folgt nach aussen eine dünne fibröse Tunica propria von mittlerem Kernreichtum, dann nach aussen zu nicht ganz regelnässig eine Ring- und schliesslich eine Lingsmuskellage mit dünner epithelloser Serosa. In der Lichtung hyaline, vakuolärschaumige Masse mit spärlich verstreuten freien kleinen runden Kernen. Im ganzen also das Bild einer blasig aufgeweiteten $\mathrm{T} u \mathrm{be}$ (Hydrosalpinx).

8. Querschnitt aus der Kontinuität des linken Nebenlıodens.

Linker Nebenhoden wie rechts. Der hier makroskopisch wenig ausgesprochene-Strang erweist sich als rein muskulös, ohne Lumen, also als lumenlose Tube".

9. Rechtsseitige Zwitterdrüse.

Die für die Untersuchung abgetragene Scheibe umfasst das g:inze Ovarium und die ganze Breite des angrenzenden Hodens; anderes Hodengewebe wird von der Näle des linken Nebenhodenliopfes entnommen.

Die Oberfläche des Eierstocks und Hodens ist frei von Keimepithel. Die Albuginea des Horlens ist etwa $3 \overline{0} 0$ " dick und schiebt sich in direkter Fortsetzung als Septum zwischen beide Organe.

Entsprechend dem makroskopischen Verhalten (Taf. IX, Fall 2) wird die Hanptmasse des Ei erstocks von den gelben Kürpern und von den Zysten eingenommen. Erstere sind vollkommen typisch gebaut; eines der auf den Schnitten zur Untersuchung gelangenden ist zystisch, der homogen geronnene Inhalt hier von verschieden zahlreichen Lagen der Luteinzellen umgeben. Die grossen Zysten sind epithellos. Ihre Begrenzung wird von etwas dichteren und stärker gefärbten Bindegewebslagen gebildet.

Das Stroma des Eierstocks ist allerwärts derb-fibrös, kern- und gefässarm, nirgends dem normalen Typus des klein-, dicht- und spindelzelligen Gewebes entsprechend. Primordialfollikel sind nur ganz vereinzelt und wenig deutlich zu finden, des öfteren weitere Entwicklungsstadien, aber meist durch Kompression seitens der benachbarten gelben Körper oder der grossen Zysten deformiert, atrophisch. Durch die noch erhaltene Eizelle sind sie indessen auch bei starker Abplattung und Verzerrung stets leicht festzustellen.

Der makroskopisch charakterisierte Markteil (Taf. IX, m) ist frei von Parenchym, enthält nur grosse weite Blutgefässe. -

Der Hoden ist mikroskopisch durch schmale bindegewebige Septen in Läppchen abgeteilt, allerdings in wenig regelmässiger Art und ohne ersichtliche Bildung eines Corpus Highmori. Das Bindegewebe der Septen ist bald straffer, bald lockerer und enthält oft schmale, kürzere oder längere Züge von Zwischenzellen. Diese sind hier zum Teil kleiner als im ersten Falle, von $11 \mu$ mittlerem Durchmesser, die grösseren Formen gleichfalls polyedrisch, sämtlich frei von Pigment und Kristallen, an den Sudanpräparaten auch von Fett. 
Auch hier bestehen die Lobuli wieder lediglich aus Zwischenzellen und Tubulis. Bindegewebe ist nur unmittelbar um die Tubuli in Form einer ansserordentlich dünnen Tunica vorhanden, die mit zartesten elastischen Fasem durchmischt ist Ihrer Quantität nach halten sich innerbalb der Läppchen Tubuli und Zwischenzellen etwa die Wage. Letztere gleichen denen der Interlobulärsepten. Sie sind von einem zarten Netz von Blutkapillaren durchzogen.

Die bei einem mittleren Durchmesser von 230 "gleichmiissig kalibrierten Tubnli. in den verschiedensten Richtungen getroffen, zeigen mannigfache Windungen, zuweilen auf längerer Strecke in der Ebene des Schnittes. Sie liıgen nur selten unter volliommener Reduktion des Stromas aneinander. fast stets schicben sich zwischen sie mehr oder minder reichliche Lagen von Zwischenzellen. (Manz gleichmïssig und in allen Teilen des Hodens sind sie von einer einfach en Epithelzellenlage mittlerer Höhe als einziger Zellart ausurekleidet. und gan\% gleichmässig sind diese Epithelzellen an den Balsamprïparaten so stark und unregelmässig vakuolisiert, dass dic ganze Epithellage ohne deutliche segenseitigre Begrenzung der Zellindividuen vollkommen durchsichtig schaumig elscheint. Die Sudanfïbung zeigt in den den Valkuolen entsprechenden \%ellabschnitten zwar anch ziemlich reichlich kleinere uni griossere Fettropfen, aber zugleich auch eine feinkörnige Masse, die nicht die Sulanrealition wibt. Die Kerne von mittlerem Chromatinreichtum, rundlich oder lïngli:h, finden sich an die Zellperiphorie, überwiegend an die Zellbasis, sedrïngt und so allermeist unmittelbar der Tınica der Kanälchen aufgelagert, dabei dimm vielfach ganz abgeplattet.

Im Lumen der Kan̈̈llchen liegt nicht selten teinfädige, vakuolïrc, mit Hämalaun blaugefärbte Masse, die auch mit dem Epithel direkt verbunden sein kann.

\section{Fall 3.}

Der iussere Eindruck des Tieres war vom weiblichen nicht irgendwie auffillig abweichend.

Das Genitale ist in zwei Stücken entfernt. Das eine Stück umfasst den Uterus nebst den Tuben und die Keimdritsen (T'af. XIII, Fall 3); das zweite Stück umfasst das äussere Genitale nebst dem daran ansetzenden Stück des Urogenitalsinus. Wiederum sind beide durch den Schlächterschnitt, der Urethra und Blase entfernt hat. an der Stelle der Urethraleinmündung voneinander getrennt. Ausserdem ist auch die Scheide nebst dem distalsten Stück des Sinus vom Uterus abgeschnitten und entfernt. So lässt sich über das Einmündungsverhältnis der Scheide in den Urogenitalsinus (ob von hinten her ?) und die Art der Mündungsstelle (verengt?) auch in dtesem Falle, wie in Fall 2, nichts Sicheres aussagen; desgleichen nicht über die Nïndung der Vasa deferentia und über das Corpus prostatae.

lterushals und -körper bis zur Trennung des Körpers in die Hörner (ut) sind $16 \mathrm{~cm}$ lang. Das von vorn nach hinten abgeplattete Organ misst von rechts nach links fast $\overline{5} \mathrm{~cm}$, besitzt ein deutlich aufgeweitetes Cavum. Die Hörner (uh) sind beiderseits vollkommen symmetrisch; bis zum Übergang in die Tuben je $45 \mathrm{~cm}$ lang, sehr stark entwickelt, mächtig gewulstet, nur 
wenig abgeplattet, von 3 bis über $4 \mathrm{~cm}$ Dicke. Ihr Lumen ist etwas aufgeweitet, fïhrt schleimigen Inhalt; die Schleimhaut ist graurötlich, $7-8 \mathrm{~mm}$ dick, sehr weich.

Jedes der Uterushörner geht über in eine links (It [hys]) 12 und rechts (rt) $11 \mathrm{~cm}$ weit verfolgbare Tube, die ohne Tubentrichter jederseits blind an der Keimdrüse endigt.

Letztere ist nun jederseits von auffälligster Beschaffenheit, Rechts findet sich ein $6: 4,5: 4,25 \mathrm{~cm}$ messender ziemlich derber Hoden (h), von glatter Albuginea iiberzogen, und diesem iufsitzend, unter furchenartiger $\mathrm{Ab}$ setzung, ein $\check{5}, 6: 3,3: 3 \mathrm{~cm}$ messender, dem Eierstock gleichender Körper (o). Dabei sind Hoden und Eierstock so verbunden, dass sie in der Richtung ihrer grössten Durchmesser aneinander gelagert sind. Die Oberfläche des Eierstocks ist glatt, nur ein wenig flach gebuckelt.

Auf dem Durehschnitt im grössten Durchmesser ergibt sich (vergl. Fall 3 [rechts] anf Taf. $\mathrm{L}$ ] : dis hellbriunliche Hodengewebe (h) ist durch unregelmässig sich verzweigende Bindegewebsstränge in verschieden grosse Läppchen greteilt, lie sich ohne besondere Regelmässigkeit um ein eben angedeutetes Corjus I lighmori (cH) gruppieren. Der Eierstock (o) enthält auf der nämlichen Schnittfliiche etwa ein halbes Dutzend gelber Körper (cl) und dabei einige ïberbohnengrosse, zum Teil aneinander gerüclite zystische Vollikel (H) mit blasier, glatter Innenfliche und zum Teil gallertig geronnenem Wrhalt. Auch an den gelhen Körpern ist gelegentlich das Zentrum zystisch, mit gallertiger, klar geronnener Masse gefüllt. Mit einem zentralzystischen Corpus luteum wölbt sich der Eierstock etwas in die Hodensubstanz hinein. Eine besondere Markzone ist nicht abgesetzt.

Dic Grenzlinie zwischen Eierstock und Hoden ist im übrigen eine vollkommen scharfe, so zwar, dass stellenweise in der grauweisslichen Grenzlinie noch die Albuginea des Hodens einerseits, die feste granweissliche OberHlichenschicht des Eierstocks andererseits sichtbar ist (vergl. Taf. $\mathrm{X}$ ).

Die vorher erwälnte rechte T'ube (Taf. XIII, rt) zieht als stopfnadeldicker Strang zum Ovarium. Sie liegt im freien Rand des Ligamentum latum, aber neben ihr, ihr anfs dichteste angeschlossen, zieht mit ihr parallel der kräftige Nebenhoden ( $\mathrm{rnl}$ ), und zwar grenzt sie unmittelbar an seinen scharfen Rand.

Der rechte Nebenhoden (rnh) entspringt vom Hoden etwa dem Ovarium gegenüber mit freibeweglichem Kopf und zieht in $14 \mathrm{~cm}$ Länge und $18 \mathrm{~mm}$ Körperbreite (mit der Tube) im freien Rand des Ligamentum latum mit seinem Schwanz bis vor die Stelle, wo das Uterushorn in die Tube übergeht, dann weiter als Vas deferens (Gd) durch die Substanz des Ligamentum latum bis zur Einsenkung in das Corpus uteri.

Beide Ligamanta lata sind ebenso wie der seröse Oberflächenbezug der Uterushörner und des unpaaren Uterusteiles diffus verdiclit, nicht sehr durchsichtig, jedoch genügend transparent, um das Vas deferens verfolgen zu lassen.

Die Verhältnisse der anderen Seite liegen im ganzen analog. Auch hier ist Hoden und Eierstock zu einer Drüse vereinigt in gleicher Situation vorhanden. Hodenmaße: $\check{0}, \tilde{0}: 3,7: 4 \mathrm{~cm}$; Eierstocksmaße: 4,2:3,2:4 cm. Auch hier sind die beiden Organe durch eine Einschnürung gegeneinander 
abgesetzt und in der Richtung der grïssten Durchmesser aneinander gelagert. Nur ist der Eierstocksteil hier nicht solide, sondern zystisch transparent, mit einem kleineren, von aussen betrachtet, anscheinend ebenfalls zystischen Anteil.

Auf dem Durchschnitt ist der Horlen mehr unregelmässig, ohne Andeutung eines Mediastinum testis, in Lïppchen geteilt.

Der grössere zystische Teil des Eierstocks erweist sich als ein einfacher, mit klarer Flïssigkeit gefiillter Hohlraum, in den von der dem Hoden zugekehrten Basis her ein gelber Körper hineinragt. Die Zystenwand ist derb fibrös, an der dem Floden zngekchrten Seite bis $1 \mathrm{~mm}$ dick. die Innenfliiche glatt. Der Kontur der Zyste baucht sich ein wenig in die Masse des Hodens ein. Die scharfe Trennungsschicht zwischen Hoden und Eierstock wird durch die Albuginea testis einerseits, andererseits durch die derbtibröse Zystenwand selhst gebildet.

Der übrige, kleinere Teil des Eierstocks besteht aus einer Hachen, etwa haselnussgrossen Zyste mit kiarem Inhalt und einigen unbedentenderen bis erlosengrossen Hohlräumen, so dass auf dieser Seite keine eigentliche solide Eierstocksmasse vorhanden ist. Kein Markteil.

Nebenborlen und 'lube sind links in gleicher Anurdnung wie auf der anderen Seite vorlhanden. Nur ist der Nebenhoden hier noch lïnger als rechts, im ganzen fast $19 \mathrm{~cm}$ lang. wobei cr alsbald hinter dem Ansatz seines Kopfes $V$-förmig abgeknickt ist (vergl. Tat. XIII).

J)ie Tube (1t [hys]), im freien Rand des breiten Mntterbandes, ist hier leicht aufgetrieben, transparent, an ihrem Anfang fast federkieldick, damn alsbald nur mehr stricknadeldick, aber an dem keulenförmig geschlossenen Ende wieder etwas stärker anschwellencl. Sie läuft anch hier wieler mit. dem Nicbenhoden eng verbunden, liegt auch hier an seinem scharfen Rand und zieht zum Eierstock, ilım eine kurze Strecke anliegend und in der Furche zwischen Hoden und Ovarium hlind endigend.

Das Vas deferens verhält sich links wie das rechtsseitige.

Auf beiden Uternshörnern sind ziemlich zahlreiche feine Adhäsionsreste zu sehen.

Hydatiden sind beiderseits nicht vorhanden.

Dem unteren Teil dor rechten seitlichen Cervixwand aufgelagert erscheint in $3,5 \mathrm{~cm}$ Länge, fast $2 \mathrm{~cm}$ Breite und wenigen Millimetern Diclie ein platter Kürper (Taf. XIII, rpssa), auf dem Durchschnitt von etwas. körniger Beschaffenheit (vergl. unten milkroskopische Untersuchung). Links fehlt eine ähnliche Bildung. Der rechtsseitige Kürper liegt genau in der Längsrichtung des Vas deferens. -

An dem zweiten 'Teil des Genitale ist zunächst ein $10 \mathrm{~cm}$ langes Stïck des Sinus urogenitalis erhalten, als ein im ganzen zylindrisches Rohr, das unter der glatten Mucosa von einer graugelblichen, ventral $5 \mathrm{~mm}$ dicken, dorsal und seitlich etwas dünneren weichen Schicht unkleidet ist und als Mantel um diese eine zirkulïre Schicht Muskulatur besitzt. Der Durchmesser des Rohres ist hinten an der Schnittfläche $18 \mathrm{~mm}$, verjüngt sich aber distalwärts; das Lumen hat im Nittel etwa $う \mathrm{~mm}$ Durchmesser. Drüsenlzürner, die den grossen Vorhofsdrüsen entsprechen könnten, sind makroskopisch nicht vorhanden. Dem distalen Ende des Sinus urogenitalis dorsal aufgelagert 
findet sich die ausserordentlich mächtig entwickelte und kräftig geschlängeite Klitoris mit starken Schwellkörpern. Sie hat bis zu ihrem Ende eine Länge, soweit die Windungen eine exalrte Massbestimmung zulassen, von etwa $17 \mathrm{~cm}$ !

Die den Schamlippen entsprechenden Hautfalten fehlen vollkommen. Dagegen ist der Vulvateil der Klitoris in einen über $5 \mathrm{~cm}$ langen, zeigefingerdicken drehrunden penisähnlichen Körper verwandelt, der frei vorragt und an der unteren Fläche seines abgerundeten Endes die Mündung des Sinus urogenitalis trägt.

MLan kann sich nach den Durchschnitten durch den Körper (Textfig. 2) seine Entstehung etwa so vorstellen, dass unter Verlïngerung und Verdickung der Klitoris selbst das mächtig hypertrophierende Präputium (pr) und die relativ atrophischen Labien (zl) sich rings um die Klitoris (cl) zusammenschlossen, wobei Präputium und Klitoris wenigstens zum Teil verwuchsen (a), d. h. der Präputialsack partiell obliterierte. So wurde eine mit "kutaner Schleimhaut" ausgekleidete Fortsetzung oder Verlängerung des Sinus urogenitalis (sug)

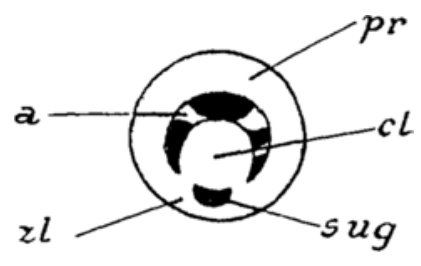

Fig. 2. entlang der Unterfäche der Klitoris gebildet, und die äussere Mündung dieses fortgesetzten Sinus urogenitalis entspricht gleichsam dem Introitus. einer verkümmerten Schamspalte.

Die Schleimhant des Sinus urogenitalis dieses ganzen Teiles ist im Vergleich zu der des erstgenannten Abschnittes diunn, kaum millimeterdick, von rötlicher Beschaffenheit.

Im ganzen also eine starke Hypertrophie der Klitoris und ihres Präputiums mit einer an die Bildung dles Penis anlilingenden ventralen Abschlussbildung, die eine entsprechende Verlängerung des Sinus urogenitalis bewirkt. Allerdings fehlt dabei jede Spur des für die Gestaltung dles normalen Penis wesentlichen Corpus cavernosum urethrae.

\section{Mikroskopische Untersuchung. \\ (Technik wie vorher.)}

1. Rechtes und linkes Uterishorn. Das Endometrium ist ausserordentlich idematös, nur in den dem Myometrium benachbarten Lagen etwas weniger von Flüssigkeit durchtränkt. Dabei sind die kleinen Blutgefässe, Arterien, Kapillaren und Venen vielfach erweitert und zum Teil strotzend gefüllt.

2. Der im Verfolg des rechten Samenleiters der seitlichen rechten. Cervixwand a ufgelagerte Körper ist drüsigen Baues. Die einzelnen Körner entsprechen lobulären Aggregaten reich verzweigter Tubuli. die von einem mässig hohen Epithel in einfacher Schicht mit basal stehenden rundlichen Kernen ausgekleidet sind. Im Lumen der Tubuli feinkörnigeGerinnungen und mehr oder minder zahlreiche Lymphozyten. Das Stroma zwischen den Läppchen wird von einem lockeren Bindegewebe mittleren Kernreichtums geliefert, das sich innerhalb der Läppchen um die Drüsenbildungen mehr konzentrisch und von dichterer Beschaffenheit anordnet. 
In dem korrespondierenden Abschnitt der linken Cervixwand ist anch mikroskopisch keine Andeutung dieser Formationen enthalten.

3. Schnitt in der Querrichtung der Pars pelvina arethrae. Die Innenauskleilung liefert ein Übergangsepithel. Die Driisen der Prostatamantelmasse besitzen hiev im Vergleich zu Fall II eine noch dichtere unil reichlichere Verzweigung. Wiellerum ist lie Prostata ventral stärker entwickelt als dorsal und auf beiden Seiten. In len grösseren Ausfüh'ungssiangen mehrsehichtiges Epithel. Das wenig kernreiche Stroma zwischrn den Drizsen, besonders aber die Schicht zwischen Drüsen und Schleimhantsbertliche führt zum Teil dicht gehïufte, weite und strotzend gefüllte, venüse Blutriume. Der Trethramuskel schliesst anch hier dorsal ohne Interbreciung ab.

4. Rechter Nabenhodankopf normal, Flimmern dentlich.

5. Rec lıter Neluenhodenkörperplus Tube. Ersterer ist normal, dic Epithelien haben deutliche Flimmern.

Die Tube hat eine gut ausgesprochene wesentlich zirkulire Muskulatur. Ihre Schleimhantoberfliche ist ranz glatt. faltenlos. Das einschichtige Epithel ist in continuo erhalten, zienlich niedrig; der Zelleib von Kern gefüllt.

6. Linker Nebonleodrnkopf wie rechts.

7. Tinker Nebenhodenkiorperplus T ube. Corpus epididymidis nolmal. Tube aufgeweitut mit stark abgeplattetem Epithel, sonst wie rechts.

s. Rechtes und linkes Vas deferens ohne Abweichung.

9. Rechtsseitige $\%$ witterdisc. Aus lem Ovarium und dem Hoden wird je eine Scheibe entnommen, und zwar wird vom Ovarium ein möglichst solider Abschnitt gewiihlt.

a) Orarium. Das Keimepithel der Oherfläche fehlt. Das Stroma ist nirgends typiseh dicht- und spindelzellig, sondern locker, faserreich, ron höchstens mittlerem Kerngehait. Primordialfollikel zu finden gelingt aut' keinem der untersuchten Schnitte. Dagegen sind Wachstums- und Reifungsstadien der Eifollikel, wenu anch nur in relatir geringer Zahl, vorhanden. Die Corpora lntea sind anch mikroskopisch typisch.

b) Die Albuginea des f o d ens (ca. 300 "dick) entbehrt gleichfalls des Keimepithels. Die fibrisen Septen zwischen den Hodenlippchen sind relativ dïnn, meist von Zwischenzellon erfiillt, die anch in grosser Nasse innerhalb der Lobuli zu finden sind. Ihr Verhältnis zu den Hodenkanälchen ist etwa 1:1; sie messen im Mittel $19, "$, sind polyedrisch geformt, frei von Fett (Sudanpräparate!), von Pigment oder Kristallen in ihrem Zytoplasma. Thre Kerne sind oft exzentrisch gelagert, rundlich, ziemlich hell, ohne deutliches Kernkörperchen, ihre Anhäufungen von einem Netz zarter Blutkapillaren durchzogen.

Die Samenkanälchen, bei einem mittleren Durchmesser von $150 \mu$ in allen möglichen Richtungen getroffen, sind in typischer Form gewunden. Die äusserst zarte Tunica propria wird von dünnen spindligen Zellen in einoder zweifacher Lage, mit mehr oiter weniger deutlich sichtbarer feinster tibrijs-elastischer Beimengung gebildet.

Ihr Epithel ist allerwärts einschichtig, aber dabei so stark von grossblasigen durchsichtigen Vakuolen durchsetzt, dass schaumige Masse das sanze Samenkanälchen vollkommen erfüllt und zentrale Lumina überhaupt 
nicht vorhanden sind. Die Vakuolen sind, wie die Sndanfarbung zeigt, durch grosse Fettropfen erfüllt. Die ziemlich hellen, einen Nukleolus führenden rundlichen Epithelkerne liegen bei nur gelegentlicher und unerheblicher Alplattung in einfacher dichter Reihe unmittelbar auf der Tnnica propriit. Hier beginnt zugleich sofort die sehaumige Auflösung des Zelleibes, so dass getrennte Epithelindividuen nicht existieren. Gelegentlich, aber nicht häufigg. sind auch Kerne oder Kernreste in das Lumen hinein vorgeschoben und in den Vakuolen oder den Vakuolensepten zu tinden.

Andersartige Zellelemente als die beschriebenen sind in den Samenkanälchen nicht vorhanden.

10. Linkseitige $Z$ witter disc.

a) Ovarium. Hier wird die grosse Zyste untersucht. Das Keimepithel fehlt. Die Zystenwand besteht aus parallel-faserigem, ziemlichl kernarmen Bindegewebe olne Innenauskleilung; sie cuthailt keine sonstigen eingeschlossenen epithelialen Elemente.

b) Hoden. Der Befund stimmt mit dem des anderseitigen rollkomnctr iibercin.

\section{Fall IV.}

Der iussere Eindruck des Tieres war ein weiblicher, der der ausseren Genitalien ein entschieden männlicher. Ob cin Scrotum vorhanien gewesch! ist, ist nicht angegeben bezw. aus dem Präparat nicht meln ersichtlich. Anscheinend ist trilher die rechtsseitige Kastration ausgeführt worlen.

Harnröhre und -blase sind hier mit dem Genitale des Thicres im Zusammenlaang belassen; das ganze Genitale wird mir in einem Stück zur tintersuchung cingeliefert (rergl. Taf. XIII, Fall 4 ); nur das rechte Uterushorn liegt gesondert bei.

Der Harmblasenkörper (hb) ist entleert, $12 \mathrm{~cm}$ lang; cs folgt ein einer weiblichen Harnröhre gleichender iiber $5 \mathrm{~cm}$ langer Teil (wur), an den sich dann erst in $13 \mathrm{~cm}$ Lünge die typische Pars pelvina ciner männlichen Harnröhre anschliesst (ppl = bst mit ur in Textfig. 3).

Ein dentlicher Prostatakörper ist auf dern Dorsum des (mäinlichenj Harnrührenanfanges mit blossem Auge nicht sicher festzustellen (wird mikroskopisch nicht verfolgt). Dagegen ist die Pars disseminata der Prostata gut ausgebildet, ventral (5 mm) stärker als dorsal und seitlich cntwickelt, sonst ron gewöhnlichem Verhalten, vom Musculus urethralis umgeben. Der Durchmesser der kräftigen Pars pelvina urethrae beträgt $2 \mathrm{~cm}$.

Der Bulbus urethrae (bl) ist ansgesprochen. Von den bulbourethralen

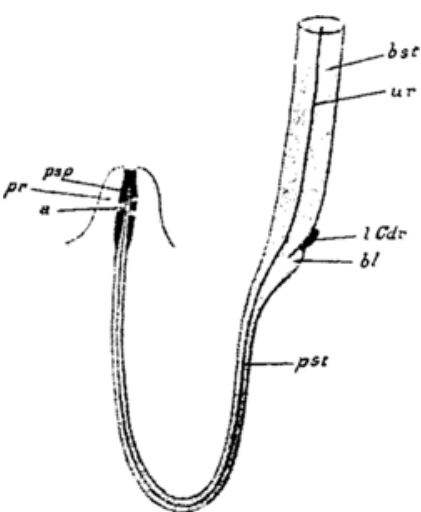

Fig. 3. Drüsen ist die linke vorhanden (ICdr), von etwa $3 \mathrm{~cm}$ Länge und $12 \mathrm{~mm}$ Breite; die rechte ist - wohl bei der Herausnahme der Organe durch de 11 Schlächter - abgeschnitten. 
Das Penisstück der Harnröhre (pst) ist $30 \mathrm{~cm}$ lang, vergleichsweise ebenso kräftig wie das eines kastrierten Ebers. Eine starke Abweichung gegeniiber dem letzteren zeigt aber der Präputialteil. Die Vorhaut (pr) ist ausserordentlich hypertrophisch, fast elephantiastisch und zwar besonders dorsal und seitlich, anscheinend zum grossen Teil mit dem Penis (a und psp) verwachsen. Der Prïputialbeutel (Nabelbeutel) fehlt.

An diese sicherlich männlichen Genitalwege schliesst sich nun proximalwärts vom Beginn der Pars pelvina urethrae (vergl. Taf. XIII) Scheide, Uterushals und Uteruskörper (ut) an, und zwar in sehr ausgesprochener Art so, diss die Scheide von der als gestrecktes Roln mit der Harnblase eine natiirliche Einheit bildenden Urethra (wur + ppl) nach hinten abzweigt. Die Vaginalmündung ist sehr eng.

Im distalen Teil der Scheide, beiderseits der seitlichen Vorderwand eng aufliegend, „Pseudosamenblasen“ (pssa), etwas über $\tilde{\mathbf{j}} \mathrm{cm}$ lang, $1 \mathrm{~cm}$ breit und $3-4 \mathrm{~mm}$ dick, also etwa von der Grösse der Samenblasen kastrierter Eber. Sie reichen mit ihrem unteren Pol bis an dic Einmündung der Vagina in die Pars pelvina urethrae. (Auf eine mikroskopische Darstellung ihrer Miündungsverhältnisse wird im Interesse der Erhaltung des Prüparates verzichtet.)

Scheile plus Uterushals und -körper sind im ganzen $25 \mathrm{~cm}$ lang. Das Lumen scheint normal. Die grösste Breite der abgeplatteten Teile beträgt $2,5 \mathrm{~cm}$. Das rechte Uterushorn (ruh) ist alggeschnitten, das linke (luh) in $36 \mathrm{~cm}$ Lünge vor'handen, kräftig, abgeplattet, von $25 \mathrm{~mm}$ grösster Breite. Das sich verjüngende Ende dieses titerushornes liiuft blind aus. Es fehlt für das blosse Auge jede Andeutung einer Tube (vergl. aber miliroskopische Untersuchung).

Im breiten Mutterband an der physiologischen Stelle des Eierstocks liegt wiederum eine exquisite Zwitterdrüse.

Sie besteht aus zwei annähernd gleich grossen, durch eine Schnïrfurche voneinander abgegrenzten Segmenten, bei im ganzen $8 \mathrm{~cm}$ grösster Breite, $5 \mathrm{~cm}$ grösster Lünge und ïber $3 \mathrm{~cm}$ Dicke. Dabei ïberwiegt der Lüngendurchmesser des Ovariums (o) mit $50 \mathrm{~mm}$ den des Hodens (h) mit $42 \mathrm{~mm}$. Der zum Uterushorn gekehrte Teil entspricht dem Eierstock, der andere dem Hoden.

Der Hoden ist von glatter Albuginea überzogen, der Eierstock aus kleinerbsen- bis doppeltbohnengrossen, blasig-transparenten Zystchen tranbig zusammengesetzt. Die meist sehr schmalen Septen zwischen den Zystchen stellen die einzigen soliden Anteile der Drüse dar.

Auf dem Durchschnitt (vergl. Fall IV [links] auf Taf. IX) besteht das Hodenparenchym (h) aus einer grossen Zahl unregelmässiger Läppchen. Ein Corpus Highmori fehlt vollkommen. Die einzelnen Zystchen des Eierstocks (o) sind mit klarer (nach der Härtung in 10 proz. Formalin gallertig geronnener) Nasse gefüllt und mit glatter Innenfläche versehen.

Ein Markteil (m) ist angedeutet in Form eines ca. $2 \mathrm{~mm}$ langen und ca. $1 \mathrm{~cm}$ breiten derben, soliden Streifens.

Die Grenze der beiden Organe ist eine absolut scharfe. Die Albuginea testis überzieht auch die zum Eierstock gewendete Hodenoberfläche. Dabei 
sitzt der (vergl, oben) in der Länge etwas überwiegrende Eierstock dem Hoden kappenartig auf. Nur gegen den Ansatz am Mesovarium hin schiebt sich zwischen beide ein dichtes, auf dem Durchschnitt über $1 \mathrm{~cm}$ breites Konvolut von Blutgefässen.

Der Nebenhoden (Taf. XIII, lnh), der mit frei beweglichem Kopf am Hoden etwa gegenüber dem Orarium (keine Hydatide!) ansitzt, ist $6-7 \mathrm{~cm}$ lang, aber ganz ausserordentlich (iiber $4 \mathrm{~cm}$ !) breit, dabei entsprechend platt. Das Vas deferens (Gd) liauft geschlïngelt in über $6 \mathrm{~cm}$ Lünge im freien Rand des Ligamentum latum und biegt an dem Ende des Oterushorns zwischen die ziemlich transparenten Blïtter des Ligamentum latum um. Hier ist es leicht bis zum Eintritt in das Corpus uteri verfolgbar.

Diss rechte, abgetrennt vorliegende Uterushorn ist $10 \mathrm{~cm} \mathrm{lang,} \mathrm{in}$ breite Verwachsungsmembranen eingehiullt.

Tube und Keimdrüse der rechten Seite fehlen. Der Befund entspricht der fitüher auf der rechten Seite ausgeführten Kastration.

\section{Mikroskopische Untersuchung. (Technik wie vorher.)}

1. Endometrium. Kleine Blutgefïsse des Endometrium vielfach strotzend gcfüllt. Im Stroma läufigg ödematïse Auflockerung, Auseinanderdrängung von Zcllen und Fibrillen durch homogen greronnene Flüssigkeit. Nur unmittelbar unter der Oberfliche ist meist an der physiologischen Dichtzelligkeit des Stromas nichts geändert.

2. Linker Nebenhode n ohne Abwcichung.

3. Linkes $V$ as deferens im freien Rand des Ligamentum latum. Neben den an sich der Norm entsprechenden Windungen des Samenleiters findet sich an den senkreclit zum freien Rand des Ligamentum latum geführten Schnitten unmittelbar unter der Serosa ein quer gretroffenes 'Tubenrolir. Es war (vergl. oben) mit dem blossen Auge ni cht festzustelien. Das Lumen erscheint sternförmig: die Epithelutskleidung wie in der Norm; das Schleimhautstroma und die Muskelhaut sind sehr kräftig ausgesprochen.

An einer zweiten nahe dem Übergang in den Nebenhoden entnommenen Stelle fehlt es. Die Stelle der gena a en Endigung des Tubenrohres kann, da sonst das ganze Vas deferens im Mesometriumrand in Serie hätte geschnitten werden miissen, nicht genauer angegeben werden. Sicher ist es, wie die entnommenen Stiicke beweisen, kürzer als $\check{5} \mathrm{~cm}$.

4. Linkes $V$ as deferens im Ligamentum latum olne Abweichung.

5. Scheide und a ufgelagerte linke Pseudosamenblase. Die Scheidenschleimhaut und Muskelhaut ist ohne besonderen Befund.

Die drüsigen, reich verzweigten Räume der Pseudosamenblase sind von einem einschichtigen, ziemlich hohen, pallisadenförmigen Zylinderepithel ausgekleidet. Die Kerne stehen basal, der nach dem Lumen gekehrte Abschnitt des Zytoplasmas ist (durch Hämalaun) blïulich gefärbt. Im Zentrum der Riiume dichte Anhäufungen von zelligem Detritus. An manchen Stellen sind auch die auskleidenden Epithelien in den Zerfall einbezogen.

Das Stroma liefert fibröses Bindegewebe von mittlerem Zell- und Blatgefïssreichtum. 
6. Pars pelvina urethrae. Das mikroskopische Bild des Querschnittes gleicht vollkommen dem oben beschriebenen Querschnitt des Sinus urogenitalis in Fall III. Im besonderen fehlen anch die weiten, strotzend gefïllten venissen Bluträume - namentlich in der Schiclit zwisch $* n$ der Pars disseminata prostatae und der Oberfläche - nicht.

Der Musculus nrethralis ist anch hiel dorsalwarts nicht muterbrochen und sogar dorsal von besondercr Mïchtigkeit.

7. Zwitterdrüse. Es wird aus ihrer Fontinuitit ein floden und Eierstock umfassendes Stïck ansgeschnitten.

a) Ovarinm. Das Keimepithel fehlt. Das Eierstocksstroma ist teilwoise, namentlich an der Oberftiche, ziemlich reich an kleinen Spindelzellen und so einigermassen dem pliysiologischen entsprechend. Im ïbrigen ist es wcit mehr fibrös, von mittlerem Kernreichtum.

Neben den malirosliopischen Zysten, die bei einer virlschichtigen Epithelauskleidung sich simtlich als zystisch gewordene Gra a fohe Follikel erweisen, finden sich wachsende und $\mathrm{G} r \mathrm{r}$ a f sche Follikel mit typischt.n Ovula in grosser Zahl, oft Dutzende auf einem Schnitt. Dagegen werlen Primordialfollikel and Corpora lutea in dem untersuchten Stiick rermisst.

b) II oden. Dis Keimepithel ist verlorn gregangen, lin Albuginea ist zart, $1 \bar{j} 0$ " dick.

Die Bindegrewebssepten zwischen den uncogelmässigen Läppehen des Hodemparenehyms sind einfach fibrös, stellenweise sogar aufitallend liernarm. Binlagerungen lileinerer Sträge und Inseln von \%wischenz: $\cdot 11 \cdot \mathrm{n}$ in ihnen sind spärlich. Innezhalb der hïppchen sind letztere ziemlich leich entwiokelt. In ihrer Nasse erreichen sit schätzungsweise nicht ganz die Masse der Hodenkanälchen. Sie sind ron polyedrischer form, der rundliche, ziemlich dunkle Kern liegt meist exzentrisch. Ihr mittlerer [nuchmesser ist 15 "; der Zelleib zeigt weder Pigment noch Kristalle oder (Sudanprïparate!) Fett. Inre Anhïufungen sinil von zit'ten Blutkapillaren durchzogen.

Die Samenkanälchen $\sin 1$ von typischer gelinäuelter Forn und besitzen einen mittleren Durchmesser von $180 u$.

Die Tunica propria besteht aus einer einfachen oder doppelten Lage dunkler spindliger Kerne mit zuweilen sichtbarer Beigabe feiner fibröser ind elastischer Fasern. Die zellige Auslieidung ist nur insofern deutlich, als sich unmittelbar anf der 'Tunica propria eine einfache Lage of platter und dann in ihrer Vellaufsrichtung der Tunica piralleler Kerne ausbreitet. Sie sind hell, mehr bläschenförmig, die Nakleolen wenig deutlich. Ihre Lage ist aber nicht immer kontinuierlich, und jedenfalls ist nirgends ein deutlicher Plasmaleib oder gar eine Schicht abgegrenzter Zellindividuen vorhanden. Vielmehr ist das ganze Lumen der Kanälchen von einem grossblasigen Schaum erfüllt. Ferner lagern in den Septen der runden Vakuolen zahlreiche rundliche bläsenförmige Kerne, oder Kerne liegen innerhalb der Vakuolen und sind unter entsprechender Abplattung entweder gegen ihre Peripherie geschoben oder in die Peripherie eingefügt, so dass der Eindruck der Siegelringzellen entsteht. So wird es auch schwer. mit Sicherheit festzustellen. ob hier eine ursprüngliche Ein- oder Mehrschichtigkeit des Epithels im Hoden- 
kanälchen vorliegt. Wie die Sudanfärbung lehrt, entsprechen den Vakuolen grosse eingelagerte Fettropfen.

Keine Geschlechtszellen in irgendwelchen Stadien.

\section{Fall V.}

Das Prïparat stammt von einem ca. 8 Monate alten, in seinem Äusseren vom weiblicken Typus nicht abweichenden Schwein. Das innere und iussere Genitale ist hier zusammenhängend entfernt (Tat. XIII, Fall jo zeigt den inneren Teil des Genitale). Die Blase nebst Harnröhre ist ahgeschnitten. Die Ansatzstelle der Harnröhre (um) klafft als weites Loch. Der Gesamteindruck des inneren Genitale ist zunächst ein zweifellos weiblicher: es besteht ein kräftig ausgebildeter zweihörniger Uterus (nt) mit gut entwickeltem Körper und Hals nebst stark entwickelter Scheide (va). Nur mündet diese mit einer auffallend engen öffnung in einen langen und dicken Sinus urogenitalis (sug). Ob dieser, wie beim Schwein die Regel, die ullmittelbare Fortsetzung der Scheide bildet oder die der Harmöhre, ist, da letztere abgetrennt ist, nicht sicher zu sagen.

Corpus plus Cervix uteri plus Scheide sind $32 \mathrm{~cm}$ lang, der Sinus urogenitalis bis zu seiner Ausmündung $14 \mathrm{~cm}$. Das Corpus uteri und die Scheide, beide von vorn nach hinten abgeplattet, messen fast $35 \mathrm{~mm}$ von rechts nach links.

Zu beiden Seiten der Sehcile, anf ihrer Vorderwand, liegen zwei etwa $12 \mathrm{~cm}$ lange, bis (rechts) $2 \mathrm{~cm}$ breite und üher $1 \mathrm{~cm}$ dicke körniggelappte ziemlich derbe Körper (pssa), die sich nach unten hin verjüngen und sich in die Wand des Anfanges des Sinus urogenitalis hinein einsenken ihre bezw. die Mündungsverhältnisse der Vasa deferentia werden nicht mikrosliopisch untersucht). Ihr Durchschnitt zeigt dicht gestellte, mit zähem Schleim gefüllte bis über linsengrosse, etwas eckige Höhlen.

Der Durchschnitt von Scheide und unpaarem Uterusteil zeigt keine Ahweichung.

Ein makroskopisches Corpus prostatae fehlt ikeine mikroskopische ITntersuchung). Der Sinus urogenitalis misst auf dem Durchschnitt $2, \overline{5} \mathrm{~cm}$ von rechts nach links, $2 \mathrm{~cm}$ von vorn nach hinten, ist also wie Vagina und Uterus von vorn nach hinten abgeplattet. $\mathrm{Er}$ besitzt ein enges Lumen, das von einer graugelblichen, über $1 \mathrm{~cm}$ dicken und sehr reich vaskularisierten weichen Schicht unter der glatten Schleimhaut gleichmässig umkleidet ist. Die Aussenschicht bildet eine gleichmässige Muskellage.

Die beiden Hörner des Uterus sind kräftig ausgebildet, aber von ungleicher Entwicklung. Das linke (lh) ist bei weitem stärker, länger sowohl wie dicker, als das rechte (rh). Es ist bis zu seinem verjuingten Ende, an seinem äusseren Umfange gemessen, fast $40 \mathrm{~cm}$ lang und, bei gleicher $\mathrm{Ab}$ plattung von vorn nach hinten wie der unpaare Oterusteil, bis $22 \mathrm{~mm}$ dick.

Das rechte Horn ist $23 \mathrm{~cm}$ lang und bis $14 \mathrm{~mm}$ dick. Seine Windungen sind weniger ergiebig als die linksseitigen.

Dieselben quantitativen Verschiedenheiten zeigen Schleimhaut und Muskelhaut auf dem Durchschnitt der Hörner. Der Oberflächenbezug ist beiderseits diffus verdickt und durch zahlreiche feine Adhäsionsreste rauh Archiv f. mikr. Anat. Bd. 84 . Abt. II. 
Das linke kräftigere Horn des Uterus läuft in einen nur kurzen, $6 \mathrm{~cm}$ langen und etwas dünnen Eileiter ( $t$ ) aus, dessen an sich ziemlich weites Infundibulam verschlossen erscheint. Die daneben gelegene linke Keimdrüse ist ein an sich typisch aussehendes Ovarium (o). Die Bursa ovarii ist ziemlich gut ausgesprochen.

Der Eierstock ist klein, 2,5:2,5:1 cm lang. An der Oberfläche ist er flach und ziemlich grob gebuckelt. Der Durchschnitt wird zum grössten Teil von vollkommen typischen gelben Körpern besetzt. Daneben finden sich einige erbsengrosse, glattwandige, mit klarer oder blutiger Flüssigkeit gefüllte Follikel. Auf der medialen Seite erscheint die Kapsel (Albuginea) auf dem Durchschnitt zu einem 1-2 mm breiten Streifen verdickt, in dem dunkle Quer- und Lüngsschnitte feinster Blutgefässe sichtbar werden.

Das Ligamentum latum ist diffus verdickt, namentlich gegen das Uterushorn hin, und lässt vom Parovarium oder Gartner schen Gang nichts durehscheinen. Medialwärts rom Ovarium steht ein liurzer Rest des linken Ligamentum teres (lr).

tuf der rechten Seite ist von einer Tube oder einem T'ubenostium nichts vorhanden. Das verjüngte Uterushorn endet hier ziemlich spitz.

Hier wird die Keimdriise repriisentiert durch einen mit Nebenhoden und Vas deferens ausgestatteten Hoden (h). Er liegt im Ligamentum latum genau di. wo anf der anderen Seite das Ovarium sich befindet. Der Hoden misst $5,6: 4, \overline{7}: 4,5 \mathrm{~cm}$, ist von glatter Albuginea überzogen und fällt auf dem Durchschnitt durch den Mangel eines Corpus Highmori und einer regelmïssigen Septiermg iuf. Unregelmässig ziehende Bindegewebsstränge dïnnen Killilers grenzen grössere und kleinere ganz unregelmaissige tüppchen al). Der Nebenhoden (nh) ist nicht auffällig hypertrophisch, sitzt locker, frei beweglich am distalen Hodenpol, liegt in $8 \mathrm{~cm}$ Länge mit scharfem Rand dem Hoden an, zieht auf weitere $8 \mathrm{~cm}$ im freien Rand des Mesometrium und geht dann unter mächtiger Aufknäuelung zu einem über walnussgrossen Konvolut (w) in das Vas deferens über. Dieser Wulst liegt genau kaudalwärts von dem zugespitzten blinden Ende des Uterushorns. Lateral neben dem Wulst setzt das in $3,5 \mathrm{~cm}$ Länge erhaltene Gubernaculum testis ( $\mathrm{gH}$ ) an, und von ersterem aus zieht das Vas deferens (Gd) in etwa 13-15 mm Abstand von der mesometrischen Kante des Uterushorns, in dem auch hier verdickten Mesometrium leicht verfolgbar, bis zu seiner Einsenkung in den Uterus.

Hydatiden sind weder links noch rechts nachweisbar.

Das äussere Genitale (betreffs des Sinus urogenitalis vergl. oben) zeigt am Präparat Teile der Labien und am ventralen Winkel der Vulva einen stark ausgebildeten kegelförmigen Hautanhang. Die Klitoris ist, wie die Präparation nach hinten ergibt, über $8 \mathrm{~cm}$ lang, geschlängelt und tritt mit einer fast zentimeterlangen Spitze aus einem kleinen, in ihrem dorsalen Umfang ausgebildeten Präputialsack heraus. Sie lirümmt sich dabei mit dem freien Ende nach rechts und ist hier durch eine kleine Hautbrücke mit der Aussenfläche des Präputialsackes verbunden.

Ventralwärts von der Klitoris liegt der sehr enge Eingang in den Sinus urogenitalis. Die präparatorische Darstellung grosser Vorhofsdrüsen gelingt nicht. 


\section{Mikroskopische Untersuchung.}

(Technik wie vorher.)

1. Ein Unterschied in der mikroskopischen Ausbildung des rechten männlichen und des linken weiblichen Uterushorns, insbesondere des Endometriums, ist nicht erweislich. Das Endometrium ist hier wie dort mässig injiziert, das Stroma ödematïs.

2. Der rechtsseitige $\mathrm{H}$ ode n (vergl. Taf. IX, Fig. 3). Das Keimepithel fehlt. Die Tunica albuginea ist $80 \mu$ dick. Die fibrösen Septen der unregelmässigen Lobuli sind fast total von Zwischenzellen erfüllt, so dass die Scheidewände nahezu vïllig verdeckt sind. Auch innerhalb der Lüppchen ist die Masse der Zwischenzellen ( $\mathrm{zw}$ ) eine ausserordentliche, die der Hodenkanälchen (hk) (etwa im Verhältnis 3:2) überwiegende.

Sie sind im Mittel $19 u$ gross, polyedrisch, reichlich von zarten Blutkapillaren (blc) durchzogen, im übrigen von der nämlichen Beschaffenheit wie in den vorbeschriebenen Fiillen.

Die Hodenkanälchen, in den verschiedensten Richtungen getroffen, besitzen einen mittleren Durchmesser von $145, \mu$ und eine Tunica propria (mpr) aus einer einfachen Lage zarter Spindelzellen, mit ganz unerheblichem faserigen elastisch-fibrïsen Anteil.

Es folgt nnmittclbar dieser Tunica aufgelagert eine einfache Schicht rumdlicher oder etwas eckiger, mehr bläschenförmiger Kerne, von mittlerem Chromatinreichtumı und ohne deutliche Kernkörperchen. Das (durch Hämalaun grauliche, etwas trübe Protoplasma erführt alsbald eine gross-vakuoläre Auflïsung, so dass grossblasiger Schaum das ganze Lumen der Kanälchen (vergl. Taf. IX, Fig. 3) vollkommen erfüllt. Eine gregenseitige Abgrenzung von Einzelzellen ist nicht möglich.

Die Kerne auf der Tunica propria werden bei der Vakuolenbildung zuweilen abgeplattet. Sie liegen dann innerhalb der Vakuole an die Peripherie gepresst oder in die Peripherie unter Bildung einer Siegelringzellform eingeschaltet.

Eine andere Zellart ist in den Kanälchen nicht vorhanden. Überhaupt sind auch mehr zentral in der Schaummasse gelegene Kerne selten. Wie die Sudanfärbung zeigt, entsprechen die Valsuolen grossen Fettropfen. In einem der schaumerfüllten Kan̈̈lchen zentral ein grosses, konzentrisch geschichtetes Kalkkörperchen.

Auf keinem der zahlreichen untersuchten Schnitte dieser Seite ist etwas ron ovariellem Gewebe zu finden.

3. Der linksseitige Eierstock. Die untersuchte Scheibe stammt ans der ganzen Dicke des Organs.

Das Keimepithel der Oberfläche ist teilweise erhalten. Das Stroma ist einfach fibrös, ziemlich zellarm, aber relativ gut vaskularisiert. In sämtlichen Schnitten des untersuchten Stückes (das übrige Ovarium ist am makroskopischen Prïparat konserviert) finden sich wesentlich typische Corpora Iutea, keine sicheren Primordialfollikel oder Reifungsstadien. Nur gelegentlich erscheint ein Gra a scher blutgefüllter Follikel. 
Dagegen bietet sich (Taf. XI, Fig. 4 und Taf. X, Fig. 5) in der leicht fibrös verdickten medialen Oberflächenzone des Organs - in dem parallel zur iusseren Oberfläche streichenden fibrösen Bindegewebe (str! zwischen Kuimepithel (ke) einerseits und Peripherie der vorgeschobenen trelben Körpor (ch) andererseits - ein höchst auffallender und überraschender Befund.

Hier sind lileine Gruppen von $K a n a ̈ l c h e n$ oder auch is soliert t Kanalchen (vhk und vlk') eingesprengt, die in ihrem Aufbau rollkommen identisch sind mit den Hodenkanalchender rechtsseitigen Keimdriise. Sie besitzen die niimliche zarte spindelzellige Tunica propria (fibroelastica), die nimliche Auskleidung mit einschichtigem Epithel, die an der T'unica lagernden blischenfïrmigen, gelegentlich abgeplatteten Kerne, die schaumige Anflösung des durch Himalaun granlich gretönten Zytoplasmas und die (meist rollkommene vakuolite Füllung des Lumens. Das grösste der gefundenen Kaniilichen (Taf. X, lijg. 5 , vhli) licgt. wie auch andere, in der Lïngsrichtung der Binclegewebszïgre (str), ist deutlich gewunden und auf weiter Strecke verfolgbar. Es misst auf d(mm I)ul'chschnitt im Mittel $140 \mu$.

Daneben sind auch kleincre und kleinste Kanälchen dieser Art zu treffen, gelegentlich g:nz isoliert, und les öteren lieine, noch solide EpitheIstriinge mit durchsichtigen Epithelien. Indem diese mit wachsondem Durchmesser des Stranges sich alsbald vakulisieren mil wantstïnlig ordnen, fïhren die Bildungen zu den als Hodonkanïlchen eindentig chizrakterisierten erstgeninnten Formen über.

Die typischen Hodenkanälchenformen sind stets von (a)enso typischen $\mathrm{Z}$ wischenzellen (zw) in kleineren und grösscren Ziigen begleitet. Wo letater in der Nachbarschaft ron Corpus Intenm-(icwebe liegen, ist leicht ersichtlich. dass hier die minnlichen $Z$ wischenzellen die volle Grïsse der Lateinzellen nicht ganz erreichen und sich zumeist bei weitem stirker mit Eosin fürben.

Bernerkenswerterwcise erstrecken sich diese verschiedenen Formationen (Kanälchen und $Z$ wischenzellen) anch in die fibrösen Septen der gelben Körper zentripetal weit in das Ovarium hinein, so rlass hier tine wirkliche D u r chmischung der in sich wohlbegrenzten gelben Kör'per einerscits und der testikulïren Gewebe andererseits erfolgt.

4. Die linke Tube zeigt, abgesehen von ihrem geringeren Durchmesser gegen die Norm, normalen Bau, kein begleitendes Rudiment eines Nebenhodens oder Vas deferens.

5. Nebenhoden und

6. Vas deferens der rechten Seite sind ohne Abweichung. Eine Tube ist auch mikroskopisch rechterseits nicht erweislich.

7. Querschnitt durch den Sinus urogenitalis. Die Ausbreitung der Pars disseminata prostatae um den Kanal ist hier ventral, seitlich und dorsal ohne quantitativen Unterschied, die Prostatamasse selır bedeutend. Der Bau entspricht im übrigen, auch betreffs der weiten venösen Bluträume, den vorigen Fällen.

Der Musculus urethralis umfasst auch hier das Dorsum des Sinus olme Unterbrechung. 
8. Die P s e u d os a me n bla sen (rechts und linlss) zeigen, entsprechend dem makroskopischen Befund, eine reichliche Schleimproduktion und Schleimanhäufung. Das Epithel ist zylindrisch mit basal gestiellten Kernen und klarem Zelleib, bei stärkerer Aufweitung der Drüsenriüme entsprechend niedriger.

\section{b) Die anatomisch untersuchten sicheren Fälle des Hermaphroditismus verus beim Menschen.}

\section{Fall W. Simon (60).}

20 jühriges Individurm mit ausgesprochenem Mannesbewusstsein. Schon frihzeitig starke Entwicklung der Brüste, links stärker als rechts, die seit 3 Jahren bisweilen voriibergehend anschwellen: zugleich - später nicht mehr in zeitlicher Gebundenheit -- mehrtiigige unbedentende Blutungen aus dem Genitale. Auch in der Klinik wurde eine eintïgige geringe Blutung aus dem Genitale, bei leichten Kreuzschmerzen, beobachtet. Seit einigen Jahren dann und wann, meist unter geschlechtlicher Erregung, deren Mittelpunkt stets ein weibliches Wesen ist, und unter Erektion des Geschlechtsgliedes Alygrng von weisslich-schleimiger Flïssigkeit. Spermien wurden in dem gelegentlich untersuchten Schleim, der vor dem Genitale lag, nicht nachscwiesen.

Das Individuum sucht die Klinik auf in dem sehnlichen Wunsche, anch seinen Körper so umgestaltet zu schen, dass jeder ihn als männlichen anerkennen mïsse.

Kï̈rpergrö̈sse $158 \mathrm{~cm}$. Die Formen sind gut gerundet. Ganz geringer Bartanflug auf der Oberlippe. Kehlkopf wenig prominent. Basaler Umiang des Brustkorbes ïberragt den Beckenumfang nicht. Becken breit und flach. Schamhaargrenze etwas oberhalb des Schambeinrandes horizontal abschneidend. Sehr deutliche Michaelis sche Rante.

An der Symplyyse ist ein penisaltiger Körper (4 cm lang, 6,5 cm limfang) angeheftet, mit Präputium und mit etwa haselnussgrosser Glans (vergl. l. c. Taf. II! Nach unten setzen sich zwei wulstige, stark behaarte Hantfalten an, die hinten durch eine breite Kommissur vereinigt sind; zwischen ihnen ein Orificium, entweder die äussere Mündung der weiblichen Urethra oder eines Canalis urogenitalis. Eine Entscheidung kann nicht getroften werden. (Andeutung kleiner Labien?)

Vor der Öffnung tes rechten Leistenkanals ein iiber kirschgrosser, etwas länglicher reponierbarer Körper mit glatter Oberfläche und von solider mittelfester Konsistenz. Uterus (per rectum in Narkose) nicht fühlbar. Links im Becken ïber einem walzenförmigen bleistiftdicken ein etwa kastaniengrosser, leicht höckeriger Körper, dessen Konsistenz etwa der eines Ovariums bezw. Hodens entspricht.

Im ganzen sind im Bau des Körpers münnliche und weibliche Typen miteinander innig gemischt, wenn auch das weibliche Element bis zu einem gewissen Grade vorherrscht. Am Genitale selbst scheint der männliche Typus zu überwiegen.

Das Individuum willigt in die zwecks Geschlechtsbestimmung voryeschlagene Probeexzision aus dem vor dem rechten Leistenkanal gelegenen 
als Keimdrüse angesprochenen Körper ein. Bei der Operation (1. c. Tuf. II) erweist sich der gefühlte Körper als etwas über kirschgross, eifürmigr, von der Konsistenz etwa eines normalen Hodens, bei glatter spiegelnder Oberfläche und hellgelbbräunlicher Farbe. An dem einen Pol setzt sich ohne eine erkenubare Organgrenze ein etwa erbsengrosser, mebr weisser und derberer Knoten an. Ausserdem findet sich eine $7 \mathrm{~cm}$ lange Tube mit Ostium, von etwa Zweistreichholz-Dicke, befestigt an einer dünnen, Herlermausfliggelartigen Peritoneallamelle (Ligamentum latum). In dieser fast nnmittelbar unter dem distalen Tubenende ein Parovarium, etwa ein Drittel so lang als die Tube. Die Keimdrüse ist an der Peritoneallamelle fixiert. Ausserdem in letzterer ein Vas deferens and $1 \mathrm{~cm}$ von der Keimlriise entfernt und ganz getrennt von ihr eine etwa halberbsengrosse, lü̈kerige, gelblichweisse Epididymis.

Von der Keimdriise werden aus beiden Teilen zwoi kleine Keile exzidiert. Auf dem schnitt Hodenteil gelblich, zalt grekïrnt, der nebrngelegene Knoten (Eierstocksteil) derb, grauweiss, strcitig.

Tube und Parovarium wirl abgetragen: anch ans dom neben dem Vas deferens gelegenen Körper (Epididymis) wird ein kleines Stiick ausgeschnitten. Parovarium (1. e. Tarf. I, Fig. 5) and Epididymis (Fig. 6) werden durch mikroskopische Untersuchung identifiziert. Für die Keindrïse ergiht sich:

1. Eierstocksteil: stark ausgebildete Albusinen mit zum Teil erhaltenem Keimepithel. Ovarialrindenstroma mit Primordialfollikeln ohme weitere Entwicklungsstadien (Fig. 1 und 2).

2. Hodenteil (Fig. :3 and 4): lockeres, schr zartes Bindegewebsstroma mit $Z$ wischenzellen, meist in kleinen Häufchen und Zügen $(\mathrm{R}$ c i i k e sche Kristalle im Zwischenzellplasina).

Die Bilder der Hodenkanälchen gleichen vollkommen den von Félizet und $\mathrm{B} r \mathrm{a} \mathrm{n}$ a für den Leistenhoden Erwachsener aufgestellten Typen a und b, den ,cellules de Sertoli it protoplasma commun und den ,formations columnaires ou coniques implantées perpendiculairement on obliqu'ment sur la paroi propre".

Die Wand del Hodenlianälchen ist teils die typische fibrös-elastische Membran, meist aber zeigt disse hyaline Degeneration. so dass dis Lumen stellenweise fast völlig erdrückt ist. Dem Epithel fehlen :alle Zeichen der Spermatogenese".

Das ganze Bild , entspriclit einer Hodenpartie im Ruhestadium, zugleich mit schweren degenerativen Verïnderungen".

Doch stammt das exzidierte Stïck aus der dem Hilus entgeggengesetzt gelegenen Konvexität der Drüse. Da die von dem Rete testis entfernten Partien im Leistenhoden der Regel nach in ihrer Entwicklung am meisten zuriickgeblieben sind und am frühesten regressive Veränderungen erleiden (Finotti), so müchte $\mathrm{Sinnon}$ in seinem Befunde einen sicheren Beweis für die Funktionslosigkeit des Hodens nicht sehen.

II. Fall O. Uffreduzzi $(69 a, b$ und $c)$.

Uffreduzzi machte seine Beobachtung, die von ihm erschöpfend in mehreren Publikationen behandelt ist, an einem 7 jährigen, als Mädehen er- 
zogenen Kind, bei dem im Spiel mit seinen Altersgenossen melır knabenhafte Neigungen aufgefallen waren. Bei dem Kind bestanden doppelseitige äussere (schräge) Leistenhernien, die auf einer Seite zweimal zu Inkarzerationserscheinungen geführt hatten. Die Eltern wünschten eine Radikaloperation dieser Seite und gleichzeitig eine Feststellung des ihnen fraglichen Geschlechts. So lam das Kind in die Hände des Arztes.

Der allgemeine äussere Eindruck, besonders auch der des Gesichts des Kindes, war ein weiblicher. Das Haupthaar ist lang, der Fettansatz reichlich, und die Formen sind so gerundet, dass die Muskelkonturen allerwärts verdeckt sind. Brüste nicht entwickelt, Becken olne Besonderheit.

Das äussere Genitale zeigt ein $3-4 \mathrm{~cm}$ langes penisartiges undurchbohrtes Gebilde, etwas darunter die auffallend weite Mündung der Urethra also im ganzen einen Zustand von Hypospadie; ferner zwei nicht verwachsene Scrotalhälften, in denen jederseits ein kleines hartes, bewegliches und empfindliches Körperchen gefühlt wurde; letztere werden als Leistenhoden angesprochen. Die Untersuchung (auch per rectum) ergab Fehlen von Vagina, Uterus, Prostata. So wurde ein Pseudohermaphroditismus masculinus, eine Hypospadie mit Kryptorchismus angenommen. Bei der Herniotomie (auf welcher Seite ist nicht angegeben) fand sich im Bruchsack Hoden. Nebenhoden und Vas deferens, in einen Samenstrang übergehend, der durch den Leistenkanal zieht. Am oberen Pol des Hodens ein weisslicher Kürper, ühnlich einer Verdickung der Albuginea, mit einer an den Nebenhoden gelöteten Zyste von 1,5 mm Durchmesser. Alle diese Gebilde wurden exstirpiert.

Der Hoden besitzt eine typische Albuginea und ein Stroma ans kernarmem Bindegewebe; er ist in typischer Weise lobuliert (Lïppehen ron 0,2-0,8 mm Durchmesser). Die Auskleidung der mit fibrös-elastischer Membran versehenen Hodenkanälchen (bei einem Durchmesser von $35-50$ ") bilden plasmatisch verschmolzene Sert olizellen (ein ,follikuläres Synzytium ") bei radiärer Stellung der länglichovalen, gut gefärbten, in eintacher Liage vorhandenen Kerne. Archispermiozyten fehlen. Die Kerne mit je einem Nukleolus lagern nahe der Membrana propria. Die plasmatische Substanz ist geliörnt. Ein Lumen in den Kanälchen fehlt.

Gut ausgebildetes, obschon etwas rudimentäres Rete testis in dem an die Epididymis grenzenden Teil. Das relativ reichliche kernarme Bindegewebsstroma ist $\mathrm{frei}$ von $\mathrm{Zw}$ is chenzellen. Die Drüse ist , vollkommen identisch mit einem kindlichen Hoden von leicht zuriickgebliebener Entwicklung in der Periode der zellulären Unifikation (follikuläres Synzytium)" bezw. "mit einem kindlichen retinierten Hoden".

Gegen den oberen Hodenpol wird das Bindegewebe allmählich dichter („„poco a poco più duro"), kernreicher und enthält typische Primordial-

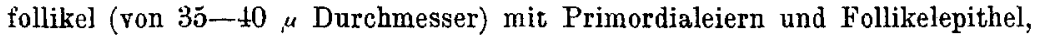
das an einigen Stellen unter kubischer Umformung Stadien einer Weiterentwicklung bietet.

Die nach dem Nebenhoden gelegene Zyste ist ein typischer Gra a f scher Follikel mit Eizelle (vergl. 69 c, Fig. 3 und 4 ).

Neben der Epididymis, durch lockeres Bindegewebe dieser angeschlossen, liegt eine Tube mit typischem Infundibulum und einer Fimbria ovarica, die 
zum Eierstock zieht. Das distale Tubenende endet blind, etwas unterhalb des Schwanzes der Epididymis, und zwar nicht mehr mit dem Nebenhoden verbunden, sondern frei flottierend im Leistenkanal. Ein Parovarium fehlt.

III. Fall J. F. Gudernatsch (23).

Eine 40 jährige Köchin sucht das Krankenhaus auf, um einen Tumor der rechten Leistengegend operieren zu lassen. Im linken Leistenkanal ein ähnlicher, etwas kleinerer Tumor, der nicht entfernt wurde.

Äusseres Genitale weiblich; aber ausserordentlich starke Klitorishypertrophie. Uterus nicht fühlbar. Um die Urethra ein prostataähnlicher Körper, doch will Verfasser sich mangels miliroskopischer Untersuchung nicht bestimmt entscheiden. Behaarung des Körpers von weiblichem Typus. Becken geräumig. Uncntwickelte Brüste. Kehlkopf üusserlich von männlichein Typus. Die Patientin fühlte sich als Weib und hatte stets als solches gegolten. Menstruation war nie vorhanden gewesen. Geschlechtsverliehr hatte niemals stattgefunden: die Libido f'chlte

Die exstirpierte Geschwulst prïsentierte sich als Testikel mit Epididymis, von den Maßen $6: 5: 5 \mathrm{cn}$.

(Die Präparate wurden in New-York von James Ew ing, in Prag von Prof. A. Ko h n und von den Mitgliedern des VIII. Internationalen Zoologenkongresses in (rraz begutachtet und als Ovotestis anerkannt; vergl oben S. 134.)

1. Hodenteil. Sehr starke Tunica albuginea. Das Hodengewebe zeigt an den moisten Stellen nicht ïberalli die, typische hyaline" Degeneration der Samenkanälchenmembranen des Süugetierbodens hei Retentio inguinalis. Der mittlere Durchmesser der Tubuli contorti ist weit geringer als normal. Das auskleidende Epithel besteht aus einer einfachen Schicht von Sertolizellen. Keine Spermatogenesc bezw. Zelltypen dieser Reihe (there are no indications of spermatogonia, spermatids or spermatozoa). Die Sertolizellen zeigen verschiedene Stadien der Degeneration, entsprechend den Befunden Fin ot tis.

Durch zentralwärts vordrängende hyaline Degeneration der inneren Schichten der Tunici propria der Samenkanälchen erfolgt oft unter völligem Zugrundegehen der Epithelien vollkommene Obliteration. Die noch erhaltenen bindegewebigen Teile der Membrana propria führen gleichzeitig elastische Easern.

Es besteht eine ausserordentlich starke Vermehrung der Zwischenzellen, so dass die Samenkanälchen stellenweise auseinandergedrängt werden. Dabei erscheinen die Zwischenzellen, zwischen denen Bindegewebsfasern nur sehr spärlich zu sehen sind, von, normaler Beschaffenheit". Reinkesche Kristalle enthalten sie nicht. Die Zwischenzellen liegen entwedel in kleinen unregelmässigen Gruppen oder schmalen Strängen, oft aber in bedeutenden dichten Haufen. Aller Wahrscheinlichkeit nach handelt es sich um die in kryptorchischen Hoden gewöhnliche Vermehrung.

Rete testis, Vasa efferentia, Nebenhoden und Vas deferens sind vorhanden. Im Lumen der Nebenhodenkanälchen zelliger Detritus, feingranulierte Massen und zahlreiche Konkremente. Das Epithel des Nebenhodenkopfes ist stellenweise stark degeneriert. Es ist zum Teil gleichmässig, niedrig kubisch, 
zum Teil von gewöhnlicher Anordnung, d. h. von normalem Wechsel der kubischen und zylindrischen Zellen. Für die Kanälchen mit flacher Zellanskleidung betont der Verfasser die Ähnlichkeit mit der Parovarialstrulitur. Die Zusammensetzung des Ductus epididymidis ist normal. Das Vas deferens besitzt eine sehr licke Muskulatur.

2. Eicrstocksteil. Der weibliche Anteil der Keimdrüse ist reprüsentiert durch ein rudimentäres Ovarium in der Form eines kleinen 3: 2: : 2 $\mathrm{mm}$ messenden Knotens. Es liegt (vergl. Taf. I, Fig. 1) in einer kleinen zystischen Kavitat der Tunica, zwischen dem Hoden und Nebenhodenkopt. Das stroma des Kürperchens ist das typische spindelzellige des Eierstucks, eine Rinden- and Mirrischicht lassen sich unterscheiden. In der Rindenschicltt ist das Bindegewebe dicht und zellreich nnd führt nur unbedeutende Blutgefïsse. Die Zellen liegen in Strïngen oder Wirbeln. In der Xarlisubstanz ist das Bindegewele weniger zellreich und führt grosse greschlïngelte Blutgefïsse. An der Oberfliiche eine einfache Schicht kubischen bis zylindrischen Epithels (vergl. I. c. Fig. 5,6 und 7 auf Taf. III). In dieser Zellschicht sind einzelne Elemente grösser, die Kerne bedeutender und rundlich, chromatinärmer als die ler Nachbarzellen. Sehr wahrscheinlich sind diese Elemente Prinurdialeier: obschon eine bestimmte histologische Diagnose sich nicht stellen liisst (a definit diagnosis cannot be made. However the decision that the body is ovarian in structure is sufficiently wirranted by the typical stroma with its surfice epithelium). Ehenso fehit vollstindigr die Bildung von Primordialfollikcln oder weiteren Entwicklungsstadien. Verfasser verweist alf die Analogie dieses Befundes mit der Tatsache (1. c.. S. 272 u.), dass bei allen Fillen von Hermaphroditismus (wahrem oder falschem) der epitheliale Teil des Eierstocks eine Unterentwicklung zeigt.

1V. Fall Ernst Salén (57).

Über den Fall von Ernst Salén (Stockholm) ist zum erstenmal auf der zweiten Tiagung der Deutschen Pathologischen Gesellschaft in München 1899 (durch Ernst Ziegler) berichtet worden. Ich gebe diesen Bericht hier zunichst wörtlich wieder:

-Augusta Persdotter, 43 Jahre, unverheiratet. Monatliche Regel seit dem 17. Jahre. Passive Coitusversuche schmerzhaft; keine alitiven.

Weiblicher Habitus, Klitoris penisïhnlich, beinahe $5 \mathrm{~cm}$ lang, mit haseInussgrosser Glins. Labia majora und minora normal entwickelt. In das Vestibulum münden die Urethra und die Vagina aus, die letztere aus einem feinen Gange, in welchen eine Sonde $8 \mathrm{~cm}$ weit hineingefïhrt werden kann, bestehend. Im November 1898 Laparotomie : Exstirpation eines zystischen mannshopfyrossen kurzgestielten Myoms plus Kastration.

Der Uterus war etwas vergrössert, mit mehreren kleinen Myomen besetzt. Beiderseits fand man die Tube und die Ligamente normal und an dem gewöhnlichen Platze des Ovariums eine Geschlechtsdrüse. Von der Klinik den j. Januar 1899 gesund entlassen.

Die Untersuchung der Geschlechtsdrüsen ergab linkerseits ein ziemlich kleines höckeriges Ovarium mit $G r a a f s c h e n$ Follikeln und Eiern; rechterseits eine $Z$ witterdrüse, deren eine Hälfte Eierstocks- 
gewebe, deren andere Hodengewebe zeigte. Der Ovarialteil ist grobhöckerig, von gelber Farbe und derber Konsistenz und zeigt bei der mikroskopischen Untersuchung Graaf sche Follikel nnd ganz typische Eizellen in einem spindelzellreichen Stroma eingelettet.

Der Hodenteil ist eben, von ziemlich weicher Konsistenz, mit weissglinzender Tunica albuginea. Das Parenchym ist locker, von braungrauer Farbe und von weissen Bindegewebssepta durchzogen; mikroskopisch zeigt es Tubuli seminiferi, die in einem lockeren, von grösseren und kleineren Anhäufungen fett- und pigmentreicher $Z$ wischenzellen durchsetzten Bindegewebsstroma liegren. Die Tubuli sind stark geschlängelt, von beinalie gleicher Weite. Ihre Membranae propriae sind grösstenteils verdickt, sehr reich an konzentrisch angeordneten elastis chen Fasern. Das Epithel besteht aus Follikelzellen und Sertolischen Zellen. Nirgends Spermatngonien oder anderc Samenzellen.

Die Strnktur zeigt im ganzen eine auffallende Ähnlichkeit mit derjenigen des ektopischen Hodens nach der Pubertiit."

Diese Mitteilung - die e r ste eines sicheren Falles von H. A. verus beim Menschen - ist selnr kur\% gehalten und durch Abbildungen nicht unterstützt, Mängel, die, wenn anch dem Fall die Beweiskruft allerwärts zugestinden wird, doch gelegentlich nicht olne Berechtigung hervorgehoinen werden (verol. z. B. S a uerbeck, S. 340 . S a léns anch mir gegenüber vor etwa 11 Jahren geäusserte Absicht, eine genaue Darstellung des Falles \%u geben, wurde durch seinen allzu friihen Torl zunichte. Seine Präparate. Photographien und seine mit grosser Kunst und Soryfalt angetertigten Zeichnungen iabernalım aus der FFand von Dr. śaléns Gattin. Frau Dr. Signe Salín, jetzt Franenärztin in Stocliholm, Salóns Freund, Herr Protét Ul rich Quensel, Direktor des Patlologischen Instituts der Universitiit Cpsala.

Ich hatte noch bei Lclozciten Sa léns von ilım selbst eine Anzahl von Schnitten, mit denen das Wesentliche seiner Mittcilung zu belegen war, erhalten und diese der Sammlung der $L$ a $\mathbf{n}$ da a schen Klinik einverleibt. Diese Schnitte sind gelegentlich auch bereits ron mir selbst und später von Herm Theodor Landau (40) in der Berliner MLedizinischen Gesellschaft vorgelegt worden.

Mit der Zeit hatte dieses kostbare Material nun allerdings ron seinem Demonstrationswert so gut wie alles verloren, weil die mit Thionin oder nach van Gies on gefärbten Schnitte vollständig ausgeblasst waren. Ich musste daher an eine Umfürbung bezw. Nachfïirbung der Schnitte (mit Hämalaun, Hämalaun-Eosin, van Gieson, Karmin und We igerts Elasticafürbung) gehen, die erfreulicherweise vollkommen gelang.

Zugleich stiess ich aber bei der Nachuntersuchung dieser neugefürbten Schnitte auf Befunde, von denen Salén nach dem eben zitierten Text seiner damaligen Mitteilung ausdrücklich bemerkt, dass er sie nicht getroffen habe. Sie bedeuteten für den Fall eine gewichtige Ergänzung, für die ganze Frage des H.A. verus eine grundsätzliche Erweiterung.

Es musste unter diesen Unständen von ganz besonderem Werte sein, auch das iibrige Matcrial des Falles nach diesen weiteren Gesichtspunkten 
za untersuchen, und so begrüsste ich mit grosser Freude das rückhaltlose and liebenswürdige Entgegenkommen von Frau Dr. S a lén und Herrn Kollegen Quensel, die mir das gesamte anatomische Material des Falles, alle Schnitte sowohl wie die noch vorhandenen Zelloidinblöcke, nebst sämtlichen $S$ a lén schen Zeichnungen und (zum Teil stereoskopischen) Photographien, auch den Negativen, in die Hände legten. Beiden zolle ich für ihre ganz besondere Freundlichkeit auch an dieser Stelle herzlichen Dank.

Die von Ernst Salén angefertigten Zeichnungen sind anf Taf. $\mathrm{X}$ (Figg. 8 and 9), Taf. XI (Fig. 11) und Taf. XII (Fig. 6, 7 und 10) reproduziert. Die Textfig. 4 und 5 sind Zeichnungen, die nach den damaligen photographischen Aufnahmen Saléns jetzt hergestellt sind; Fig. 12 auf Taf. XI ist unter Anlehnung an eine Originalzeichnung Saléns angefertigt.

Die Schnitte, die bis auf wenige gleichfalls mehr oder minder ansgefahlt waren, habe ich wiederum nach- bezw. ungefärbt. Die Hïrtung des Materials war in Formalin geschehen, die Einbettung in Zelloidin bezw. Paraffin erfolgt. Kleine Stïckchen der Hodensubstanz waren auch in Flemming scher Flüssigkeit fixiert. Von Fürbungen wurden von mir angewendet: Hämalaun, Hämalaun-Eosin, Hämalaun-van Gieson, Eisenhïmatoxylin nach Heidenhain und Hansen, Eisenhämatoxylin-ran Gieson nach Weigert, Weigerts Elastikafärbung mit Karmingegenfärbung. Orcein nach Unna-Tünzer.

Salón nennt den Habitus der Augusta P. weiblich. Die Briiste sind in der Tat gut entwickelt. Doch spielt (Fig. 4) der grobe Schnitt des Gesichts und der gegenüber der weiblichen sanften Rundung mehr eckige Kontur der Schultern und oberen Extremitaten sowie die grobe Form der Hände entschieden in das Männliche hinüber.

Vom Genitale liegen mir drei photographische OriginalAufnahmen vor. Ich habe zur Reproduktion Fig. 5 gewählt. weil die Hypertrophie der Clitoris und ihrer Glans, andererseits die Norm der grossen und kleinen Labien, darauf ausgezeichnet zum Ausdruck kommt. Weiblich ist auch die gut sichtbare horizontale Begrenzung der Behaarung des Mons veneris nach oben bin. Am After treten Hāmorrhoidealknoten hervor.

Fig. 6 auf 'Taf. XII zeigt die durch die Kastration gewonnenen Geschlechtsdrüsen im frischen Zustand gemäss der Salén schen Originalzeichnung.

Die grösste Länge der rechtsseitigen Zwitterdrüse (rot) ist mit 4 , die grösste Breite mit 2,5, die geringste Breite mit 2, die grösste Dicke mit 1 , die kleinste mit $0,5 \mathrm{~cm}$ angegeben. Die beiden auf Fig. 6, 'Taf. XII, oben gelegenen Figuren stellen die Zwitterdrüse mit gleichgrossem Eierstocks- und Hodenteil, von 
den beiden Seiten betrachtet, dar. An der rechts gelegenen ist auch die Abtragungsstelle vom Iigamentum latum deutlich.

Die groben Höcker des gelbgefarbten (in der Konsistenz derben) Eierstocksteils treten (Fig. 6, oben rechts) dentlich hervor. Auch die weissglïnzende Albuginea des (ziemlich weichen) glatten Hodenteils ist auf dieser Higur deutlich.

Auf der Gegenflaiche des Ovotestis (Fig. 6, oben links) besitzt der Ovarialteil kleinere Höcker, die Albuginea ungleichmisssige

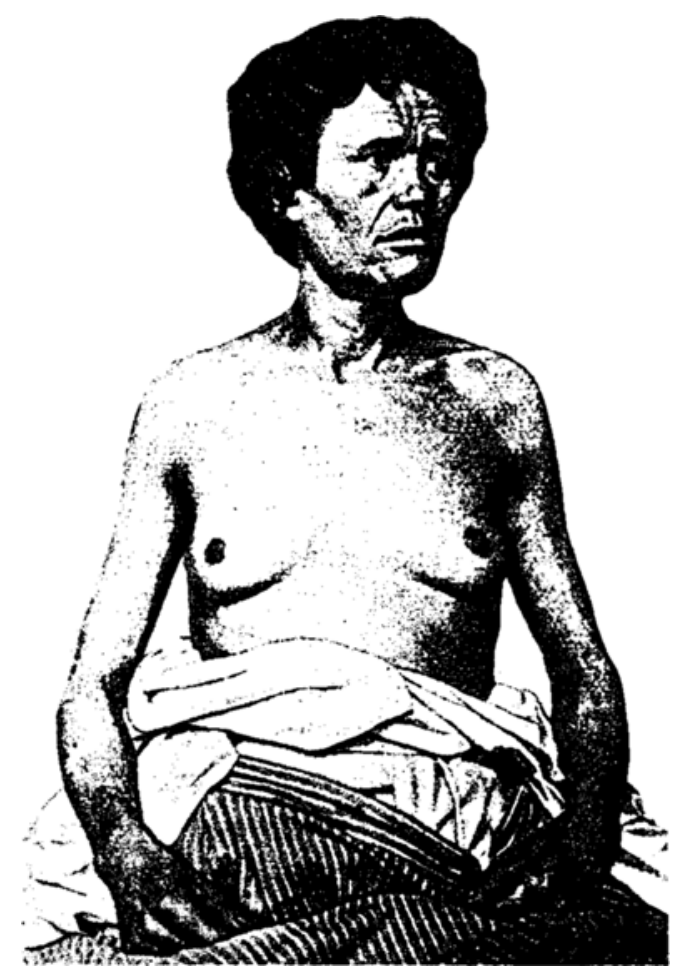

Fig. 4.

Dicke, so dass grauweissliche Streifungen auf der grösstenteils mehr braungrauen Oberflache entstanden sind.

Auf dem etwas über die Mittellinie hinausgeführten Durchschnitt (Taf. XI, Fig. 6, drot) ist der Ovarialteil gegen den Hodenteil scharf abgesetzt. Ersterer erscheint wiederum ausgesprochen gelb. letzterer braungrau (locker). 
Im Eierstocksteil liegen drei zystische Follikel und ein Corpus candicans. Eine besondere Markzone ist nicht vorhanden.

Der Hodenteil besitzt für das blosse Auge, wie eben erwähnt, eine scharfe grauweissliche Abgrenzungslinie gegen den Eierstocksteil hin (Jortsetzung der Albuginea?), und namentlich in der Năhe dieser Linie, aber auch in den anderen Abschnitten des Parenchyms grauweissliche, gegen den (in der Fig. 6, drot, unteren) freien Pol hin etwas regelmässiger radiär angeordnete Bindegewebsseptula.

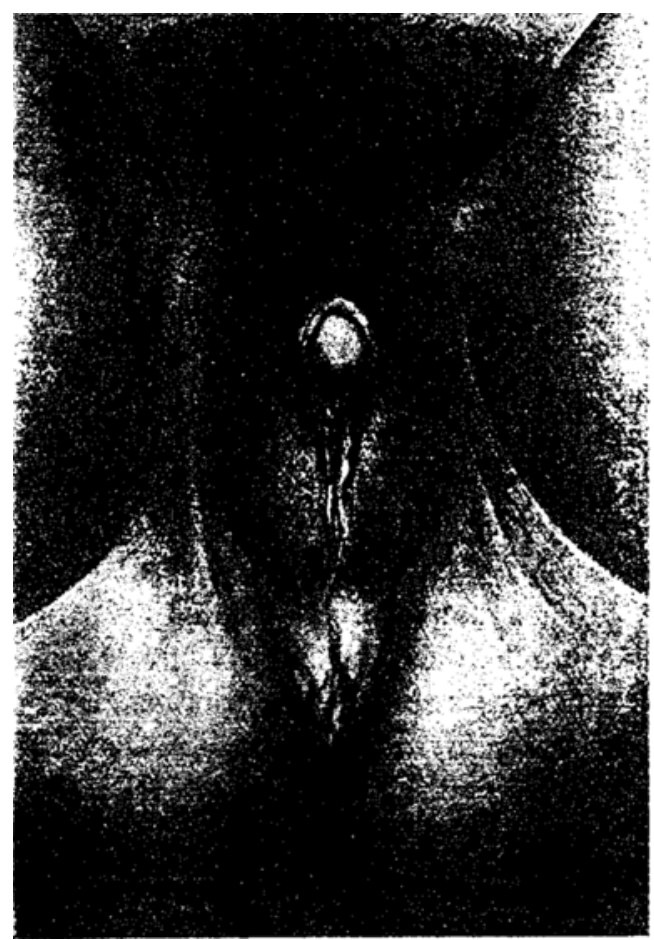

Fig. 5.

Gleichzeitig lehrt aber auch der Durchschnitt, dass unterhalb der Albuginea des Hodens die Eierstockssubstanz, zum mindesten auf einer Seite, noch über die Mitte des Organs hinaus auf den Hodenteil binüberzieht. Denn es erscheint auf dem abgebildeten Durchschnitt (drot) - ebenso auch (Fig. 7) auf den durch die ganze Dicke des Organs geführten mikroskopischen Schnitten unten links eine kleine, die Hodensubstanz einbuchtende, um- 
schriebene gelblich-weissliche Gewebsmasse, die von Salén in den den Figuren beigegebenen Notizen ausdrücklich als Ovarialsubstanz bezeichnet ist.

Das linke ziemlich kleine Ovarium ist (auf der Originalzeichnung; vergl. Taf. XII, Fig. 6) $27 \mathrm{~mm}$ lang und $13-14 \mathrm{~mm}$ breit. Saléns Angaben bedürfen zu diesem Punkte weder in makroskopischer noch in mikroskopischer Richtung - es ergaben sich für die Eierstocksstruktur typische Befunde (Primordialfollikel bis zu Graatschen Follikeln reifend) - einer Ergänzung.

Die mikroskopischen Übersichtsschnitte (Taf. XII, Fig. 7) entsprechen dem auf Taf. XII, Fig. 6 unten links (drot) dargestellten Durchschnitt. Im Hodenteil (h) wird die in dem genannten Bezirk angedeutete septierte Anordnung der Hodenkanïlchen (hk) noch deutlicher; andererseits wird der makroskopische Befund insofern etwas korrigiert, als die (bis $215 \mu$ dicke) Albuginea (at) sich als solche keineswegs zwischen Hoden und Eierstocksteil als (xrenzmembran einschiebt.

Letzterer (o) liefert in allen seinen Abschnitten, auch in dem sich über den Hodenteil schiebenden Auslüufer $\left(0^{\circ}\right)$, ein dem Alter der Trägerin vollkommen entsprechendes normales bild, nur fehlt ein Markteil auch bei mikroskopischer Betrachtung ganz. Das Keimepithel ist nicht selten erhalten, besonders in den Hacheren Nischen und tieferen Buchten zwischen den Höckern der Obertlaiche. Stellenweise ist eine schmale, ziemlich hyaline Albuginea deutlich. Das Stroma ist durchweg das typische kleinund spindelzellige der normalen Eierstocksrinde (Taf. X, Fig. S und 9 ostr bezw. str). Primordialfollikel sind nur noch spärlich vorhanden, daneben alle Stadien des Wachstums bis zum Graafschen Follikel (Fig. 8, Grf und Fig. 9). I)as auf der Schnittfläche (Fig. 6, drot) getroffene Corpus luteum (Fig. 7, cl) ist von gewöhnlicher Zusammensetzung, noch ziemlich frisch; das geronnene Blut im Zentrum ist in einer schmalen peripherischen Zone organisiert. Typische Corpora candicantia und fibrosa (narbige Stellen im Stroma) fehlen nicht. Daneben sind in grösster Häufung grössere und kleinere Komplexe wellig-hyaliner Bänder (Fig. 8, atrf) als Plodukte der physiologischen Follikelatresie in das Stroma eingesprengt. Dicht unter der Oberfläche finden sich vereinzelte (wohl vom Keimepithel herzuleitende), mit einschichtigem Epithel ausgekleidete kleine Zystchen. 
Die grossen, auf dem Durchschnitt getroffenen Follikelzysten (vergl. auch Fig. 7, fc und $\mathrm{fc}^{\prime}$ ) haben, wie gewöhnlich, eine Auskleidung mehrschichtigen Granulosaepithels. Die Blutgefiisse im Eierstocksgewebe, besonders die kleinen Arterien, zeigen nicht selten, auch bei Elastikafürbung, mehr oder weniger hyaline Wandungen.

Der Übergang des Eierstocksteils in den Hodenteil ist entsprechend dem makroskopischen Eindruck ein unvermittelter (Taf. XII, Fig. 7, Taf. X, Fig. 8).

Das spindelzellreiche Stroma des Ovariums (Fig. 8, ostr) wird unmittelbar abgelöst durch das bedeutend zell- bezw. kernärmere Stroma des Hodens. Dieses (Fig. 8, hstr; anch Taf. XII, Fig. 10 str $^{\prime}$ nebst Taf. XI, Fig. 11 und Fig. 12, str) wird dargestellt durch ein lockeres fibrilläres, zu einem grossen l'eil leicht hyalin erscheinendes (mit Eosin stark getöntes) Bindegewebe von höchstens mittlerem Kernreichtum; es führt kleine normal strukturierte Arterien und Fenen (Fig. 12, blg). Allerdings ist die Grenzlinie zwischen Hoden und Eierstocksstroma nicht allerwärts eine linienscharfe, vielmehr greifen beide auf manchen strecken zahnartig ineinander.

In einem grossen 'Teil der nnmittelbar an den Eierstock grenzenden Hodenzone breitet sich flach ein relativ reich entwickeltes, gegenüber der Norm freilich etwas rudimentires Rete testis ans (Fig. 7 und Fig. 10, rt).

Hierbei sind einzelne Kanälchen des Rete bis an das spindelzellige Ovarialstroma unmittelbar herangeschoben oder sogar schon von ihm umschlossen. Ebenso einzelne der gleich zu beschreibenden Hodenkanalchen, die sich unmittelbar an das Rete schliessen. Ausserdem ist in dem Bereich des Rete das Bindegewebsstroma an sich weniger locker, faser- ( $\mathrm{n}$ icht zell-) reicher, so dass ein gewisser Gegensatz zu dem mehr lockeren Stroma zwischen den Hodenkanälchen besteht (Fig. 10, str und str").

Eine Steigerung der in gewissen Hodenabschnitten vorhandenen makioskopischen Septierung (vergl. auch das Übersichtsbild Taf. XII, Fig. 7) in Form einer irgendwie mikroskopisch deutlicheren, sei es regelmässigen oder unregelmässigen Läppchenform, ist nicht vorhanden, auch nicht in dem vom Rete testis ganz entfernten Hodenabschnitt.

Die einzelnen Hodenkanälchen (Fig. 8, 10 und 11, hk) sind bald durch geringere, bald durch reichlichere Stromamasse von- 
einander getrennt, die in ihrer Cresamt(quantitat die Gesamtmasse der Hodenkanälchen sicherlich übertrifft (vergl. Fig. 7). An der Oberflache ist das Stroma zu einer typischen kraiftigen Albuginea (lig. 11, at) verdickt. Das Kaliber der stark gewundenen Kanälchen schwankt in nicht sehr erheblichen Grenzen. Es beträgt im Nittel $125 "$, die kieinsten Formen messen $90 \mu$, die grössten $165 \mu \mathrm{im}$ Durchmesser.

Die zellige Auskleidung bietet ziemliche Variationen, doch lassen sich leicht dabei drei Typen (Fig. 12) unterscheiden: ${ }^{1}$ ) 1. Sanalchen mit völliger Füllung des Lumens $\left(t^{1}\right)$ durch grösstenteils plasmodial verschmolzene Elemente. Nur da und dort werden äusserst zarte Zellgrenzen sichtbar. Das, was von Zytoplasma erkennbar ist, ist durchsichtig, nur leicht feinkörnig truibe. Die Kerme sind kugelig oder doch rundlich, ziemlich hell. mit deutlichen Kernkörperchen versehen. Solide Formationen dieser Art sind durchaus in der Minder"ahl. Zuweilen ist die plasmodiale Missse auch von grösseren oder kleineren Vakuolen durchbrochen.

2. Ganz überwiegend sind die Kanälchen von mehreren bis vielen epithelialen zelligen Lagen ausgekleidet (Fig. 12, $\mathrm{t}^{2}$; auch hk in Fig. 8 oder Fig. 11). Die Kerne sind die nümlichen wie bei dem sub 1 geschilderten Typus. Ebenso sind die Zelleiber. wie das Zytoplasma dort, durchsichtig. Ihr Kontur ist sehr muregelmässig; die Zellindividuen sind nicht gerade selten wenigdentlich getrennt. Fon diesen zuweilen kegelförmig vorspringenden Elementen aus führen feire netzförmige Fortsïtze in das Lumen hinein, und durch den Zusammentfuss dieser Fortsätze entsteht ein das Lumen kreuz und (quer oft (aber keineswegs immer') rollkommen durchsetzendes grossblasiges oder schaumiges Netzwerk, wobei sich auch einzelne Kerne zentralwärts rorschieben.

Es kann diese die Lichtung füllende Taknolenmasse so überwiegen, dass nur mehr eine einzige Zell- bezw. Kermrejhe in der Peripherie des Kanälchens übrig ist.

3. Wiederum der Zahl nach zurücktretend sind Formen $\left(\mathrm{t}^{3}\right)$, deren Auskleidung durch lange hohe schmale Zylinderzellen mit stärker gefärbtem Protoplasma und basalen Kernen in einfacher Lage gebildet wird. Sie sind um ein zentrales Lumen radiür

3) Für die Beschreibung werden zweckmässig reine Querschnitte der Kanälchen gewählt, um alle Trugbilder, die betreffs der zelligen Füllnng der Lumina bei Oberflächenschnitten entstehen könnten, auszuschliessen. 
gruppiert. Auch diese Elemente erscheinen mehr oder minder verschmolzen - eventuell wiederum auch vakuolisiert - , und das Lumen kann durch ihren zentripetalen Zusammenschluss aufgehoben sein.

Die Membrana propria der Hodenkanälchen ist durchweg gut ausgesprochen. $\mathrm{Zu}$ einem kleinen Teil bestelit sie aus feinell konzentrischen collagenen Faserlagen mit ziemlich krïftig gefärbten spindeligen Kernen und leicht darstellbaren sehr reichlichen elastischen konzentrisch geordneten Beimengungen. Aber meist zeigt sie insofern Veränderungen, als ihre innerste schicht zu einem zunächst zarten, dann breiteren, ganz fein gefaserten hyalinen Band aufquillt. Ias Band ist meist frei von Zellen bezw. Kernen, auch von elastischen Fasern, und mit Eosin sehr lebhaft gefärbt (Fig. 10, mpr).

Die zentripetal vordrängende hyaline Cimwandlung der Menbrana propria führt zur spaltförmigen Einengung des Lumens, dann zum Schwund der Epithelauskleidung und schliesslich zur völligen Obliteration des Hodenkanälchens, dessen Kontur peripherisch meist noch durch erhaltene spindelige kerne und zarte elastisch-konzentrische Fasern um das auf dem (Querschnitt wellig gewulstete breite hyaline Band angedeutet ist.

Sowohl die genannten epithelialen Typen in del Anskleidung der Kanalchen wie die verschiedenen Degenerationsstadien der Nembrana propria sind in der regellosesten Art kombiniert und dabei durch vielerlei morphologische Zwischenformen verbunden.

Ebenso regellos ist das im ganzen ziemlich häufige. wemn auch keineswegs vorstechende Auftreten von $Z w$ ischenzellen (Fig. 11, zw). Sie sind entweder frei im Stroma oder öfter an einzelne oder gruppierte Hodenkanälchen gebunden in stark wechselnder Anordnung, bald in grösseren, bald in kleineren Komplexen, bald zu kleinsten Inselchen vereinigt, zu finden. Die einzelnen Elemente sind polyedrisch und führen den runden, mässig hellen, mit Kernkörperchen versehenen Kern meist zentral. Das Plasma ist entweder sehr reichlich und hat ausserst zahlreiche feinste bräunliche Pigmentgranula, an den FlemmingPräparaten auch durch Osmiumsäure geschwärzte kleinere und grössere Fettröpfchen, eingelagert. Oder - diese Bilder überwiegen - der Zelleib ist unbedeutend, und die Kerne sind dicht aneinandergeriickt. Zuweilen sind innerhalb der Zwischenzellmassen feine verzweigte Blutkapillaren deutlich. 
In den zellig gefüllten Hodenkanälchen sowohl wie in den mit Lichtungen versehenen, in den Kanälchen des obigen Typus 1 und 2 , tindet sich nun aber noch eine weitere Zellform, die ganz besondere Hervorbebung verdient (Taf. IX, Fig. 13a, b). ${ }^{1}$ )

Es erscheinen ganz distinkte grosse, kugelige, auffallend helle Zellen (gz), die durch die besondere Transparenz ihres Protoplasmas sich gegen ihre Nachbarelemente stark abheben. Ihr rundlicher Ker'n ist gleichfalls heller als die meist dunklen Nachbarkerne. Er liegt zentral und führt ein rundes Kernkörperchen.

Ganz besonders auffallig aber ist das syntopische Verhältnis der Nachbarzellen bezw. ihrer Kerne zu diesen hellen kugeligen Zellen: die Nachbarelemente schmiegen sich um ihre Peripherie (kfz) und umgeben sie nicht selten melı oder minder kontinuierlich. So kommen förmlich follikelühnliche Anordnungen zustande, in denen eine grosse helle zentrale kugelige Zelle - ganz abnlich dem Primordialfollikel im Eierstock - von einer Hüllzellanlage abgeplatteter Epithelien umgeben ist. Bilder dieser Art sind nicht gerade hïufig, aber doch fast auf allen Schnitten zu finden. Nicht selten fermer sind die grossen kugeligen Elemente in ein und demselben Querschnitt in grösserer Zahl, gelegentlich sogar gehänft (Fig. 13a, b), zil treffen.

\section{'I e il III.}

\section{Tabellarische Übersicht der von mir untersuchten bezw. wiedergegebenen Fälle.}

Ich gebe im folgenden eine tabellarische Übersicht der von mir neu unter'suchten Fälle (fünf Tierfälle; Fall Salén) und sümtlicher ïbrigen Fülle von sicherem Hermaphroditismus verus beim Menschen, also des älteren Falles von Simon sowohl, wie anch der neuen von Uffred azzi und Gudernatsch, nach dem Yuster der von Sauerbeck erdachten tabellarischen Synopsis.

Ich habe versucht, in den Kolumnen der Tabelle möglichst das zusammenzufassen, was Sa uerbeck in seiner Tabelle III ( , sichere und sehr walurseheinliche Falle von $H$. A. verus bei lier und Mensch“), Tabelle VI („Beschaffenheit der Geschlechtsdrüse bei H. A. verus") und Tabelle VII ("Zustand der tubularen und konjugalen Geschlechtsteile beiderlei (Geschlechts bei H. A. verus ${ }^{*}$ )

1) Auch hier werden, um Trugbilder auszuschalten, lediglich Querschnitte beschrieben. 
anatomisch analysiert, und ich habe mich darum in der Aufstellung der Rubriken auch möglichst genau an die von Sa uerbeck aufgestellten Reihen gehalten. So mag meine Tabelle als eine unmittelbare f'ortsetzung der mühevollen Sauerbeckschen Zusammenstellung vielleicht von einigem Nutzen sein.

Die Fälle Simon und Salén finden sich auch bei Sauerbeck. Ich habe sie, zumal meine Nachuntersuchung im Falle Salén die obigen prinzipiell bedeutungsvollen Ergänzungen aufdeckte, der gerade für den Menschen von mir erstrebten Vollstindigkeit wegen hier nochmals eingestellt. Sa u e r beck (S. 833) rechnet gegenüber anderen Autoren ${ }^{1}$ ) allgemein Vagina und Prostata zu den inneren Sexualorganen, den Sinus urogenitalis des weiblichen Schweines - mit Recht - zu den itusseren (S. 865). Er zählt auch den stark männlichen (vergl. unten) Sinus urogenitalis des hermaphroditischen Schweins, bei Pseudohermaphroditismus wie bei echtem Hermaphroditismus, zu den iusseren Geschlechtsorganen, und hier entspricht der Sinus urogenitalis durchaus der Pars pelvina der männlichen Urethra. Nun besitzt aber dieser wie jener unterhalb seiner Schleimhaut eine rollkommene Umkleidung durch die Pars disseminata prostatae, und so entsteht für die Sauerbecksche Auffassung der Widersplruch, dass ein äusseres Sexualorgan - der Sinus urogenitalis bezw. die Pars pelvina urethrae - in einer bestimmten Schicht seiner Wand zugleich ein inneres ist, oder aber man müsste die Konzession machen, den kleinen Prostatakörper des Schweins, der dorsal und seitlich vom Anfang der Pars pelvina urethrae liegt, zu den inneren, die innerhalb der Harnröbren(bezw. Sinus urogenitalis-) wand liegende Pars disseminata prostatae zu den äusseren- Geschlechtsorganen zu zählen.

Ich selbst rechme mit den genannten Autoren die Prost a ta zu den äusseren Organen, habe sie aber, um mit den Unterabteilungen der Sa u erbeckschen Tabelle die Übereinstimmung zu erhalten, auch in meiner Tabelle unter der Rubrik der inneren Organe belassen.

Lediglich aus praktischen Gründen sind in diese Kolumne auch die bulbourethralen Drüsen (Cowperschen bezw. grossen vestibularen) eingestellt.

1) Feldmaier, Schönfeld, Brühl; vergl. auch 0rth (50) und Fibiger (16) bei E. Kaufmann (31 a), S. 906. 


\section{Teil IV.}

\section{Die „phänomenologischen Gesetze" beim Hermaphroditismus verus der Säugetiere und des Menschen.}

I. Die Geschlechtsdrüsen beim Hermaphroditismus verus.

Die erste nicht anzuzweifelnde Beobachtung eines $H$. A. verus (H. A. verus lateralis masculinus dexter beim Süugetier [Schwein]) stammt aus dem Jahre 1885 (Reuter). Der erste unbedingt sichere Fall beim Menschen ist der von Ernst Salén (5̈) in Jahre 1899 berichtete.

Die sonstigen sicheren Fälle beim Säugetier sind bei Sauerbeck (5s) eingehend verwertet und tabellarisch zusammengestellt (vergl. Tabelle II, III, VI, VII), die beim Menschen von nir sämtlich wiedergegeben (vergl. oben 'T'eil I und die 'Tabelle, Teil III).

Mit meinen neuen fünf Beobachtungen verfügen wir nunmehr über mindestens zwölf unbedingt gesicherte Fïlle beim Sâugetier, und falls der Fall Gudernatsch (23) mitgezahlt wird, über vier sichere Fälle beim Menschen.

Die zwölf sicheren Fälle beim Sängetier sind ausnahmslos beim schwein beobachtet. ${ }^{1}$ )

Ich möchte diese auffallende Tatsache sowohl gegeniiber der geringen Zahl der Fälle beim Menschen wie gegenüber dem Fehlen sicherer Fälle bei anderen Süugern wesentlich durch it ussere Gründe erklüren. Gegenüber den Millionen-Schlachtungen und der Millionen-Fleischbeschau an Schweinen, wie sie in den Schlachthäusern der Großstädte tagaus tagein geübt wird, verschwindet die Gesamtzahl der menschlichen Obduktionen, und auch die Schlachtzahl anderer Süuger kann damit keinen Vergleich aushalten. ${ }^{2}$ )

1) Die "sehr wahrscheinlichen Fälle" betreffen zweimal das Reh (B o: 5 ) und einmal die Ziege (Ma yer), die sicheren und sehr wahrscheinlichen Fialle zusammengenommen also insgesamt Haustiere der Huftiergruppe (Sa u erbeck, S. 692 and 868).

Auch die am besten und allein genïgend beschriebenen Fälle ron Ps. H. A. der Säuger sind bemerkenswerterweise beim Schwein beobachtet (vergl. S a uerbeck, Tabelle XIV und S. 864).

2) A uf dem Berliner städtischen Schlachthofe wurden 1912 geschlachtet: 1826000 Schweine gegenüber 998403 Schafen, 218883 Rindern (Bullen; Ochsen, Kühen, Jungrindern und Kälbern). 


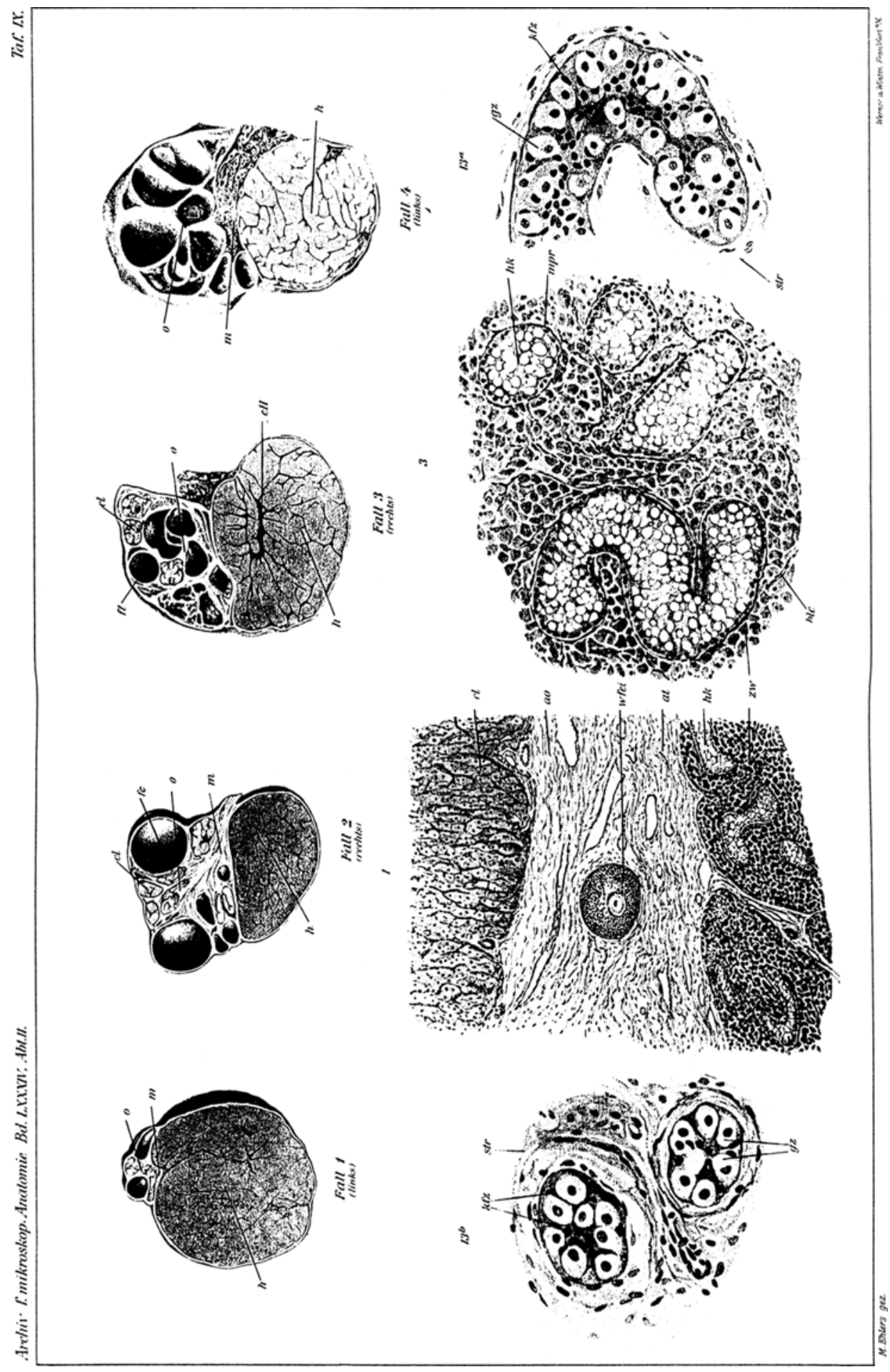




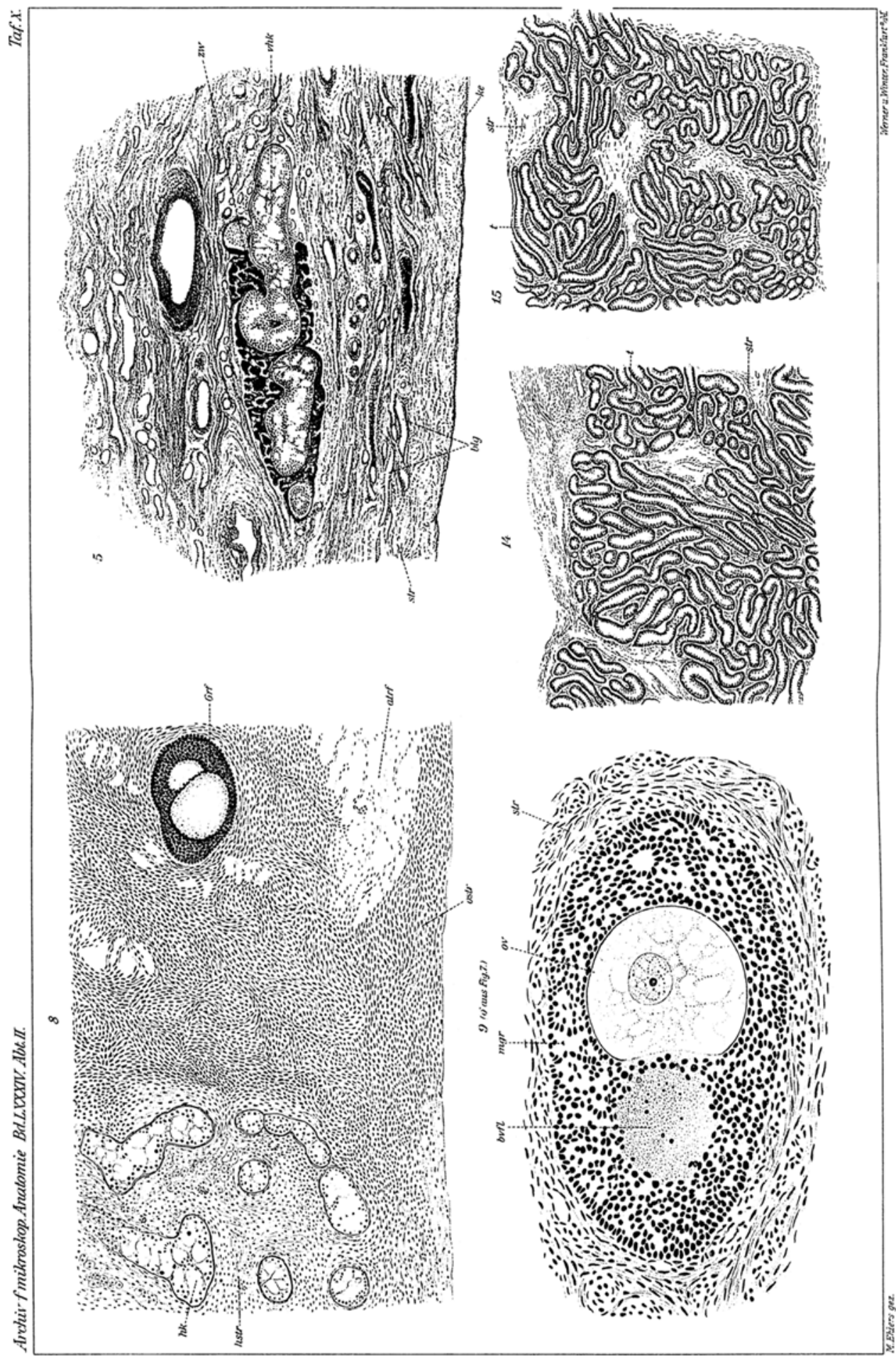




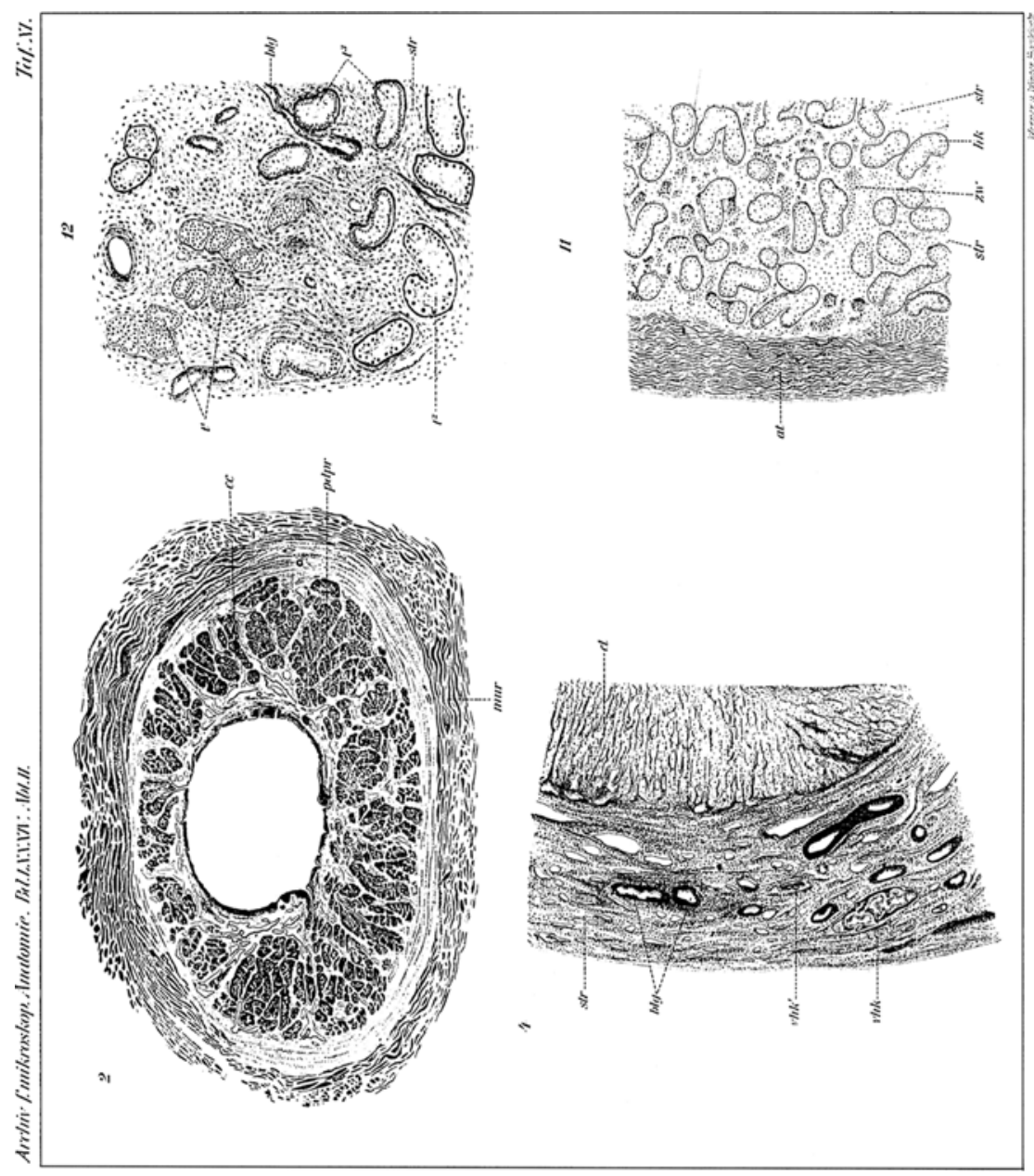




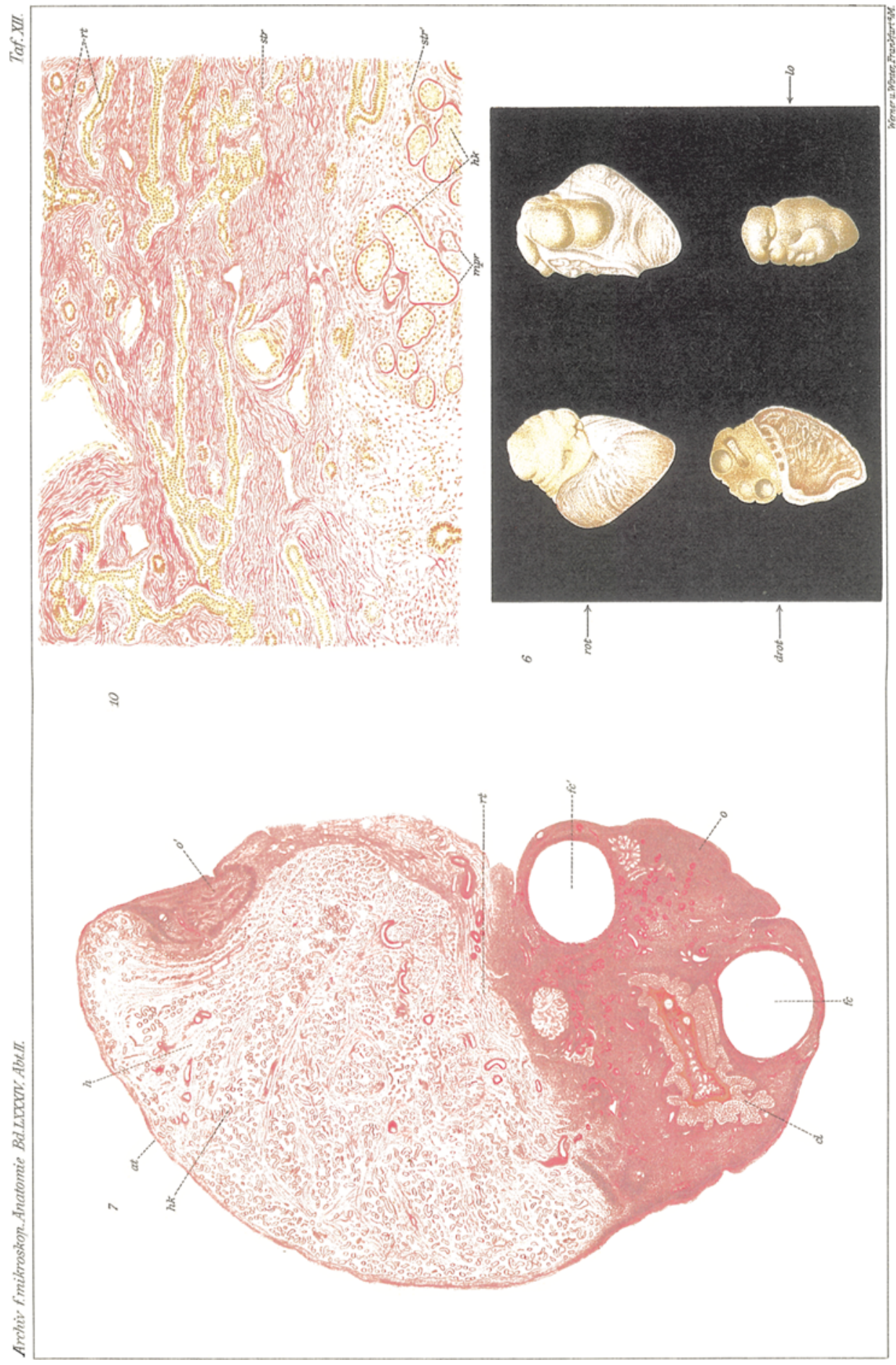




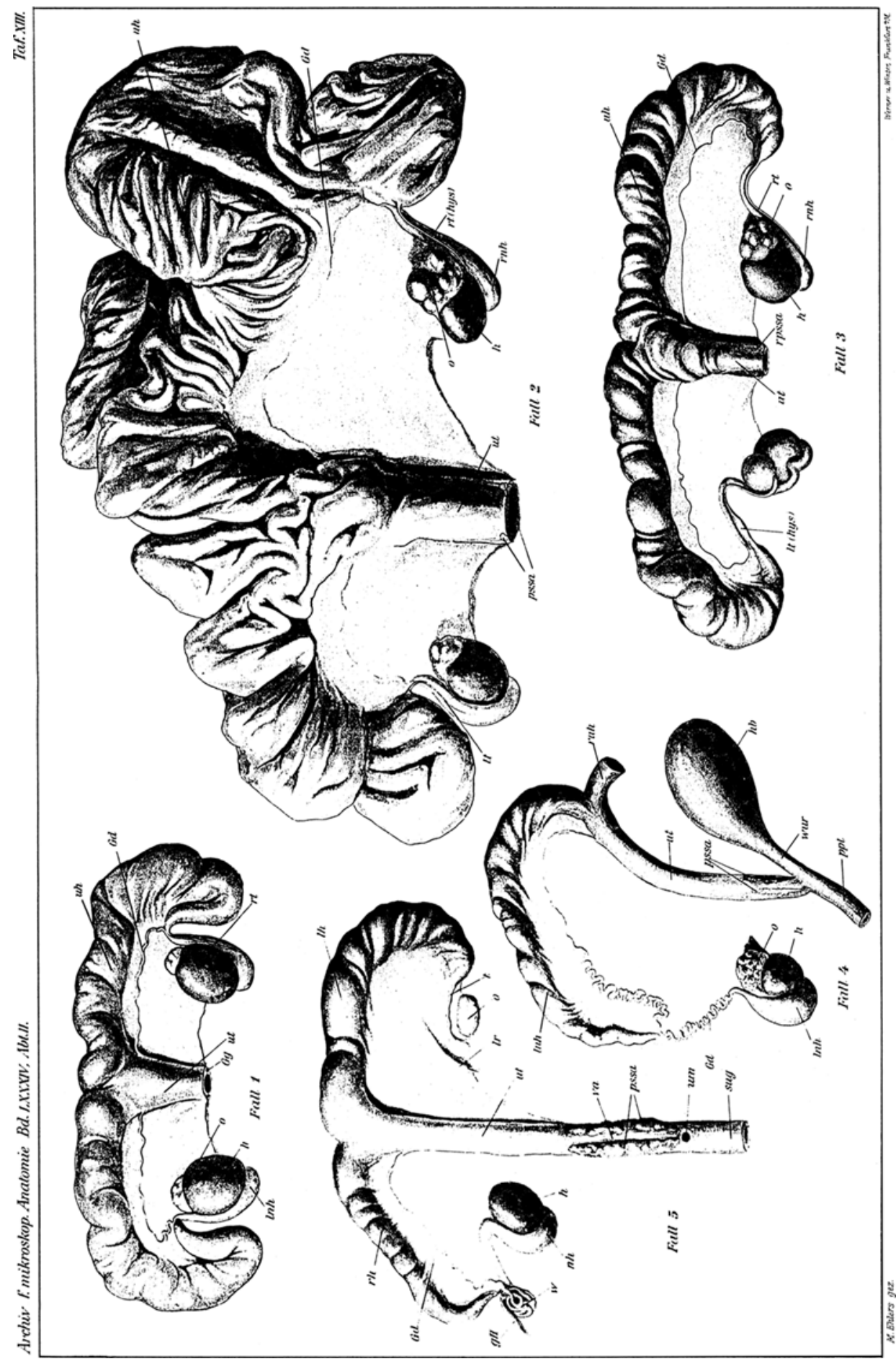

